\title{
Management of Helicoverpa armigera (Hübner) with botanical extract (Balanites aegyptiaca) and endophytic entomopathogenic fungus Metarhizium brunneum (6c1) reared on okra plant
}

\author{
Dissertation \\ to obtain the Ph.D. degree \\ in the International Ph.D. Program for Agricultural Sciences in Göttingen (IPAG) \\ at the Faculty of Agricultural Sciences, \\ Georg-August-University Göttingen, Germany \\ presented by \\ Elhadi Morzog \\ born in Wadiushar, Republic of the Sudan
}

Göttingen, July 2021 
Name of Supervisor: Prof. Dr. Stefan Vidal

Name of Co-Supervisor: PD DR. Rainer Meyhöfer 


\section{Summary}

Leaves chewing insects are widely recognized as herbivores which can influence agricultural productivity. Cotton bollworms are one of the most important crop pests worldwide. The larva is mainly responsible for causing damage; it is a polyphagous in nature and attacks more than 182 plant species. Moreover, well-managed pests like the cotton bollworm (Helicoverpa armigera) developed resistances against often used insecticides. Hence, concerns about the widespread of the environmental negative impacts of chemical insecticides coupled with the great damages in many areas that expected to be caused by the bollworm have led to focus on environmentally sound and sustainable alternative strategies for pest control. The development of new biopesticide against these and other pests is therefore of high importance, to overcome disadvantages of chemically synthetic plant protection products, which can be highly efficient but with indeterminate environmental effects.

Overall hypotheses of the thesis were that Metarhizium brunneum (Mycoinsecticide) and extracts of Balanites aegyptiaca L (Botanical insecticide) are effective in controlling cotton bollworm Helicoverpa armigera insect pest.

- Chapter 1 General introduction focus on literature review.

- Chapter 2 An Metarhizium brunneum strain 6c1 was evaluated for its capability to colonize okra plant with toothpick inoculation method. The studies reflected the ability of Mb-6c1 to colonize the whole plant tissue. Different parameters such as pupae success, area consumed, weight gain and faeces dry weight bioassay were tested to evaluate whether the colonization of $\mathrm{Mb}-6 \mathrm{c} 1$ could affect the performance of bollworm by means of toothpick. The results revealed that $M$ brunneum (6c1) showed a positive effect on the survival of cotton bollworm larvae conducted in the bioassay.

- Chapter 3 and 4 of this focus on B aegyptiaca as a botanical insecticide

- Chapter 3 A review on Desert Date Balanites aegyptiaca L. \& Del.: general uses and future prospective as botanical insecticide.

- Chapter 4 Deleterious effects of oil and water extracts (2\% (v: v): 5\% (v: v) oil extract and $5 \%(\mathrm{w} / \mathrm{v}): 10 \%(\mathrm{w} / \mathrm{v})$ water extract) of seed kernel of $B$ aegyptiaca Del on the $2^{\text {nd }}$ 
instar larvae $H$ armigera were studied. All results showed that larval survival was significantly influenced by treatments. Oil and water extracts have properties of larvicidal against $H$ armigera which could potentially be used as an attractive alternative for pest management.

In order to clearly and widely identify the active ingredients which caused the deleterious effects and the modes of action, this study recommends that the bioassays should be applied in a field study and modes of action should be identified and dose-response curves assessed additionally, efficacy of different parts (leaves and roots) of $B$ aegyptiaca against $H$ armigera should be screened as well. 
To the blessed memory of my father and mother My my beloved wife, Bothina and son, Ibrahim 


\section{Table of Contents}

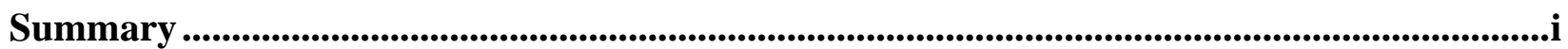

Chapter One.........................................................................................................................................

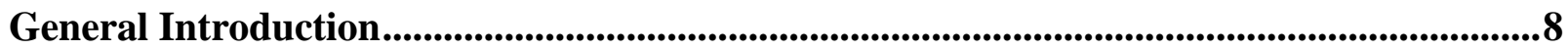

References ................................................................................................................................................. 11

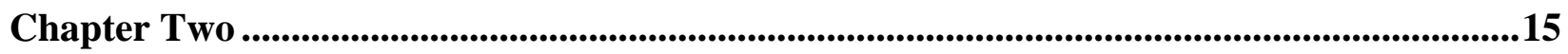

Efficacy of endophytic (Metarhizium brunneum) strain 6c1 in the control of old-world

Bollworm (Helicoverpa armigera) in okra ......................................................................................15

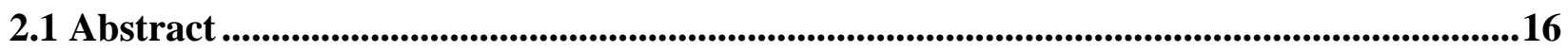

2.2 Introduction ........................................................................................................................................... 17

2.3 Materials and methods ..................................................................................................................................19

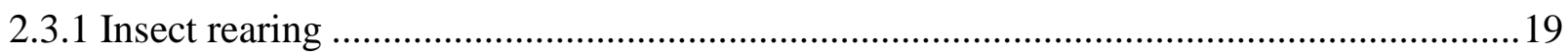

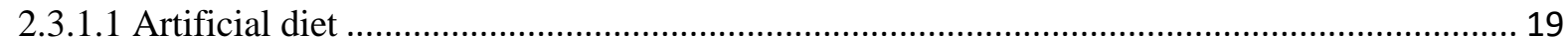

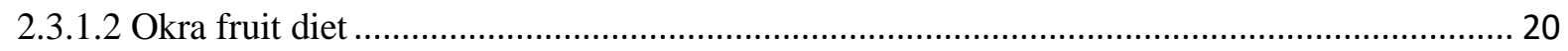

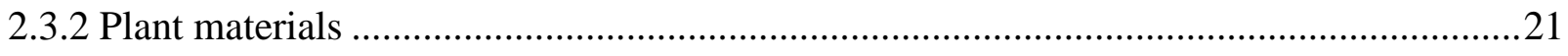

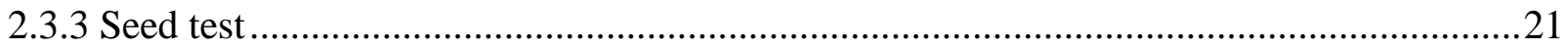

2.3.3.1 Surface sterilization of okra seeds ............................................................................ 21

2.3.3.2 Okra plant inoculation .............................................................................................. 21

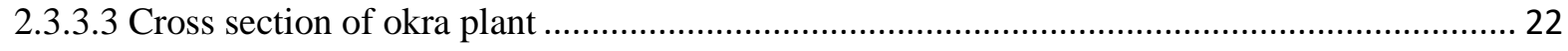

2.3.3.4 Effect of Metarhizium brunneum (6c1) on Helicoverpa armigera ...................................... 22

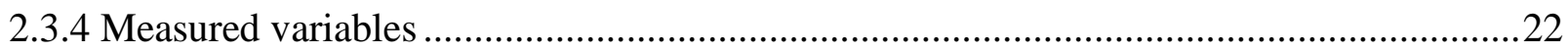

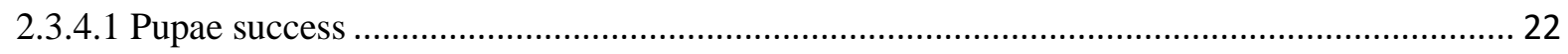

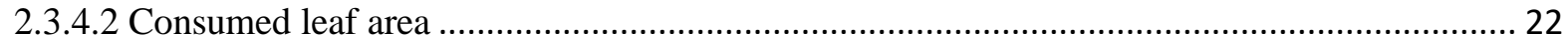

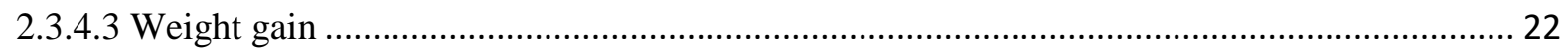

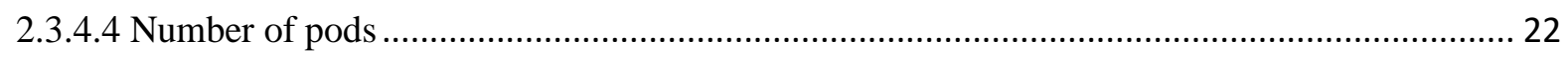

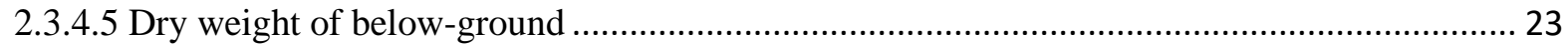

2.3.5 Statistical analysis......................................................................................................

2.4 Results ..........................................................................................................................................................24

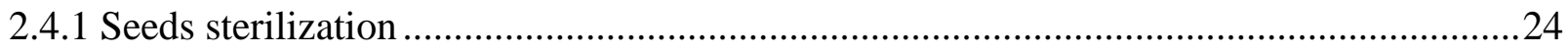

2.4.2 Cross section of okra plant .....................................................................................24

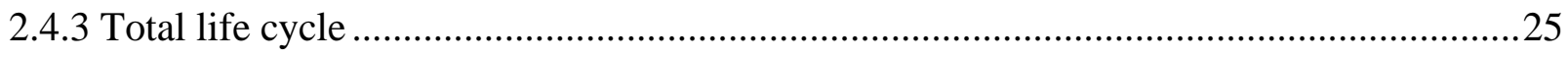

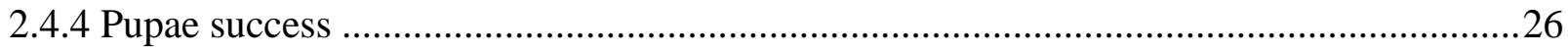




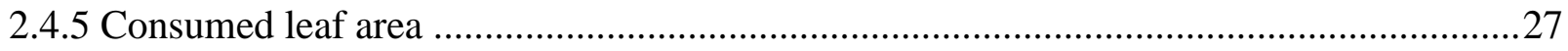

2.4.5.1 Consumed leaf area of Helicoverpa armigera larvae for each treatment per day .................. 28

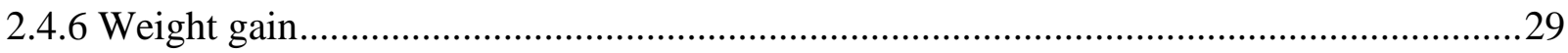

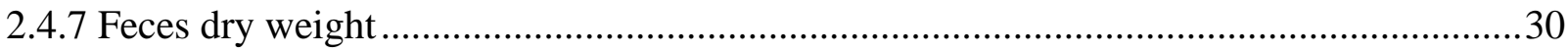

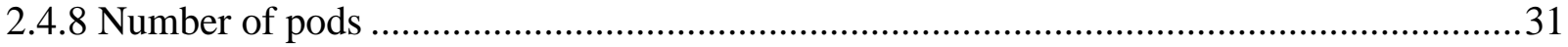

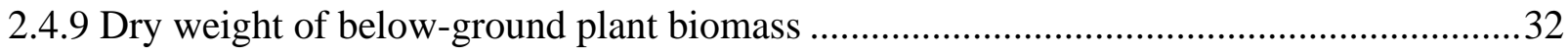

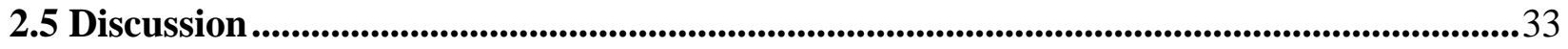

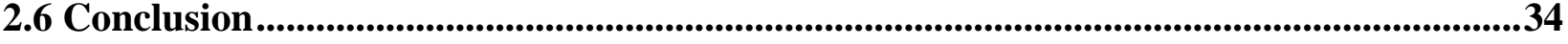

References

Chapter Three ...............................................................................................................................................42

A review on Desert Date Balanites aegyptiaca L. \& Del.: general uses and future prospective

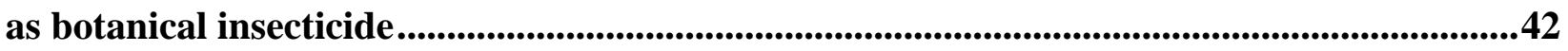

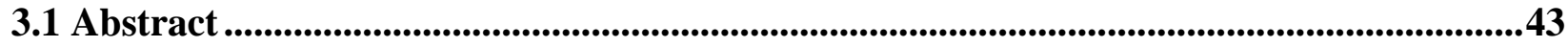

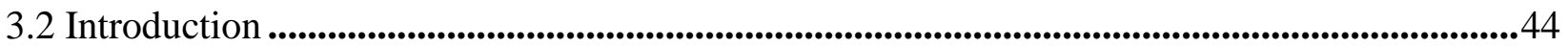

3.3 Botanical taxonomy.....................................................................................................................................44

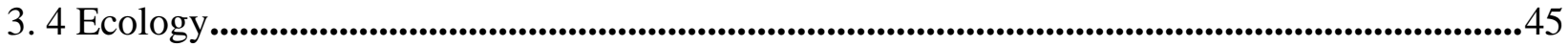

3.5 Botanical Description ..............................................................................................................46

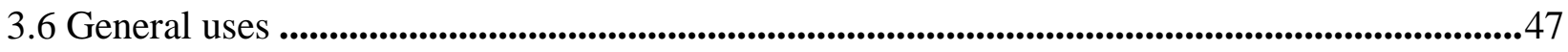

3.7 Balanites aegyptiaca as botanical insecticide ..............................................................................49

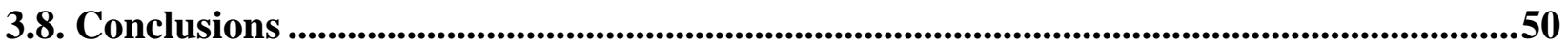

References

Chapter Four .............................................................................................................................................57

Potential applications of botanical extracts of the Balanites aegyptiaca against Helicoverpa armigera reared on okra ...................................................................................................................57

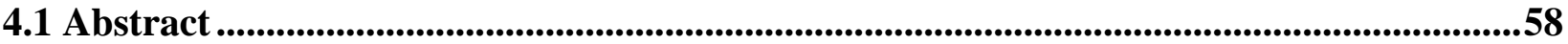

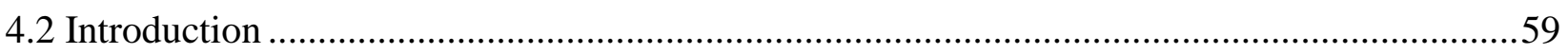

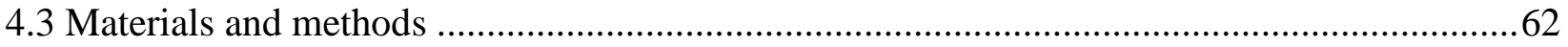

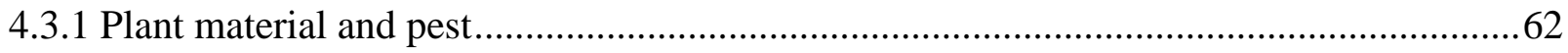

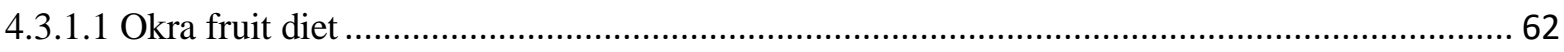

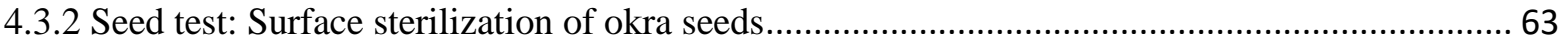

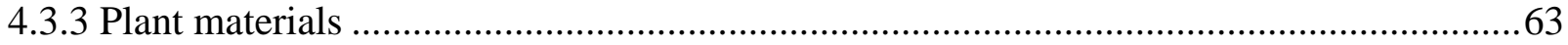

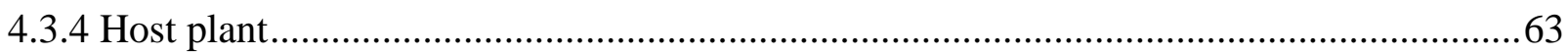




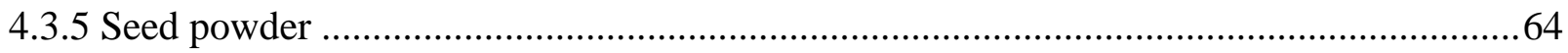

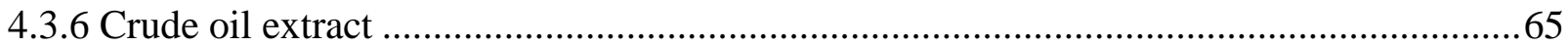

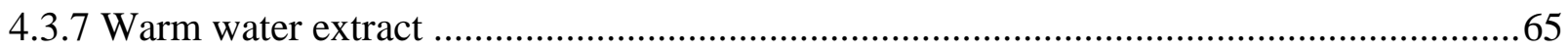

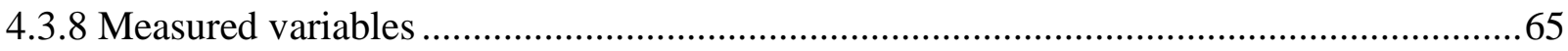

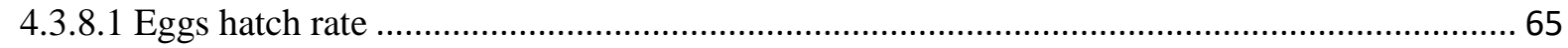

4.3.8.2 Repellent activity of water and oil extracts (Balanites aegyptiaca)....................................... 66

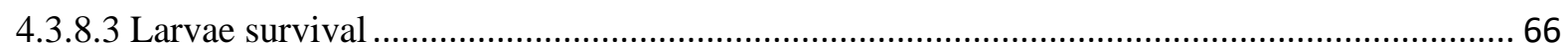

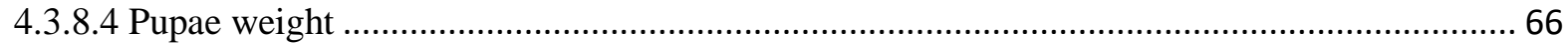

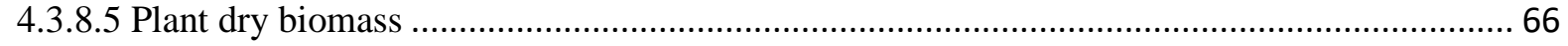

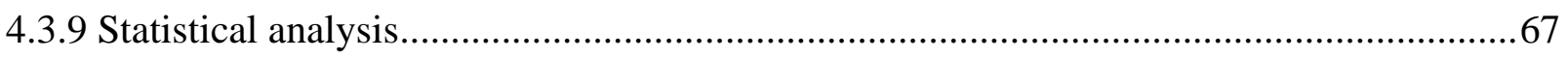

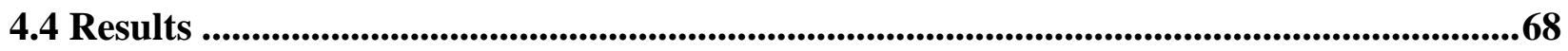

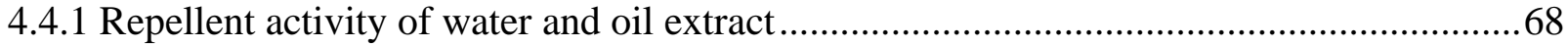

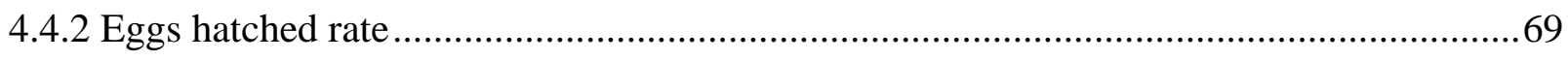

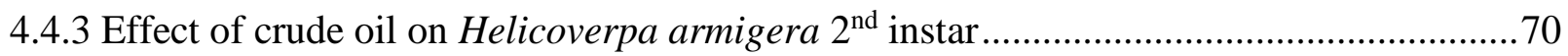

4.4.4 Effect of warm water extracts on Helicoverpa armigera $2^{\text {nd }}$ instar ..............................71

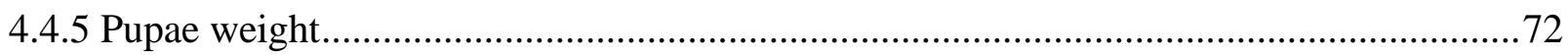

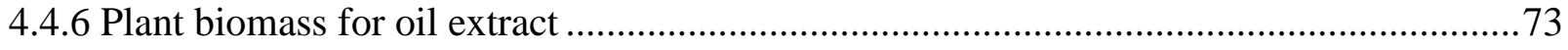

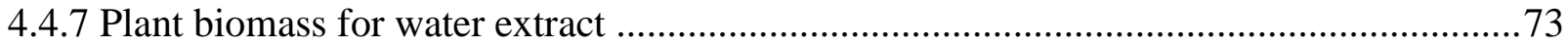

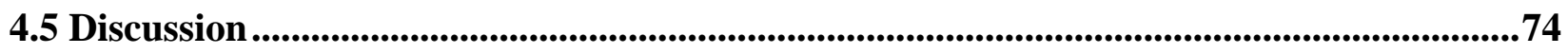

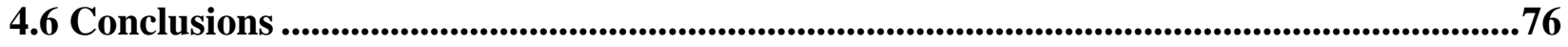

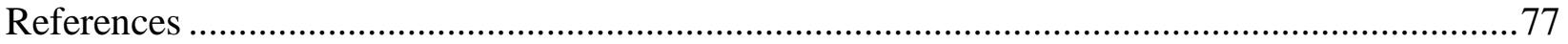

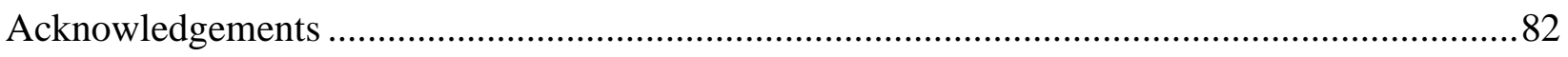

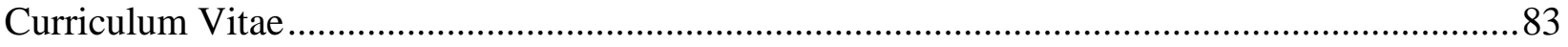

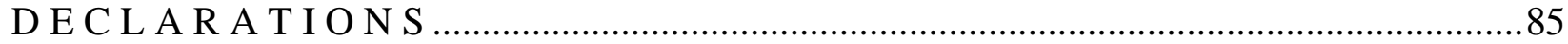




\section{Chapter One}
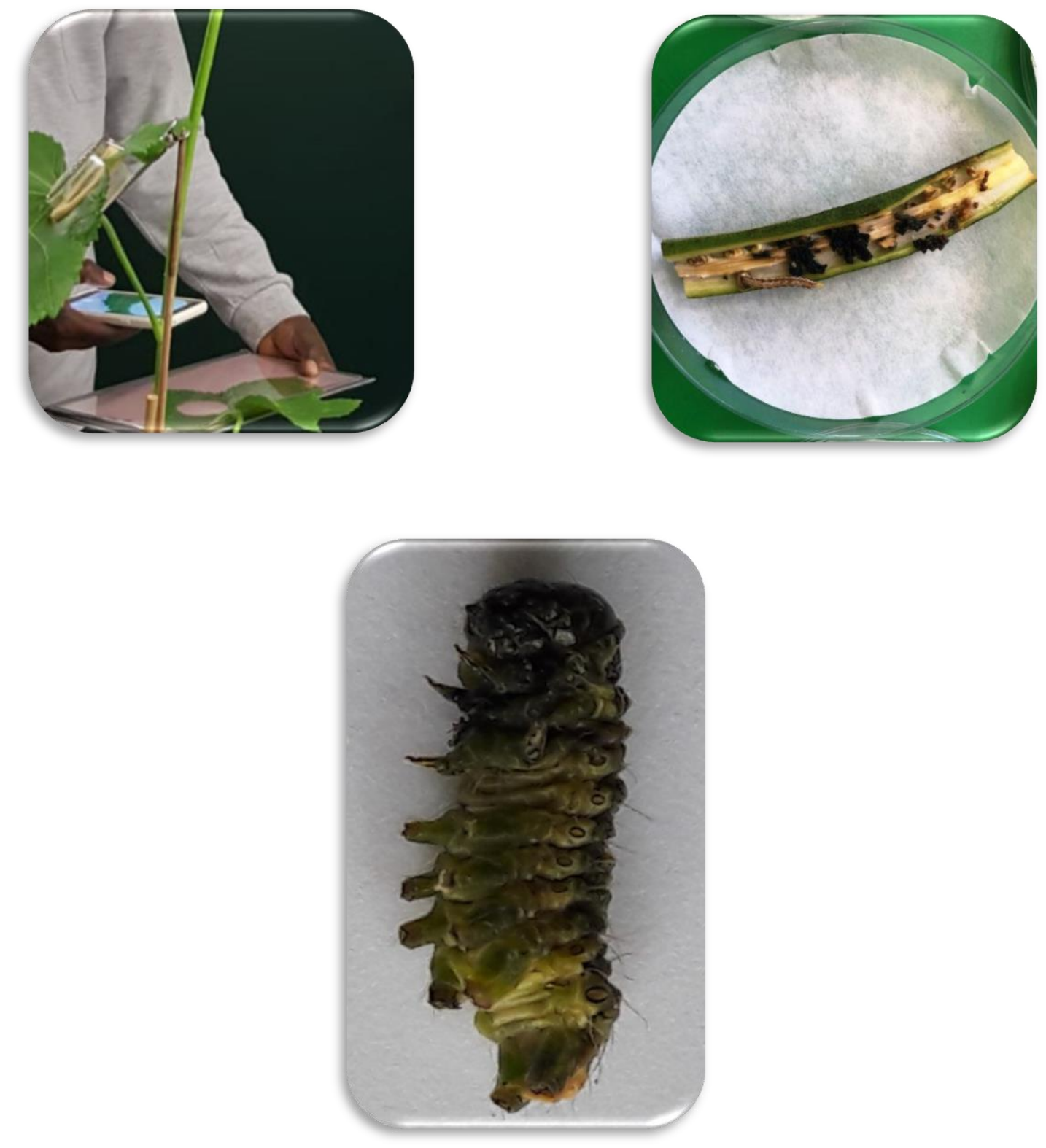


\section{General Introduction}

Cotton bollworm (Helicoverpa armigera Hübner 1808; Lepidoptera: Noctuidae) considered to be one of the important pests for many crops worldwide (Lammers \& Macleod, 2007). The larva is mainly responsible for causing damage; it is a polyphagous in nature and attacks more than 182 plant species, including different important cash crops, (cotton, sunflower, sorghum, maize), vegetables, fruit crops and tree species (Uddin et al., 2009). The annual yield loss is estimated to about US\$ 2 billion reported in tropical and subtropical area. Furthermore, US\$ 500 million worth pesticides are applied to control bollworm (Kass et al., 2018). Moreover, the bollworms cause about 10 to $60 \%$ of okra (Abelmoschus esculentus L) fruit infestations, however, under optimal environmental conditions the level of damage can boost 30 to $80 \%$ yield loss (Javed et al., 2019). Hence, concerns about the widespread of the environmental negative impacts of chemical insecticides coupled with the great damages in many areas that expected to be caused by the bollworm have led to a focus on environmentally sound and sustainable alternative strategies for pest control. Thus, a worldwide resurgence of interest in the use of predators, parasitoids and/or entomopathogenic microorganisms have intensively been studied for biological control of Helicoverpa armigera species (Gonzalez et al., 2016) and a significant advance in development and manufacturing of these agents in the future is expected with recent biotechnological discoveries (Hatting, 2012).

Plants are commonly colonized by a wide range of endophytic microorganisms, such as bacteria and fungi. Endophytes are microorganisms present in plant tissues without causing any apparent symptoms (Jalgaonwala et al., 2011). Fungal endophytes are widespread and quite diverse in nature (Arnold, 2007). Entomopathogenic fungi have been widely used for the control agricultural, for example Beauveria bassiana (Balsamo) Vullemin (Ascomycota: Hypocreales) is the best-studied endophytic fungal entomopathogen (Posada et al., 2010) and it is available as a commercial mycoinsecticide for control of the Colorado potato beetle (Faria \& Wraight, 2007). Inoculation methods tested to establish $B$. bassiana as an endophyte include soil drenches and immersions (Tefera \& Vidal, 2009), seed coatings (Jalgaonwala et al., 2011), radical dressings (Posada \& Vega, 2005), root and rhizome immersions (Akello et al., 2009), stem injections (Posada et al., 2007) and foliar sprays (Quesada et al., 2006). Using these methods, researchers have introduced B. bassiana into the different types of crops. Also the insect-pathogenic fungus, 
Metarhizium robertsii is a common inhabitant of soils worldwide that has been studied and used as an insect pathogen for biocontrol (Lomer et al., 2001). Several species of entomopathogenic fungi have been playing multiple roles in nature ranging from antagonists of plant pathogens to rhizosphere associates, endophytes, and possibly even plant-growth (Vega, 2008). Vega et al., (2012) reported that when used as mycoinsecticides, entomopathogenic fungi have demonstrable potential for the management of insect pests. Metarhizium anisopliae are producing pathogens implicated in toxicity of a number of insects, the action of cytotoxins is proposed by hyphae penetration causing symptoms such as partial or general paralysis and decrease irritability in mycoses insects that are consistent with the action of neuromuscular toxins (Sandhu et al., 2012).

The selection of fungal pathogens for controlling Helicoverpa armigera is necessary because the selection of isolates which combine the best possible characteristics for diminishing the target insects under glasshouse conditions is vital. Hence, the important characteristics of the isolate to be considered are (i) good mass production, such as high sporulation on artificial media, (ii) high virulence against target organisms, and (iii) the ability to withstand the pest environment (Hussain et al., 2014).

Botanical insecticides are made from substances extracted from plants or plant-derived secondary metabolites and used for insect control (Hikal et al., 2017). Essential oils extracted from redolent plants have been increasing considerably as insecticides due to their popularity in organic farming. These products are characterized with their repellent, insecticidal, antifeedants, growth inhibitors, oviposition inhibitors, ovicides, and growth-reducing effects on a variety of insects ( Regnault-Roger et al., 2012 ; Suthisu et al., 2011)

Different components of Balanites aegyptiaca have several bioactive substances (Al Ashaal et al., 2010) which possess distinguished characteristics and important phytochemical components for instance, alkaloids, glucosides, flavonoids, phenolics, saponins, tannins, terpenoids, steroids, lipids, proteins, carbohydrates, organic acids, furanocoumarins, Diosgenin, N-transferuloyltyramine, N-cis-feruloyltyramine, trigonelline, balanitol and cardiac glycosides (Amadou, Le, \& Shi, 2012 ; Koubala et al., 2013). Additionally, important phytochemical components (secondary metabolites) are useful for the management of various diseases and have potential insecticidal effects against medical, veterinary and agricultural pests (Pan et al., 2016) 
According to Tesfaye ( 2015), the tree is a multipurpose with considerable economic possibilities for its enormous biological active components, all parts of the plant used as food or has effects as an antidote for the cure of infections or pests control, also he recommended that the ranch of tree acting as shelterbelt and soil reformer in arid regions and in saline soil and will be helpful in conservation of biodiversity. Hence, the main objective of the current study is to address the virulent of Metarhizium brunneum (Mb-6c1) and essential oils extracted from Balanites aegyptiaca on the management of cotton bollworm Helicoverpa armigera (Hübner).

\section{The aims of the study were:}

- To investigate the efficacy of strain 6c1 of the Metarhizium brunneum on Helicoverpa armigera (Hübner).

- To examine the ability of Metarhizium brunneum Mb-6c1 to occupy the tissue of okra plant.

- To determine the potential endophytic strain $6 \mathrm{c} 1$ of the entomopathogenic fungi as a biocontrol agent against insect pests by confirming that the fungus still acts as a true insect pathogen after being introduced into plants.

- To propose essential oils extracted from Balanites aegyptiaca seed water extracts and seed crude oil in water emulsions as well. To evaluate the antifeedant and repellent of extracts from $B$ aegyptiaca against $2^{\text {nd }}$ instar larvae $H$ armigera.

- To determine the possible significant implications of the produced bio-pesticides. 


\section{References}

Akello, J., Dubois, T., Coyne, D., \& Kyamanywa, S. (2009). The effects of Beauveria bassiana dose and exposure duration on colonization and growth of tissue cultured banana (Musa sp.) plants. Biological Control, 49(1), 6-10. https://doi.org/10.1016/j.biocontrol.2008.06.002

Al Ashaal, H. A., Farghaly, A. A., Abd El Aziz, M. M., \& Ali, M. A. (2010). Phytochemical investigation and medicinal evaluation of fixed oil of Balanites aegyptiaca fruits (Balantiaceae). Journal of Ethnopharmacology, 127(2), 495-501. https://doi.org/10.1016/j.jep.2009.10.007

Amadou, I., Le, G. W., \& Shi, Y. H. (2012). Effect of boiling on the cytotoxic and antioxidant properties of aqueous fruit extract of desert date, Balanites aegyptiaca (L) Delile. Tropical Journal of Pharmaceutical Research, 11(3), 437-444. https://doi.org/10.4314/tjpr.v11i3.13

Arnold, A. E. (2007). Understanding the diversity of foliar endophytic fungi: progress, challenges, and frontiers. Fungal Biology Reviews, 21(2-3), 51-66. https://doi.org/10.1016/j.fbr.2007.05.003

Faria, M. R. d., \& Wraight, S. P. (2007). Mycoinsecticides and Mycoacaricides: A comprehensive list with worldwide coverage and international classification of formulation types. Biological Control, 43(3), 237-256. https://doi.org/10.1016/j.biocontrol.2007.08.001

Gonzalez, F., Tkaczuk, C., Dinu, M. M., Fiedler, Ż., Vidal, S., Zchori-Fein, E., \& Messelink, G. J. (2016). New opportunities for the integration of microorganisms into biological pest control systems in greenhouse crops. Journal of Pest Science, 89(2), 295-311. https://doi.org/10.1007/s10340-016-0751-x

Hatting, J. L. (2012). Comparison of Three Entomopathogenic Fungi Against the Bollworm, Helicoverpa armigera (Hübner) (Lepidoptera: Noctuidae), Employing Topical vs per os Inoculation Techniques . African Entomology, 20(1), 91-100. https://doi.org/10.4001/003.020.0112

Hikal, W. M., Baeshen, R. S., \& Ahl, H. A. H. S. (2017). Botanical insecticide as simple extractives for pest control. Cogent Biology, 35(1), 1-16. 
https://doi.org/10.1080/23312025.2017.1404274

Hussain, A., Rizwan-ul-Haq, M., Al-Ayedh, H., \& Al-Jabr, A. (2014). Mycoinsecticides:

Potential and Future Perspective. Recent Patents on Food, Nutrition \& Agriculture, 6(1), 45-53. https://doi.org/10.2174/2212798406666140613113905

Jalgaonwala, R. E., Mohite, B. V., \& Mahajan, R. T. (2011). A review : Natural products from plant associated endophytic fungi. 1(2), 21-32.

Javed, M., Majeed, M. Z., Luqman, M., \& Afzal, M. (2019). Development and Field Evaluation of a Biorational IPM Module against Okra Shoot and Fruit Borers, Earias vittella and Helicoverpa armigera (Lepidoptera: Noctuidae). Pakistan Journal of Agricultural Research, 32(1). https://doi.org/10.17582/journal.pjar/2019/32.1.170.176

Kassi, A. K., Javed, H., \& Mukhtar, T. (2018). Screening of okra cultivars for resistance against helicoverpa armigera. Pakistan Journal of Zoology, 50(1), 91-95. https://doi.org/10.17582/journal.pjz/2018.50.1.91.95

Koubala, B. B.; Miafo, A.P.T.; and Bouba, D. (2013). Evaluation of Insecticide Properties of Ethanolic Extract from Balanites aegyptiaca, Melia azedarach and Ocimum gratissimum leaves on Callosobruchus maculatus (Coleptera: Bruchidae). ). Asian Journal of Agricultural Sciences, 5(93-101).

Lammers, J. W., \& Macleod, a. (2007). Report of a Pest Risk Analysis. Plant Protection Service (NL) and Central Science Laboratory (UK), (August), 1-18.

Lomer, C. J., Bateman, R. P., Johnson, D. L., Langewald, J., \& Thomas, M. (2001). B Iological C Ontrol of L Ocusts and G Rasshoppers . Annual Review of Entomology, 46(1), 667-702. https://doi.org/10.1146/annurev.ento.46.1.667

Pan, L., Ren, L., Chen, F., Feng, Y., \& Luo, Y. (2016). Antifeedant activity of Ginkgo biloba secondary metabolites against Hyphantria cunea larvae: Mechanisms and applications. PLoS ONE, 11(5), 1-12. https://doi.org/10.1371/journal.pone.0155682

Posada, F., Aime, M. C., Peterson, S. W., Rehner, S. A., \& Vega, F. E. (2007). Inoculation of coffee plants with the fungal entomopathogen Beauveria bassiana (Ascomycota: 
Hypocreales). Mycological Research, 111(6), 748-757.

https://doi.org/10.1016/j.mycres.2007.03.006

Posada, F. J., Chaves, F. C., Gianfagna, T. J., Pava-ripoll, M., Hebbar, P., Programa, I. A. P. D., ... No, C. (2010). Establishment of the fungal entomopathogen Beauveria bassiana as an endophyte in cocoa pods (Theobroma cacao L.). Actualidad \& Divulgación Científica, 13(2), 71-78.

Posada, F., \& Vega, F. E. (2005). Establishment of the fungal entomopathogen Beauveria bassiana (Ascomycota: Hypocreales) as an endophyte in cocoa seedlings (Theobroma cacao). Mycologia, 97(6), 1195-1200. https://doi.org/10.3852/mycologia.97.6.1195

Quesada-Moraga, E., Landa, B. B., Muñoz-Ledesma, J., Jiménez-Diáz, R. M., \& SantiagoÁlvarez, C. (2006). Endophytic colonisation of opium poppy, Papaver somniferum, by an entomopathogenic Beauveria bassiana strain. Mycopathologia, 161(5), 323-329. https://doi.org/10.1007/s11046-006-0014-0

Regnault-Roger, C., Vincent, C., \& Arnason, J. T. (2012). Essential Oils in Insect Control: LowRisk Products in a High-Stakes World. Annual Review of Entomology, 57(1), 405-424. https://doi.org/10.1146/annurev-ento-120710-100554

Sandhu, S. S., Sharma, A. K., Beniwal, V., Goel, G., Batra, P., Kumar, A., ... Malhotra, S. (2012). Myco-Biocontrol of Insect Pests: Factors Involved, Mechanism, and Regulation. Journal of Pathogens, 2012, 1-10. https://doi.org/10.1155/2012/126819

Suthisut, D., Fields, P. G., \& Chandrapatya, A. (2011). Contact Toxicity, Feeding Reduction, and Repellency of Essential Oils From Three Plants From the Ginger Family (Zingiberaceae) and Their Major Components Against Sitophilus zeamais and Tribolium castaneum. Journal of Economic Entomology, 104(4), 1445-1454. https://doi.org/10.1603/ec11050

Tefera, T., \& Vidal, S. (2009). Effect of inoculation method and plant growth medium on endophytic colonization of sorghum by the entomopathogenic fungus Beauveria bassiana. BioControl, 54(5), 663-669. https://doi.org/10.1007/s10526-009-9216-y

Tesfaye, A. (2015). Balanites (Balanite aegyptiaca) Del., Multipurpose Tree a Prospective Review. International Journal of Modern Chemistry and Applied Science 2, (3): 189-194. 
Uddin, M. A., Jahan, M., \& Uddin, M. M. (2009). Issn 1017-8139 study on nature and extent of damage of corn earworm,. Progress. Agric, 20(1), 49-55.

Vega, F. E. (2008). Insect pathology and fungal endophytes. Journal of Invertebrate Pathology, 98(3), 277-279. https://doi.org/10.1016/j.jip.2008.01.008

Vega, F. E., Meyling, N. V, Luangsa-Ard, J. J., \& Blackwell, M. (2012). Fungal entomopathogens. In Insect Pathology (pp. 171-220). https://doi.org/10.1016/B978-0-12384984-7.00006-3 


\section{Chapter Two}

Efficacy of endophytic (Metarhizium brunneum) strain $6 \mathrm{c} 1$ in the control of old-world Bollworm (Helicoverpa armigera) in okra 


\subsection{Abstract}

Metarhizium brunneum strain 6c1 was evaluated for its capability to colonize okra Abelmoschus esculentus (L.) with toothpick inoculation method. The results reflected the ability of Mb-6c1 to colonize the whole plant tissue. Different parameters such as pupae success, area consumed, weight gain and faeces dry weight bioassay were conducted to test whether the colonization of Mb-6c1 could affect the performance of bollworm Helicoverpa armigera by means of toothpick. The results showed that the inoculation had a significant pupae success, in particular, a gradual reduction of number of pupations were $80 \%, 73 \%, 20 \%, 13 \%$ for the control, Tween $800.01 \%$ (v: v), $\left(1 \times 10^{7}\right.$ conidia/ml $)$ and $\left(1 \times 10^{5}\right.$ conidia/ml $)$, respectively. Consumed leaf area was significantly influenced by the treatment $(\mathrm{p}<0.05)$ with a mean of $63.13 \pm 11.90 \mathrm{~cm}^{2}$ and $54.65 \pm 10.32 \mathrm{~cm}^{2}$ for the high conc and low conc treatments, respectively. Nevertheless, Mb-6c1 increased the root dry weight of okra plants and acts as plant growth regulation. Mb-6c1 was crucial for the dietary uptake and growth of $H$ armigera, and consequently could be a mycoinsecticide target for the development of pest management and environmentally friendly.

Keywords; Metarhizium brunneum, Helicoverpa armigera, Abelmoschus esculentus, Conidia, colonization 


\subsection{Introduction}

Cotton bollworm Helicoverpa armigera (Hübner) cause about 10 to $60 \%$ okra Abelmoschus esculentus (L.) fruit infestations, however, under optimal environmental conditions the level of damage can boost 30 to $80 \%$ yield loss (Javed et al., 2019). The larva is mainly responsible for causing damage: it is a polyphagous in nature and attacks more than 182 plant species, including different important and cash crops, (cotton, sunflower, sorghum, maize), vegetables, fruit crops and tree species (Uddin et al., 2009). Hence, concerns about the widespread of the environmental negative impacts of chemical insecticides coupled with the great damages in many areas that expected to be caused by the bollworm have led to a focus on environmentally sound and sustainable alternative strategies for pest control. Thus, a worldwide resurgence of interest in the use of predators, parasitoids and/or entomopathogenic microorganisms have intensively been studied for biological control of Helicoverpa armigera species (Gonzalez et al., 2016) and a significant advance in development and manufacturing of these agents in the future is expected with recent biotechnological discoveries (Hatting, 2012).

Metarhizium is a genus of fungi that belongs to the family of Clavicipitaceae (class: Pyrenomycetes-sphaeroides, phylum: Ascomycota) and is spread worldwide (Roberts \& St. Leger, 2004). Metarhizium spores attack insects and cause green muscardine disease. When the fungus comes into contact with the body of an insect host, they germinate and the mycelium penetrates the cuticle, while the fungus toxin ingestion by insect develops inside the body and ultimately kills the target after a few days (Freimoser et al., 2003). Currently, the fungus is used as a biological control agent against various insect species (Shah \& Pell, 2003). In addition, species from the genus Metarhizium are used to manage and prevent infestations of various species of pest insects, including locusts, grasshoppers Melanoplus femurrubrum (Hunt \& Charnley, 2011; Wang et at., 2011), malaria mosquitoes Aedes aegypti (Garza-Hernández et al., 2013), tobacco hornworm Manduca sexta (St. Leger et al.,1996), mealworm beetle Tenebrio molitor (Oliveira \& Rangel, 2018), diamondback moth plutella xylostella (Batta, 2013), Wireworms melanotus communis (Kabaluk et at., 2005), termite Coptotermes formosanus (Wright, Raina, \& Lax, 2009), Cockroach, Supella longipalpa (Sharififard et at., 2016), Chagas vector Meccus pallidipennis (Flores-Villegas et al., 2016) and House Fly, Musca domestica (Sharififard et al., 2011). 
Joan Webber, (1981) suggested that, a protected elm tree against the beetle (Physocnemum brevilineum) was giving by endophytic fungus Phomopsis oblonga. The ability of fungi to occupy healthy tissue of the plant symptomless is very important to be considered. Many researchers worked on fungal entomopathogens as endophytes, in preparation for subsequent assessment of endophyte biological control. Beauveria bassiana have been tested to establish an endophyte (Brownbridge et al., 2012). However, B. bassiana, has the ability to exist as an endophyte in corn as a horizontally transmitted endophyte; $B$. bassiana infects hosts via germination of dry conidia following hydration on the leaf surface (Bing \& Lewis, 1992; Wagner \& Lewis, 2000) which may lead to pioneer methods for crop protection. Also the insectpathogenic fungus, Metarhizium robertsii is a common inhabitant of soils worldwide that has been studied and used as an insect pathogen for biocontrol (Lomer et al., 2001). Several species of entomopathogenic fungi have been playing multiple roles in nature ranging from antagonists of plant pathogens to rhizosphere associates, endophytes, and possibly even plant-growth (Vega, 2008). Vega et al., (2012) reported that when used as mycoinsecticides, entomopathogenic fungi have demonstrable potential for the management of insect pests.

Metarhizium anisopliae are producing pathogens implicated in toxicity of a number of insects, the action of cytotoxins is proposed by hyphae penetration causing symptoms such as partial or general paralysis and decreasing irritability in mycosed insects that are consistent with the action of neuromuscular toxins (Sandhu et al., 2012).

The selection of fungal pathogens for controlling Helicoverpa armigera is necessary because the selection of isolates which combine the best possible characteristics for diminishing the target insects under glasshouse conditions is vital.

The aims of the study were:

- To investigate the efficacy of strain $6 \mathrm{c} 1$ of the Metarhizium brunneum on Helicoverpa armigera

- To examine the ability of Metarhizium brunneum (6c1) to occupy the tissue of okra plant.

- To explore the problematic of pesticides resistance (Helicoverpa armigera) 


\subsection{Materials and methods}

Experiments were carried out under greenhouse conditions and quarantine cabinet at the Department of Entomology, Faculty of Agriculture - Georg-August-University, Gottingen.

\subsubsection{Insect rearing}

\subsubsection{Artificial diet}

Cotton bollworm eggs were obtained from a laboratory strain (Bayer Crop Science Monheim, Germany) and incubated in a chamber at $22{ }^{\circ} \mathrm{C} ; 60 \% \mathrm{RH} ; 16: 8 \mathrm{LD}$. Larvae started to hatch three days later, reared on an agar based artificial diet modified from Wakil et al., ( 2011) (Fig 2.1). The diet recipe completed to $1000 \mathrm{ml}$, heated on magnetic stirrer until boiling point. Then the followings were added: $2 \mathrm{~g}$ Methyl-4-hydrobenzoate, $4 \mathrm{ml}$ ETOH $96 \%$, $15 \mathrm{~g}$ Agar-Agar, $20 \mathrm{~g}$ wheat sprouts, 125g Bean Flour, $2 \mathrm{~g}$ Wessons Salt Mixture, $4 \mathrm{ml}$ sunflower Oil. The mixture was then stirred well for 5 minutes and let to cool to $70{ }^{\circ} \mathrm{C}$. Thereafter $8 \mathrm{~g}$ Vitaminmix, $6 \mathrm{~g}$ Vitamin $\mathrm{C}, 10 \mathrm{~g}$ Yeast Extract and $2 \mathrm{~g}$ Streptomycin Sulfate. The diet was immediately poured into petridishes ( $5 \mathrm{~cm}$ in diameter), allowed to cool and dry. Then one neonate larva was placed on it.

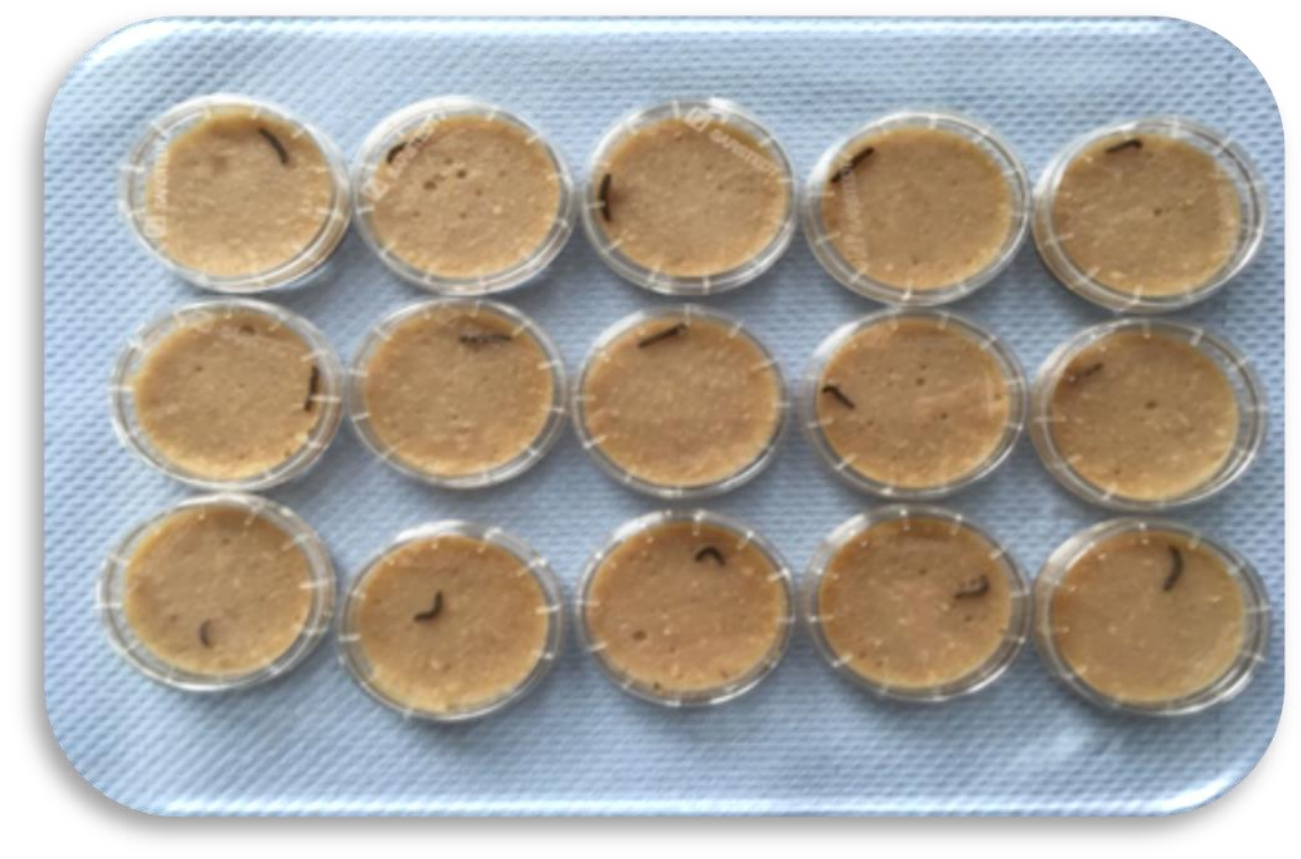

Figure 2.1. Rearing petri-dishes ( $5 \mathrm{~cm}$ in diameter) with artificial diet 


\subsubsection{Okra fruit diet}

The newly larvae from eggs brought from Bayer (Bayer Crop Science Monheim, Germany) hatched were transferred separately and placed into rearing containers petri-dishes $(9 \mathrm{~cm}$ in diameter). Each larva was supplied with okra fruit blocks. These pieces of fruit were maintained as fresh as possible by keeping them on moist filer paper. The food was renewed daily and faeces discarded, the petri-dishes were kept clean from faeces and food remains. Successive rearing experiments were conducted under climate chamber at $22{ }^{\circ} \mathrm{C} ; 60 \% \mathrm{RH} ; 18: 6 \mathrm{LD}$ (Fig 2.2a). When the larvae pupated; the date of pupation was recorded and adult emergence was watched closely to record the pupation period. The newly emerged adult's moths were sexed. The male and female were transferred into oviposition cage (Fig 2.2b). The cages were simply constructed from a cylinder with its top covered with muslin cloth and its lower end fitted on pot with water. The surface of water pot was separated from the contents of upper chamber by filter paper (125 $\mathrm{mm}$ diameter). Two small specimen glasses fitted with sponger soaked in a $7 \%$ honey solution, applied as food for adult moths, were tied on the walls of the cylinder and small fresh and tender branch of okra plant were placed inside the cage for egg deposition. The branch stalk dipped in water and such branches were renewed daily and examined for egg-laying.
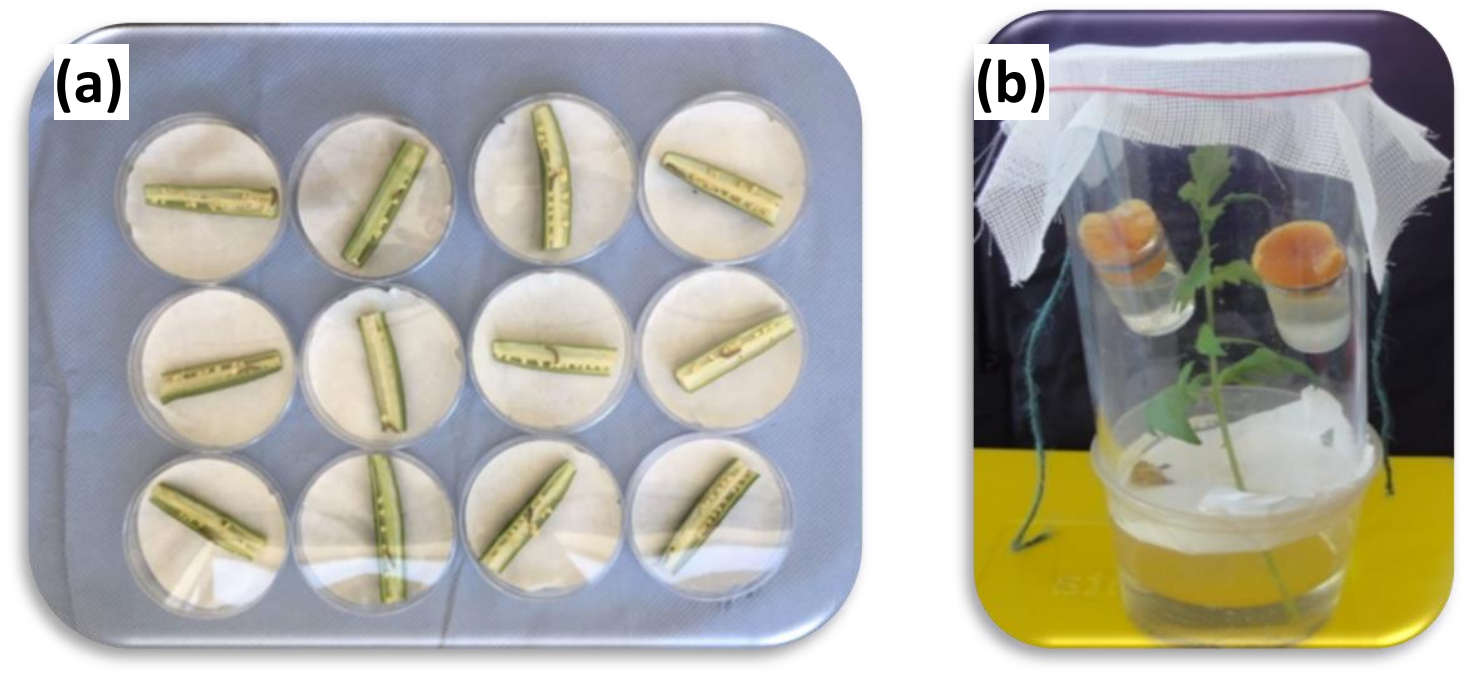

Figure 2.2 (a) Rearing petri-dishes (9 $\mathrm{cm}$ diameter) with okra block placed on moist filter paper (b) oviposition cage 


\subsubsection{Plant materials}

Seed of okra Abelmoschus esculentus (L.) obtained from Agricultural Research Corporation Sudan. Seedlings were grown in a greenhouse chamber $\left(23 \pm 3^{\circ} \mathrm{C} ; 60 \% \mathrm{RH} ; 18: 6 \mathrm{LD}\right)$. Twoweek old plants were individually transplanted into plastic pots $(15 \mathrm{~cm}$ diameter) with a mixture of non-sterile sand and soil. Plants were irrigated regularly and fertilized once a week.

\subsubsection{Seed test}

2.3.3.1 Surface sterilization of okra seeds

Okra seeds were surface sterilized in $70 \%$ ethanol for $90 \mathrm{~min}$, then $3 \mathrm{~min}$ in 5.25\% Sodium hypochlorite for, and finally again $90 \mathrm{~min}$ in $70 \%$ ethanol. Thereafter, seeds were washed in sterile water three times, then air dried on a filter paper in biosafety cabinet. For sterilization tests, randomly selected seeds were cultured on potato dextrose agar (PDA) and incubated at $25^{\circ} \mathrm{C}$ for 7 days.

\subsubsection{Okra plant inoculation}

Spore suspension of Metarhizium brunneum (6c1) was plated on autoclaved potato dextrose agar (PDA) and sub-cultured. Spores were washed from PDA by a few drops of Tween80. Then the removed material was transferred in sterile water $(200 \mathrm{ml})$. The spore suspensions were stirred with magnetic stirrer for $10 \mathrm{~min}$ and the spore concentration was adjusted at about $1 \times 10^{7}$ conidia/ml and $1 \times 10^{5}$ conidia/ml. Plants were inoculated using the toothpick method, toothpicks were autoclaved five times in distilled water, then autoclaved after cooling, toothpicks were rinsed in distilled water, and autoclaved again according to (Scandiani et al., 2011). Okra plants were divided into four groups of 15 plants each. The toothpicks were inserted in high and low concentration of spore suspension Metarhizium brunneum (6c1), Tween $800.01 \%$ (v: v) and non-contaminated toothpicks for the control. Each treatment was injected on okra plants for one week. 


\subsubsection{Cross section of okra plant}

The cross section was conducted to ensure endophytic strain of the Metarhizium brunneum (6c1) inside the plant tissue. For cross section test; randomly selected inoculated stem from each treatment was cut and then prepared on the slide and examined under light microscope.

\subsubsection{Effect of Metarhizium brunneum (6c1) on Helicoverpa armigera}

On each young plant bioassays were conducted where only unfolded new leaves were used. Consecutively, one larva per plant was transferred with fine brush onto the first growth stage 24 $\mathrm{BBCH}$ scale. The respective areas were covered with clip cages.

\subsubsection{Measured variables}

\subsubsection{Pupae success}

Pupae success was assessed at the end of larval stage and successfully entering the pupal stage. The number was recorded and expressed as percent pupal success. The date of pupation was recorded and the adult emerged was watched closely to record the pupation period.

\subsubsection{Consumed leaf area}

The setup consists of three translucent PVC sheets, black paper, a black square of precisely 100 $\mathrm{mm}^{2}$ within a red frame and a $100 \mathrm{~mm}^{2}\left[\mathrm{~mm}^{2}\right.$ paper $]$ square. For each larva the total consumed leaf area $\left[\mathrm{cm}^{2}\right]$ was used as an indirect fitness parameter and photometrically assessed through particle analysis with Fiji Image J v1.52g. (Rueden et al., 2017; Schindelin et al., 2012).

\subsubsection{Weight gain}

Larvae were obtained from eggs laid by the same female reared on okra fruit, newly larvae were transferred separately and placed in rearing containers, petri-dishes $(9 \mathrm{~cm}$ in diameter) and supplied with okra fruit blocks. When reached the second instar; larval weight was individually measured immediately before introduced into the clip-cages and again fully grown in order to calculate the weight gain (fresh fully grown instar weight - fresh second instar weight). The larvae were daily checked for molting and survival.

\subsubsection{Number of pods}

The pods were manually removed from harvested plants and number of pods per-plant was recorded. 


\subsubsection{Dry weight of below-ground}

Plants were cut at soil line above soil level and the above-ground plant parts, leaves and stems, were collected, the below-ground parts were carefully collected and thoroughly washed many times with water to remove soil particles. Then roots were detached from sand particles and organic debris by flotation. Then the root was separated from the top (cut at soil line). The collected materials were placed in towel paper for $10 \mathrm{~min}$ then transferred into a paper bag. The effect of treatment on okra was investigated by measuring the dry weight of shoot and root compared to the control. Above and below-ground parts of the plants were oven dried at $60^{\circ} \mathrm{C}$ for one week till constant weight was achieved.

\subsubsection{Statistical analysis}

Data were statistically analyzed with SigmaPlot version (SigmaPlot 14.0). Analysis of variance (ANOVA) was used to test for treatment effect if so, the differences were separated used Bonferroni test at a probability of 0.05 , unless otherwise stated. 


\subsection{Results}

\subsubsection{Seeds sterilization}

No contamination was observed with sterilized seeds, cultured on PDA and incubated at $25^{\circ} \mathrm{C}$ for 7 days (Fig. 2.3). This showed the efficacy of the tested seed sterilization procedures for its ability to germinate and eliminate contamination.

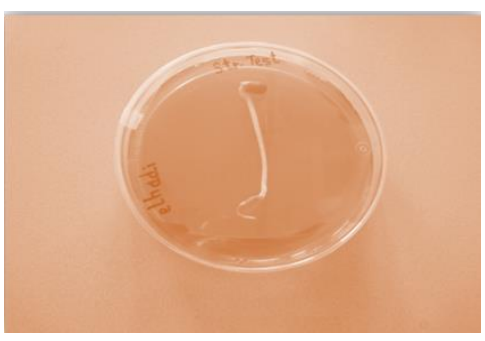

Figure 2.3 Seed sterilization

\subsubsection{Cross section of okra plant}

The cross section of okra stem was specifically conducted to test the growth the mycelium of endophytic strain of the entomopathogenic fungi Metarhizium brunneum inside the plant. The result revealed the distinctive colonization compared to the control (Fig. 2.4).
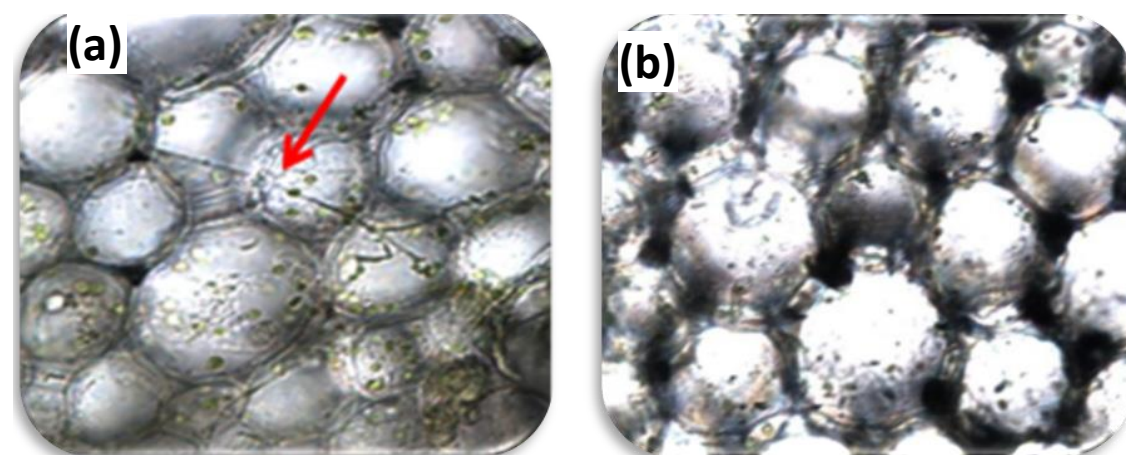

Figure 2.4 Entomopathogenic fungi on endophytic occupation of okra plants (a) red arrow shows the endophytic hyphae of Metarhizium brunneum, (b) control 


\subsubsection{Total life cycle}

Total development duration (life cycle) of Helicoverpa armigera reared on artificial diet ranged from 43 to 46 days, average $43.70 \pm 1.57$ days while for okra fruit it ranged from 43 to 48 days, average $45.6 \pm 2.10$ days (Fig 2.5)

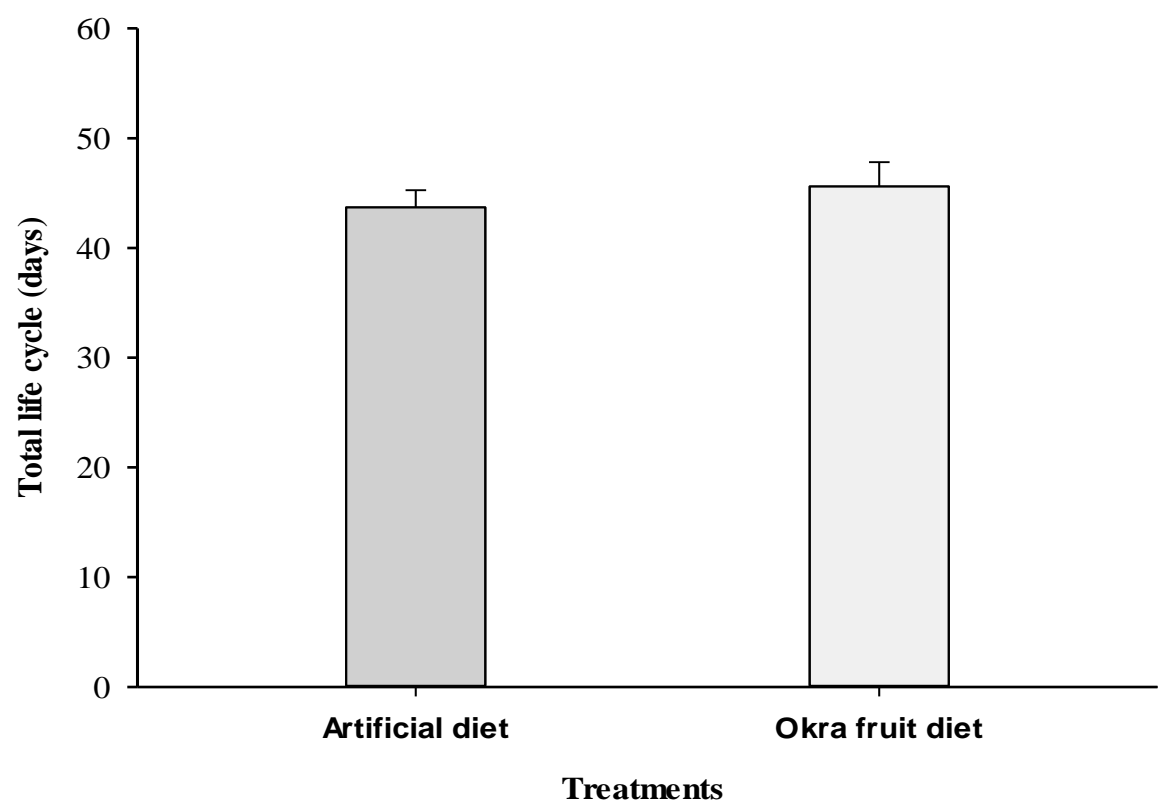

Figure 2.5 Total life cycle of Helicoverpa armigera reared on artificial diet and okra fruit under climate chamber at $\left(22^{\circ} \mathrm{C} ; 60 \% \mathrm{RH} ; 18: 6 \mathrm{~L}\right)$

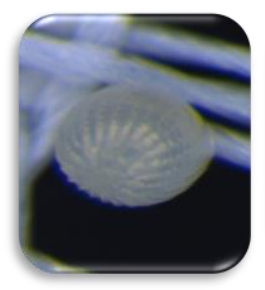

Egg

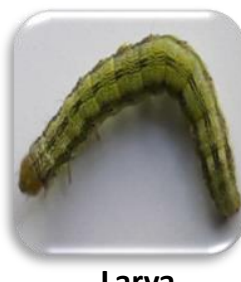

Larva

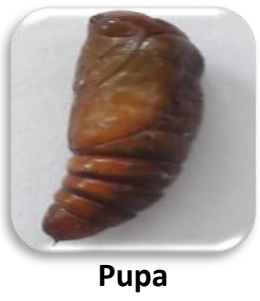

Pupa
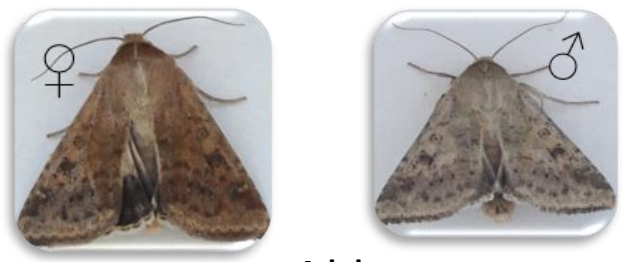

Adults

Figure 2.6 Life cycle of Helicoverpa armigera reared on okra 


\subsubsection{Pupae success}

The study showed significant differences $(\mathrm{P}<0.05)$ in the virulence of strain. After 12 days' post-treatment, in the control, the endophyte treatments reduced pupae success, however, the high conc and low conc of spoor suspension showed a gradual reduction of the number of pupations, toothpick inoculation, thus, okra plant showed high efficiency of suppression. The resulted values were $80 \%, 73 \%, 20 \%, 13 \%$ for the negative control, Tween $800.01 \%$, high conc and low conc, respectively (Fig2.7).

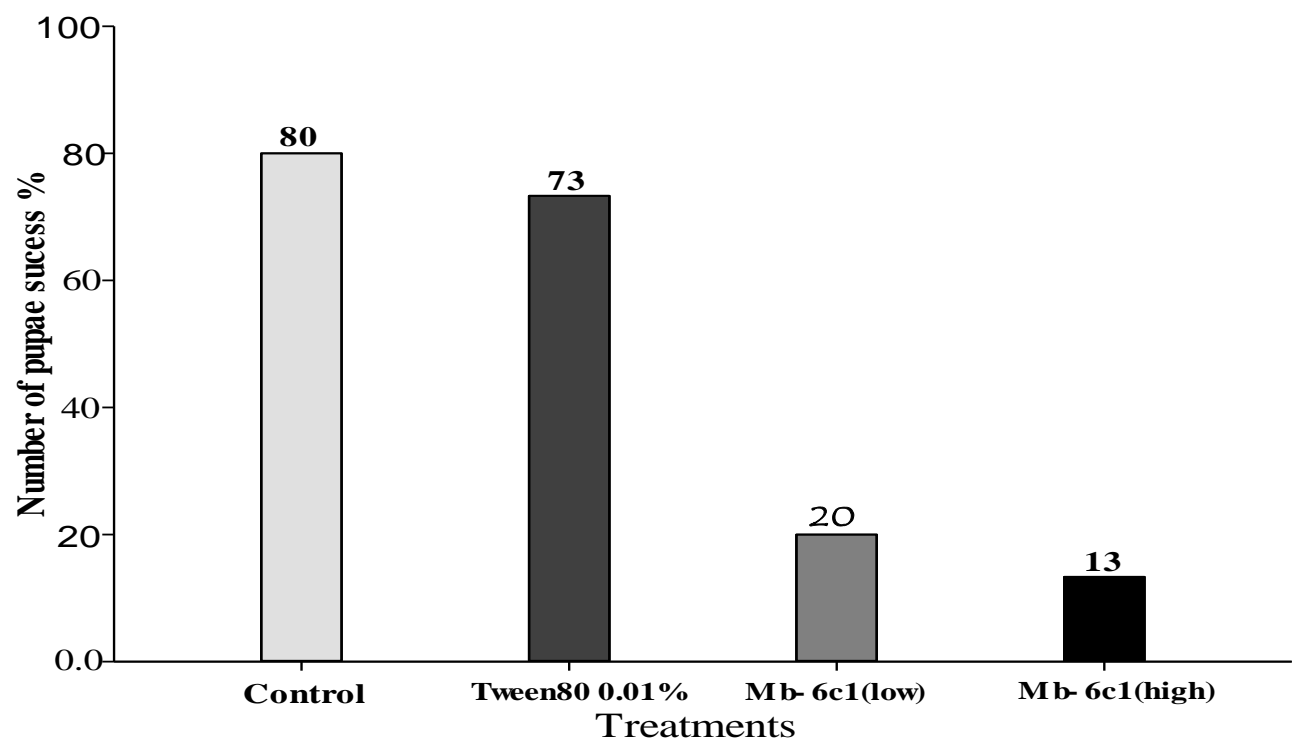

Figure 2.7 Percentage pupae success of Helicoverpa armigera on each treatment Mb-6c1 okra plant with Metarhizium brunneum low conc and high conc toothpick inoculation, okra plant, Tween80 0.01\% with tooth pick inoculation, control clean okra plant.
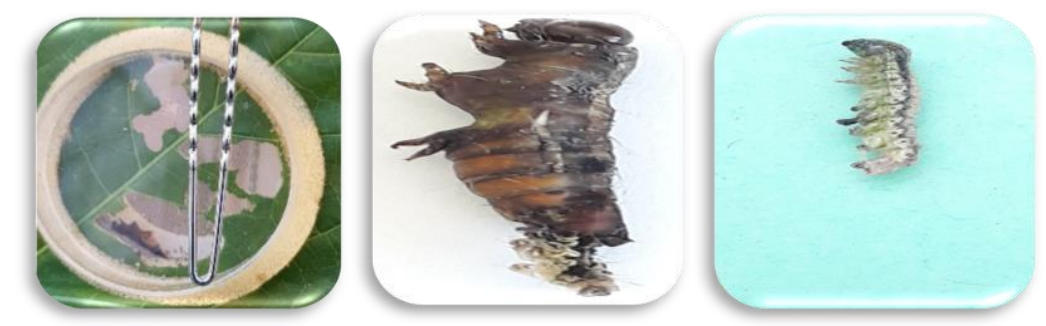

Figure 2.8 Mortality symptom of Helicoverpa armigera in high conc and low conc of spore suspension 


\subsubsection{Consumed leaf area}

Consumed leaf area (Fig 2.9) was significantly influenced by treatment ( $p<0.05)$. The mean total consumed leaf area of negative control treatment was $91.79 \pm 17.64 \mathrm{~cm}^{2}$ and $75.01 \pm 9.59$ $\mathrm{cm}^{2}$ for Tween $800.1 \%$. Both were significantly higher than the high conc and low conc where the leaf area was $63.13 \pm 11.90 \mathrm{~cm}^{2}$ and $54.65 \pm 10.32 \mathrm{~cm}^{2}$, respectively.

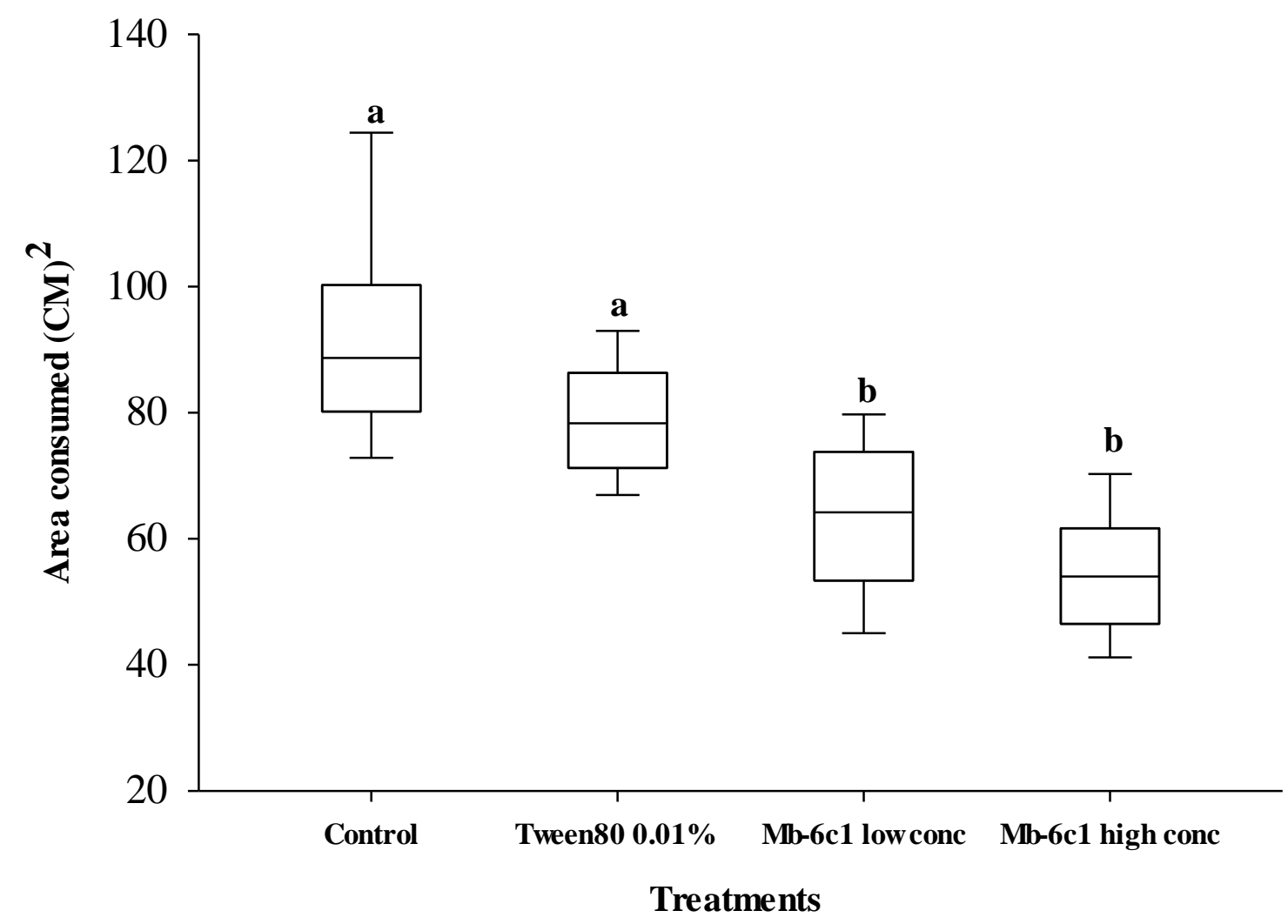

Figure 2.9 Consumed leaf area $\left[\mathrm{cm}^{2}\right]$ by Helicoverpa armigera larvae on okra plants for each treatment (Metarhizium brunneum Mb-6c1 low conc and high conc, Tween80 0.01\%, negative control). Error bars represent \pm SE. Same letters are not significantly different using least significant difference (LSD). 
2.4.5.1 Consumed leaf area of Helicoverpa armigera larvae for each treatment per day The daily consumed leaf area is resulted in the following values $19.742 \mathrm{~cm}^{2}, 12.156 \mathrm{~cm}^{2}, 8.689$ $\mathrm{cm}^{2}, 5.266 \mathrm{~cm}^{2}$ for the control, Tween80 $0.01 \%$, high conc and low conc of spore suspension, respectively. (Fig 2.10)
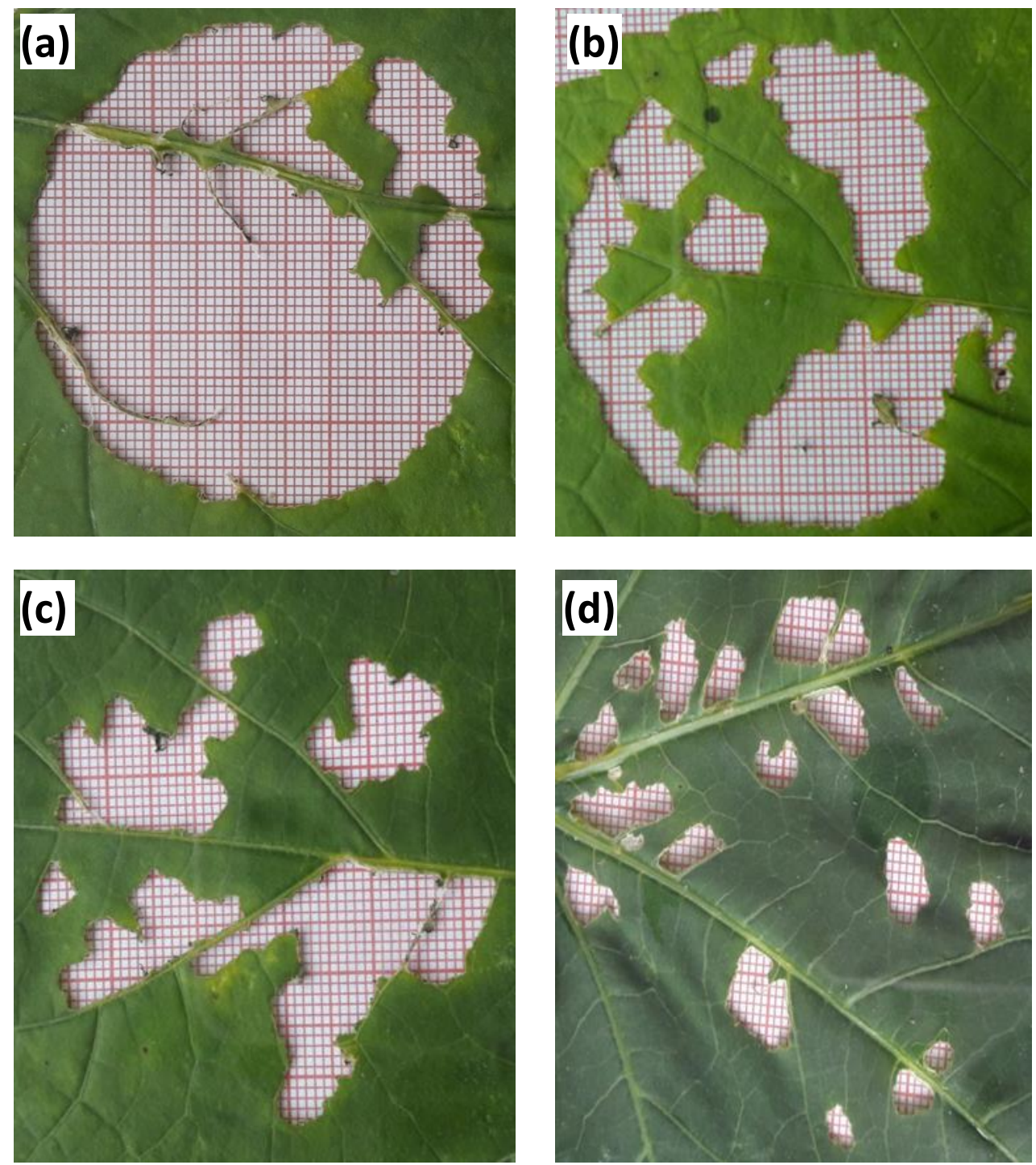

Figure 2.10 The pattern of damage on different treatments. (a) Control area consumed per day $\left(19.742 \mathrm{~cm}^{2}\right)$, (b) Tween80 $0.01 \%$ area consumed per day $\left(12.126 \mathrm{~cm}^{2}\right)$ (c) Low conc area consumed per day $\left(8.689 \mathrm{~cm}^{2}\right)$ and $(\mathbf{d})$ High conc area consumed per day $\left(5.266 \mathrm{~cm}^{2}\right)$ 


\subsubsection{Weight gain}

Weight gained by Helicoverpa armigera larvae was significantly different between treatments ( $p$ $<0.05)$ and the higher value $(0.13 \pm 0.04)$ was recorded in the control compared to values reported in the high conc and low conc of Mb-6c1 (0.05 $\pm 0.04,0.07 \pm 0.06)$, however, no significant differences were detected between control and Tween80 0.01\% (Fig 2.11)

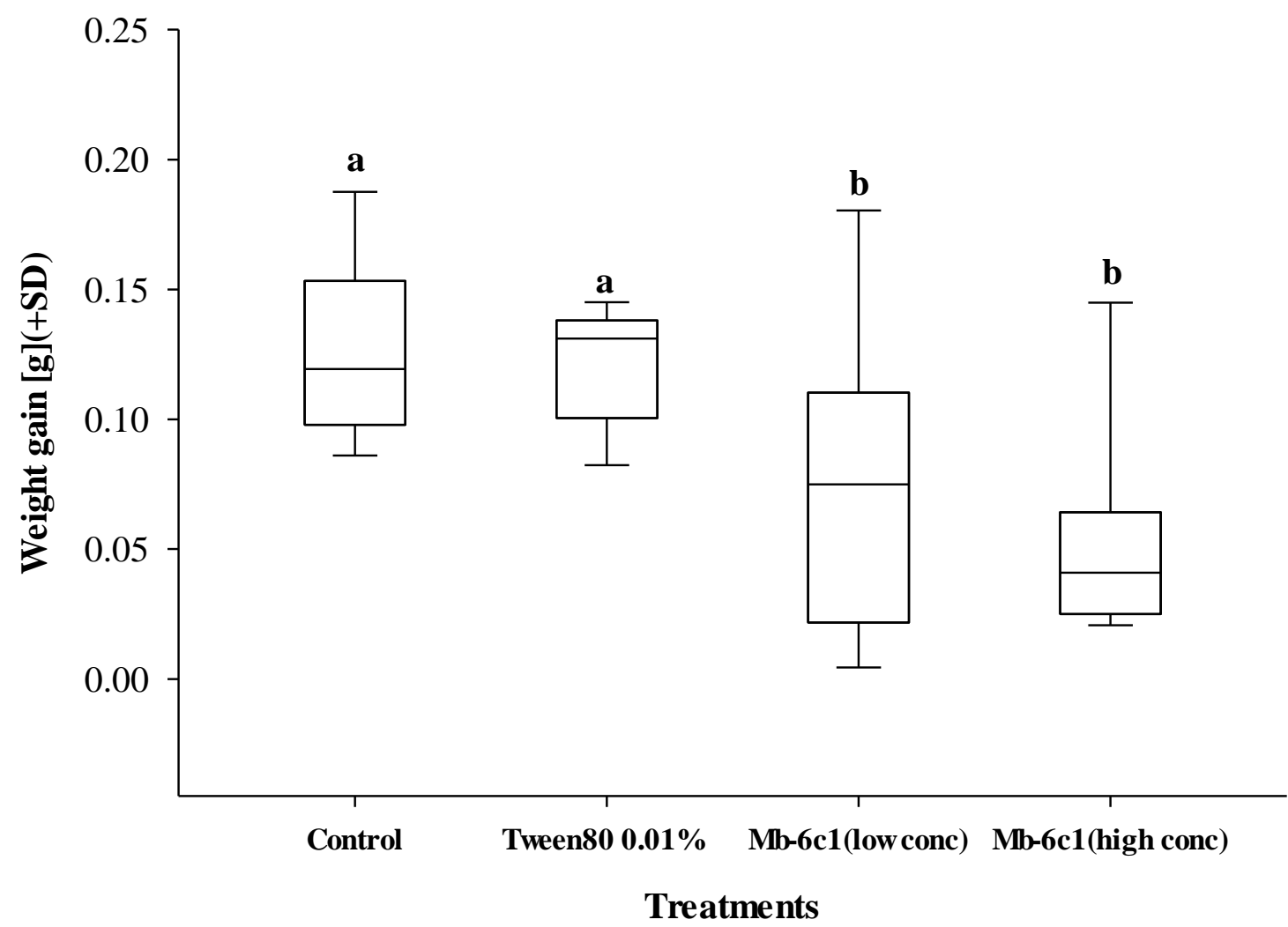

Figure 2.11 Effect of treatments (Mb-6c1 low conc and high conc, Tween80 0.01\%, negative control) on weight gained by larva Helicoverpa armigera. Vertical bars with the same letter(s) are not significantly different $(\mathrm{P}<0.05)$ using least significant difference. 


\subsubsection{Feces dry weight}

The dry weight of feces produced by the larvae Helicoverpa armigera was significantly different between treatments $(\mathrm{p}<0.05)$ and the higher value $(0.12 \pm 0.02)$ was recorded in the control compared to values reported in the high conc and low conc of Mb-6c1 $(0.06 \pm 0.0,0.08 \pm 0.02)$, however, no significant differences were detected between control and Tween80 0.01\% (0.11 \pm 0.01) (Fig 2.12)

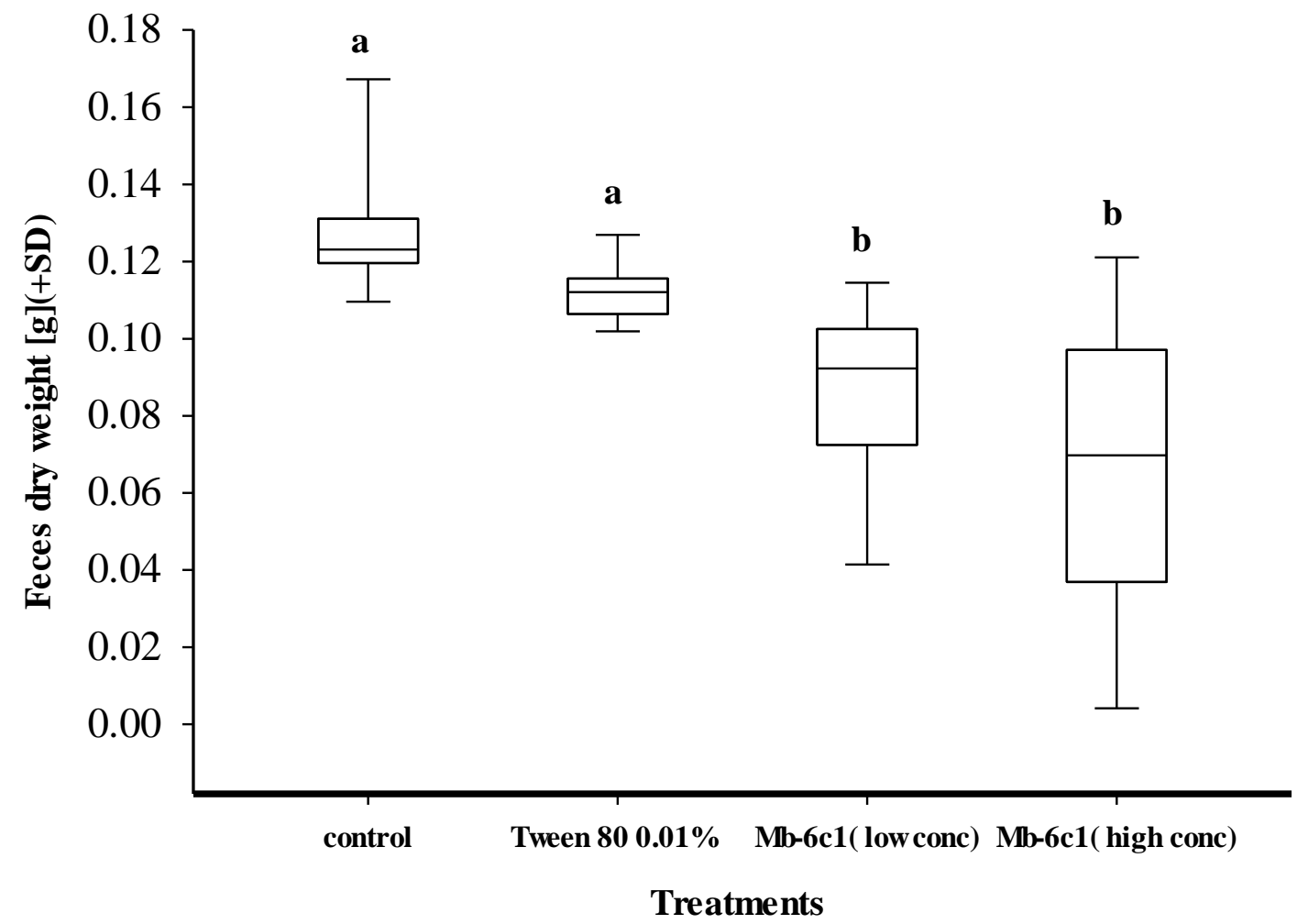

Figure 2.12 Effect of treatments (Mb-6c1 low conc and high conc, Tween80 0.01\%, negative control) on dry weight of feces produced by the larvae Helicoverpa armigera. Vertical bars with the same letter(s) are not significantly different $(P<0.05)$ using least significant difference. 


\subsubsection{Number of pods}

Pods harvested from each treatment were $2.66 \pm 1.29,2.72 \pm 1.27,2.93 \pm 1.43$, and $3.0 \pm 1.30$ for control, Twin80 0.01\%, high conc and low conc, respectively (Fig 2.13)

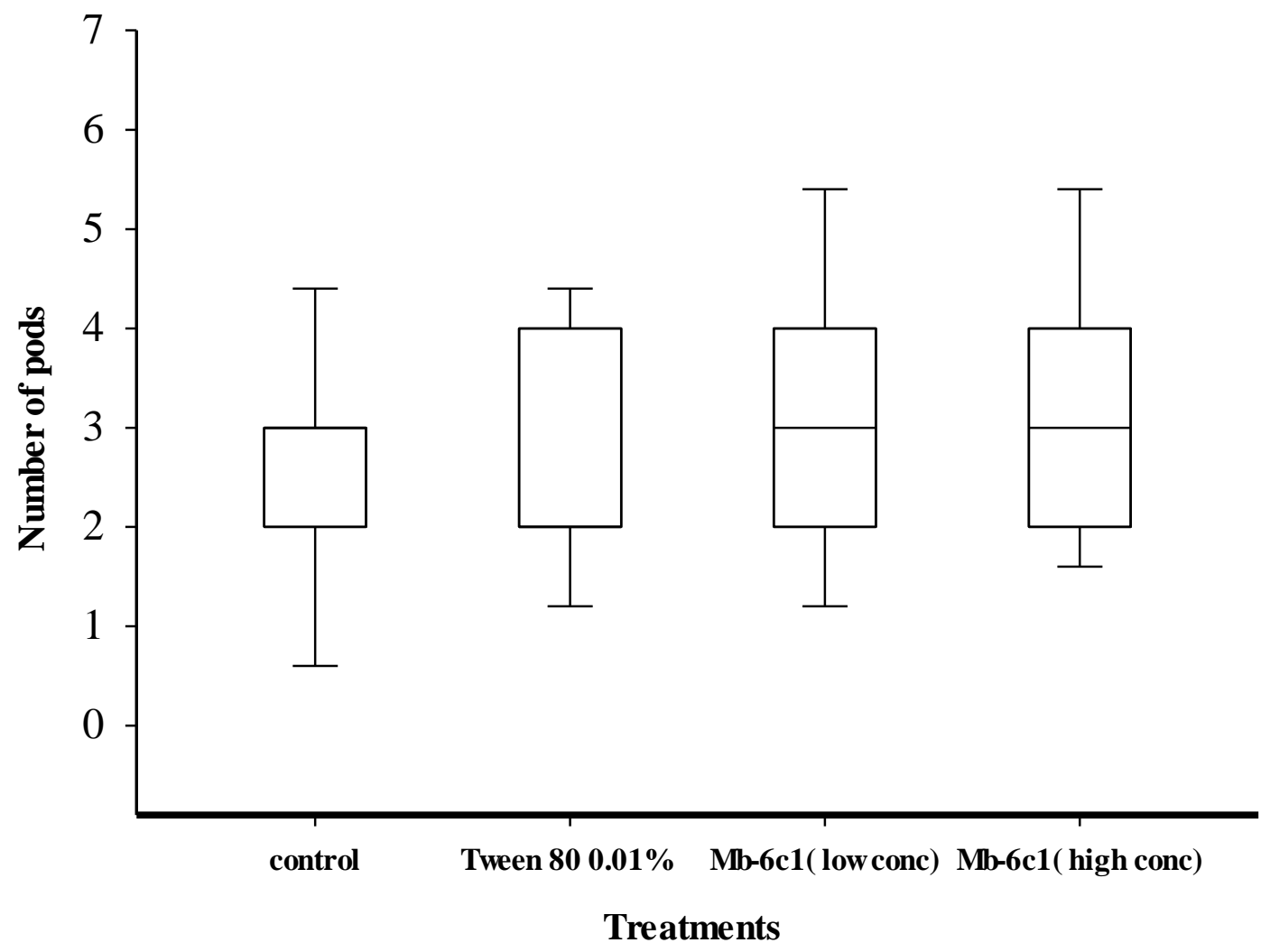

Figure 2.13 Number of pods per plant produced for each treatment (Metarhizium brunneum Mb6c1 low conc and high conc, Tween $800.1 \%$ negative control, toothpick inoculation) 


\subsubsection{Dry weight of below-ground plant biomass}

Fig (2.14) shows the results of the below-ground dry matter of okra plant obtained with high conc and low conc of Mb-6c1 that was significantly $(\mathrm{P}<0.05)$ different compared to the control and Tween $800.01 \%$, however, no significant differences were observed between the control and Tween 80 and the same result was reported between the low conc and high conc.

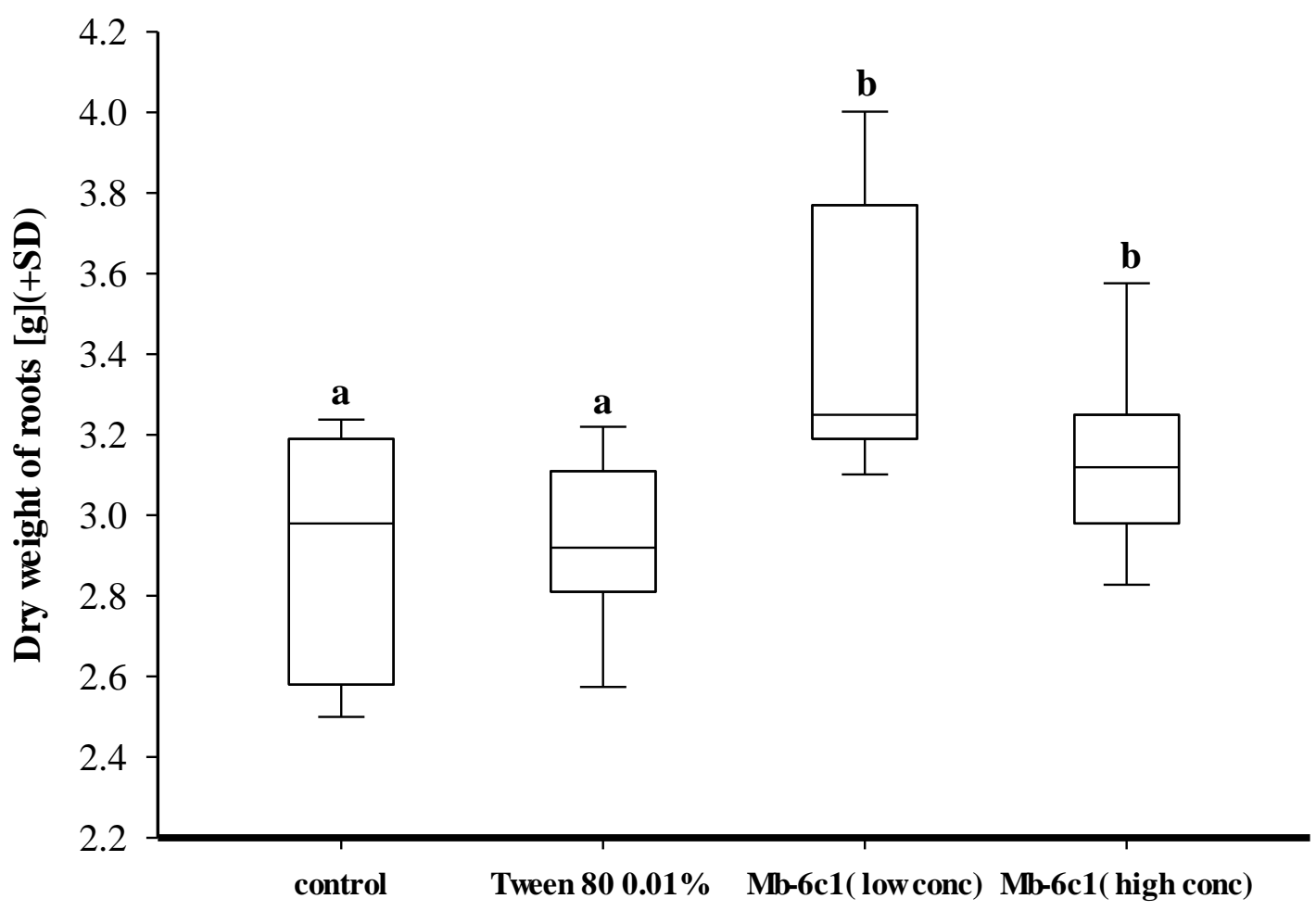

Treatments

Figure 2.14 Dry weight of roots okra plants for each treatment (Metarhizium brunneum Mb-6c1 low conc and high conc Tween $800.01 \%$, negative control, toothpick inoculation) 


\subsection{Discussion}

The possibility for utilizing a fungal delivering system through endophytic phenomena could be beneficial in managing the population insect pests with such leaves chewing insects as Helicoverpa armigera. Our result showed that the toothpick inoculation with a strain of the entomopathogenic fungi Metarhizium brunneum (6c1) was able to endophytically-colonize okra plants. After 2 weeks, the cross section of the okra plant showed colonization of Mb-6c1. Previous reported that the ideal inoculation methods include among others seed coating and immersions, root inoculation, stem injection and flower sprays which result in systemic colonization of plants by fungal entomopathogen (Tefera \& Vidal, 2009; Biswas et al., 2012; Brownbridg et al., 2012). Thus, our results are in accordance with those obtained by (Gurulingappa et at., (2010) who studied entomopathogenic as endophytic fungi in family Malvaceae. Similar results were reported in other crops, for example. coffee (Posada et at., 2007), corn (Wagner and Lewis, 2000), cassava (Greenfield et al., 2016) and potato (Jones, 1994). Moreover, the mechanism of Metarhizium species to colonize plant tissue are described by many researchers (Behie, Jones, \& Bidochka, 2015 ; Akello \& Sikora, 2012).

The diet plays an important role in the development of larvae $H$ armigera, this is evident from finding of the modified diet that showed better growth and shorter developing period compared to okra fruit block diet. Our result are in line with Wu \& Gong, (1997) who reported an average larvae duration 11,7 days for larvae fed with an artificial diet while 15 days for larvae fed on cotton leaves. However, the nutritive value of diets greatly influences the healthiness of growth and development duration of the larvae.

Entomopathogenic fungi can be effective not only when in direct contact with the target host, but thorough endophytic colonization of the effective spore or produces toxic substance acquired by larvae $H$ armigera. Our experiments showed that $\mathrm{Mb}-6 \mathrm{c} 1$ is virulent against larvae, on another hand the intoxication of the larvae can have a significant effect on the developing stages.

The patterns of okra leaves damage caused by intoxicated $H$ armigera in Mb-c61 leaves were characteristically different. For instance, in the control our negative control the damaged area was regular in shape and the larvae tended to consume the whole leaf and even tried to damage the clip cage, the same pattern was observed for Tween $800.01 \%$ with less severity. However, larvae in okra leaves treated with the low conc and high conc of $\mathrm{Mb}-6 \mathrm{c} 1$ tended to avoid the 
endophytic entomopathogenic fungi which resulted in an inconsistent pattern of consumption. Our finding concurs with Russo et al., (2019) who reported that the significant reduction in consumption has been attributed to toxic substance by entomopathogenic fungi inside the host that lead to effect the survival and development of subsequent generation. Also, aphids test choice preferred to fed on plants that were not colonized with entomopathogenic fungi Fusarium oxysporum (Martinuz et al., 2012)

In our study, Mb-6c1 was found to cause significant reduction in the larval weight, thus, the results clearly indicate that both low conc and high conc showed significant pupal success (20\%, $13 \%$, respectively) and were not able to pupate when larvae are feeding on $\mathrm{Mb}-6 \mathrm{c} 1$ treated plants. However, Tween80 $0.01 \%$ do not have an effect on larvae of $H$ armigera. Our observation is supported by (Revathi et al., (2011) who reported that $M$ anisopliae showed more than $70 \%$ mortality of $H$ armigera in bioassay. Inculcation of plant with entomopathogen fungi showed higher levels of terpenoids which are contemplated secondary metabolites to act as plant defense against an herbivorous insect (Shrivastava et al., 2015)

Survival of fungal pathogens in an edaphic habitat is reported to enhance crop canopy (ÁlvarezLoayza et al., 2011) and many of the pathogens can survive saprophytically in soils (Raaijmakers et al., 2009). M. brunneum used in this study enhanced the crop growth by means of proliferation of roots and increased vegetative growth which might have played an important role as bio fertilizer and could consequently manage pests. This finding is in agreement with the report of Mukherjee et al., (2013) who reported that the mechanisms by which Metarhizium boosts plant growth are likely to be multifactorial, similarly as reported for species of Trichoderma which stimulate plant-growth-promoting effects that include antibiosis, parasitism, induction of host plant resistance, and competition. However, M. brunneum could act as producer of plant growthpromoting auxins on roots and open new window in the industry of plant growth regulation from entomopathogenic fungi.

\subsection{Conclusion}

This study concluded that treatment of okra plant with Mb-6c1 resulted in the reduction of the consumed area, weight gain, dry weight of feces and pupae success and this could affect the performance of bollworm by means of toothpick inoculation. An endophytic application of $\mathrm{Mb}$ - 
6c1 significantly altered $H$ armigera larval behavior which larvae avoiding treated host plant and reducing their feeding activity. Further studies could evaluate the presence of fungal entomopathogenic into immature insect bodies. 


\section{References}

Akello, J., \& Sikora, R. (2012). Systemic acropedal influence of endophyte seed treatment on Acyrthosiphon pisum and Aphis fabae offspring development and reproductive fitness. Biological Control, 61(3), 215-221. https://doi.org/10.1016/j.biocontrol.2012.02.007

Álvarez-Loayza, P., White, J. F., Torres, M. S., Balslev, H., Kristiansen, T., Svenning, J. C., \& Gil, N. (2011). Light converts endosymbiotic fungus to pathogen, influencing seedling survival and niche-space filling of a common tropical tree, Iriartea deltoidea. PLoS ONE, 6(1). https://doi.org/10.1371/journal.pone.0016386

Batta, Y. A. (2013). Efficacy of endophytic and applied Metarhizium anisopliae (Metch.) Sorokin (Ascomycota: Hypocreales) against larvae of Plutella xylostella L. (Yponomeutidae: Lepidoptera) infesting Brassica napus plants. Crop Protection, 44, 128134. https://doi.org/10.1016/j.cropro.2012.11.001

Behie, S. W., Jones, S. J., \& Bidochka, M. J. (2015). Plant tissue localization of the endophytic insect pathogenic fungi Metarhizium and Beauveria. Fungal Ecology, 13, 112-119. https://doi.org/10.1016/j.funeco.2014.08.001

Bing, L. A., \& Lewis, L. C. (1992). Endophytic Beauveria Bassiana (Balsamo) Vuillemin In Corn: The Influence Of The Plant Growth Stage and Ostrinia Nubilalis (Hubner). Biocontrol Science and Technology, 2(1), 39-47. https://doi.org/10.1080/09583159209355216

Biswas, C., Dey, P., Satpathy, S., \& Satya, P. (2012). Establishment of the fungal entomopathogen Beauveria bassiana as a season long endophyte in jute (Corchorus olitorius) and its rapid detection using SCAR marker. BioControl, 57(4), 565-571. https://doi.org/10.1007/s10526-011-9424-0

Brownbridge, M., Reay, S. D., Nelson, T. L., \& Glare, T. R. (2012). Persistence of Beauveria bassiana (Ascomycota: Hypocreales) as an endophyte following inoculation of radiata pine seed and seedlings. Biological Control, 61(3), 194-200. https://doi.org/10.1016/j.biocontrol.2012.01.002

Flores-Villegas, A. L., Cabrera-Bravo, M., Toriello, C., Bucio-Torres, M. I., Salazar-Schettino, 
P. M., \& Córdoba-Aguilar, A. (2016). Survival and immune response of the Chagas vector Meccus pallidipennis (Hemiptera: Reduviidae) against two entomopathogenic fungi, Metarhizium anisopliae and Isaria fumosorosea. Parasites and Vectors, 9(1), 1-11. https://doi.org/10.1186/s13071-016-1453-1

Freimoser, F. M., Screen, S., Bagga, S., Hu, G., \& Leger, R. J. S. (2003). Expressed sequence tag ( EST ) analysis of two species of Metarhizium anisopliae reveals a plethora of secreted proteins with potential activity in insect hosts Expressed sequence tag ( EST ) analysis of two subspecies of Metarhizium anisopliae reveals a . (May 2014).

https://doi.org/10.1099/mic.0.25761-0

Garza-Hernández, J. A., Rodríguez-Pérez, M. A., Salazar, M. I., Russell, T. L., Adeleke, M. A., de Luna-Santillana, E. de J., \& Reyes-Villanueva, F. (2013). Vectorial Capacity of Aedes aegypti for Dengue Virus Type 2 Is Reduced with Co-infection of Metarhizium anisopliae. PLoS Neglected Tropical Diseases, 7(3), 1-5. https://doi.org/10.1371/journal.pntd.0002013

Gonzalez, F., Tkaczuk, C., Dinu, M. M., Fiedler, Ż., Vidal, S., Zchori-Fein, E., \& Messelink, G. J. (2016). New opportunities for the integration of microorganisms into biological pest control systems in greenhouse crops. Journal of Pest Science, 89(2), 295-311. https://doi.org/10.1007/s10340-016-0751-X

Greenfield, M., Gómez-Jiménez, M. I., Ortiz, V., Vega, F. E., Kramer, M., \& Parsa, S. (2016). Beauveria bassiana and Metarhizium anisopliae endophytically colonize cassava roots following soil drench inoculation. Biological Control, 95, 40-48. https://doi.org/10.1016/j.biocontrol.2016.01.002

Gurulingappa, P., Sword, G. A., Murdoch, G., \& McGee, P. A. (2010). Colonization of crop plants by fungal entomopathogens and their effects on two insect pests when in planta. Biological Control, 55(1), 34-41. https://doi.org/10.1016/j.biocontrol.2010.06.011

Hatting, J. L. (2012). Comparison of Three Entomopathogenic Fungi Against the Bollworm, Helicoverpa armigera (Hübner) (Lepidoptera: Noctuidae), Employing Topical vs per os Inoculation Techniques . African Entomology, 20(1), 91-100. https://doi.org/10.4001/003.020.0112 
Hunt, V. L., \& Charnley, A. K. (2011). The inhibitory effect of the fungal toxin, destruxin A, on behavioural fever in the desert locust. Journal of Insect Physiology, 57(10), 1341-1346. https://doi.org/10.1016/j.jinsphys.2011.06.008

Javed, M., Majeed, M. Z., Luqman, M., \& Afzal, M. (2019). Development and Field Evaluation of a Biorational IPM Module against Okra Shoot and Fruit Borers, Earias vittella and Helicoverpa armigera (Lepidoptera: Noctuidae). Pakistan Journal of Agricultural Research, 32(1). https://doi.org/10.17582/journal.pjar/2019/32.1.170.176

Joan Webber. (1981). A natural biological control of Dutch elm disease. Nature, 292, 449-451.

Jones, K. D. (1994). Aspects of the Biology and Biological Control of the European corn borer in North Carolina, PhD. Dissertation. Raleigh, NC: North Carolina State University, 127 pp.

Kabaluk, J., Goettel, M., \& Erlandson, M. (2005). Metarhizium anisopliae as a biological control for wireworms and a report of some other naturally-occurring parasites. IOBC/WPRS Bulletin, 28(2), 109-115. Retrieved from http://iobc-wprs.org/pub/bulletins/iobcwprs_bulletin_2005_28_02.pdf\#page=124

Lomer, C. J., Bateman, R. P., Johnson, D. L., Langewald, J., \& Thomas, M. (2001). B Iological C Ontrol of L Ocusts and G Rasshoppers . Annual Review of Entomology, 46(1), 667-702. https://doi.org/10.1146/annurev.ento.46.1.667

Martinuz, A., Schouten, A., Menjivar, R. D., \& Sikora, R. A. (2012). Effectiveness of systemic resistance toward Aphis gossypii (Hom., Aphididae) as induced by combined applications of the endophytes Fusarium oxysporum Fo162 and Rhizobium etli G12. Biological Control, 62(3), 206-212. https://doi.org/10.1016/j.biocontrol.2012.05.006

Mukherjee, P. K., Horwitz, B. A., Herrera-Estrella, A., Schmoll, M., \& Kenerley, C. M. (2013). Trichoderma Research in the Genome Era . Annual Review of Phytopathology, 51(1), 105129. https://doi.org/10.1146/annurev-phyto-082712-102353

Oliveira, A. S., \& Rangel, D. E. N. (2018). Transient anoxia during Metarhizium robertsii growth increases conidial virulence to Tenebrio molitor. Journal of Invertebrate Pathology, 153, 130-133. https://doi.org/10.1016/j.jip.2018.03.007 
Posada, F., Aime, M. C., Peterson, S. W., Rehner, S. A., \& Vega, F. E. (2007). Inoculation of coffee plants with the fungal entomopathogen Beauveria bassiana (Ascomycota: Hypocreales). Mycological Research, 111(6), 748-757. https://doi.org/10.1016/j.mycres.2007.03.006

Raaijmakers, J. M., Paulitz, T. C., Steinberg, C., Alabouvette, C., \& Moënne-Loccoz, Y. (2009). The rhizosphere: A playground and battlefield for soilborne pathogens and beneficial microorganisms. Plant and Soil, 321(1-2), 341-361. https://doi.org/10.1007/s11104-0089568-6

Revathi, N., Ravikumar, G., \& Kalaiselvi, M. (2011). Pathogenicity of Three Entomopathogenic Fungi against Helicoverpa armigera. Journal of Plant Pathology \& Microbiology, 02(04), 25. https://doi.org/10.4172/2157-7471.1000114

Roberts, D. W., \& St. Leger, R. J. (2004). Metarhizium spp., cosmopolitan insect-pathogenic fungi: Mycological aspects. Advances in Applied Microbiology, 54, 1-70. https://doi.org/10.1016/S0065-2164(04)54001-7

Rueden, C. T., Schindelin, J., Hiner, M. C., DeZonia, B. E., Walter, A. E., Arena, E. T., \& Eliceiri, K. W. (2017). ImageJ2: ImageJ for the next generation of scientific image data. BMC Bioinformatics, 18(1), 1-26. https://doi.org/10.1186/s12859-017-1934-z

Russo, M. L., Scorsetti, A. C., Vianna, M. F., Cabello, M., Ferreri, N., \& Pelizza, S. (2019). Endophytic effects of beauveria bassiana on corn (Zea mays) and its herbivore, rachiplusia nu (lepidoptera: Noctuidae). Insects, Vol. 10. https://doi.org/10.3390/insects10040110

Sandhu, S. S., Sharma, A. K., Beniwal, V., Goel, G., Batra, P., Kumar, A., ... Malhotra, S. (2012). Myco-Biocontrol of Insect Pests: Factors Involved, Mechanism, and Regulation. Journal of Pathogens, 2012, 1-10. https://doi.org/10.1155/2012/126819

Scandiani, M. M., Ruberti, D. S., Giorda, L. M., Pioli, R. N., Luque, A. G., Bottai, H., ... O’Donnell, K. (2011). Comparação de métodos de inoculação para a caracterização de agressividade relativa de dois agentes etiológicos da síndrome da morte súbita de soja, Fusarium tucumaniae e F. virguliforme. Tropical Plant Pathology, 36(3), 133-140. https://doi.org/10.1590/S1982-56762011000300001 
Schindelin, J., Arganda-Carreras, I., Frise, E., Kaynig, V., Longair, M., Pietzsch, T., ... Cardona, A. (2012). Fiji: An open-source platform for biological-image analysis. Nature Methods, 9(7), 676-682. https://doi.org/10.1038/nmeth.2019

Shah, P. A., \& Pell, J. K. (2003). Entomopathogenic fungi as biological control agents. Applied Microbiology and Biotechnology, 61(5-6), 413-423. https://doi.org/10.1007/s00253-003$1240-8$

Sharififard, M., Mossadegh, M. S., Vazirianzadeh, B., \& Zarei-Mahmoudabadi, A. (2011). Interactions between entomopathogenic fungus, metarhizium anisopliae and sublethal doses of spinosad for control of house fly, Musca domestica. Iranian Journal of Arthropod-Borne Diseases, 5(1), 28-36.

Sharififard, Mona, Mossadegh, M. S., Vazirianzadeh, B., \& Latifi, S. M. (2016). Biocontrol of the brown-banded cockroach, Supella longipalpa F. (Blattaria: Blattellidae), with entomopathogenic fungus, Metharhizium anisopliae. Journal of Arthropod-Borne Diseases, 10(3), 337-348.

Shrivastava, G., Ownley, B. H., Augé, R. M., Toler, H., Dee, M., Vu, A., ... Chen, F. (2015). Colonization by arbuscular mycorrhizal and endophytic fungi enhanced terpene production in tomato plants and their defense against a herbivorous insect. Symbiosis, 65(2), 65-74. https://doi.org/10.1007/s13199-015-0319-1

St. Leger, R. J., Joshi, L., Bidochka, M. J., \& Roberts, D. W. (1996). Construction of an improved mycoinsecticide overexpressing a toxic protease. Proceedings of the National Academy of Sciences of the United States of America, 93(13), 6349-6354. https://doi.org/10.1073/pnas.93.13.6349

Tefera, T., \& Vidal, S. (2009). Effect of inoculation method and plant growth medium on endophytic colonization of sorghum by the entomopathogenic fungus Beauveria bassiana. BioControl, 54(5), 663-669. https://doi.org/10.1007/s10526-009-9216-y

Uddin, M. A., Jahan, M., \& Uddin, M. M. (2009). Issn 1017-8139 study on nature and extent of damage of corn earworm,. Progress. Agric, 20(1), 49-55. 
Vega, F. E. (2008). Insect pathology and fungal endophytes. Journal of Invertebrate Pathology, 98(3), 277-279. https://doi.org/10.1016/j.jip.2008.01.008

Vega, F. E., Meyling, N. V, Luangsa-Ard, J. J., \& Blackwell, M. (2012). Fungal entomopathogens. In Insect Pathology (pp. 171-220). https://doi.org/10.1016/B978-0-12384984-7.00006-3

Wagner, B. L., \& Lewis, L. C. (2000). Colonization of corn, Zea mays, by the entomopathogenic fungus Beauveria bassiana. Applied and Environmental Microbiology, 66(8), 3468-3473. https://doi.org/10.1128/AEM.66.8.3468-3473.2000

Wakil, W., Ghazanfar, M. U., Sahi, S. T., Kwon, Y. J., \& Qayyum, M. A. (2011). Effect of modified meridic diet on the development and growth of tomato fruitworm Helicoverpa armigera (Lepidoptera: Noctuidae). Entomological Research, 41(3), 88-94. https://doi.org/10.1111/j.1748-5967.2011.00323.x

Wang, S., Fang, W., Wang, C., \& St. Leger, R. J. (2011). Insertion of an esterase gene into a specific locust pathogen (Metarhizium acridum) enables it to infect caterpillars. PLoS Pathogens, 7(6). https://doi.org/10.1371/journal.ppat.1002097

Wright, M. S., Raina, A. K., \& Lax, A. R. (2009). A Strain of the Fungus <I>Metarhizium anisopliae</I> for Controlling Subterranean Termites. Journal of Economic Entomology, 98(5), 1451-1458. https://doi.org/10.1603/0022-0493-98.5.1451

Wu, K., \& Gong, P. (1997). A new and practical artificial diet for the cotton boll-worm. Insect Science, 4(3), 277-282. https://doi.org/10.1111/j.1744-7917.1997.tb00101.x 


\section{Chapter Three}

A review on Desert Date Balanites aegyptiaca L. \& Del.: general uses and future prospective as botanical insecticide 


\subsection{Abstract}

The desert date Balanites aegyptiaca (L.) Del. (Zygophyllaceae) is an evergreen, woody perennial xerophytic and spinous flowering tree. The tree reaches approximately ten meters in height., widely distributed across dry lands of arid and semi-arid regions. It is traditionally used in urban and rural areas. Approximately, all parts of the plant are useful and have been used as a medication the treatment of a wide range of in Africa and Asia, thus, various parts are used in healing systems and other folkloric medicines for the treatment of wide range of diseases i.e., syphilis, jaundice, liver and spleen problems, epilepsy, yellow fever. Furthermore, it revealed insecticidal, antihelminthic, antifeedant, molluscicidal, larvicidal, and contraceptive activities. Researches have been carried out experiments using different techniques to evaluate the biological active components, in vitro and in vivo. To support most of these claims, this review presents the general uses and future prospective of desert date plant as a botanical insecticide.

Keywords; Balanites aegyptiaca, insecticide, antifeedant, antihelminthic, molluscicidal, larvicidal 


\subsection{Introduction}

Balanites aegyptiaca (L.) Delile, known as 'desert date', is a drought-tolerant perennial tropical spiny shrub or tree up to 10 meter in height. it belongs to the family Balanitaceae. It is a multibranched, evergreen tree distributed throughout the dryland areas of Africa and Asia, namely, in the Sudano-Sahelian region of Africa, the Middle East and South Asia (Hall, 1992; Hines \& Eckman, 1993). It is a prevailing natural tree that grows wildly in open woodland or natural savannah sometimes cultivated for its fiber, oil and medicinal values (Zang et al., 2018). It is a multi-purposes tree as it is used for food, fodder, construction and furniture in almost all parts of Africa and South Asia (Fadel Elseed et al., 2002). Also, the whole plant or its proportions and components contain many beneficial materials and essential minerals for human and animal health.

Different parts of Balanites aegyptiaca have several bioactive substances (Al Ashaal et al., 2010) which possess distinguished characteristics and important phytochemical components; that include alkaloids, glucosides, flavonoids, phenolics, saponins, tannins, terpenoids, steroids, lipids, proteins, carbohydrates, organic acids, furanocoumarins, Diosgenin, N-transferuloyltyramine, N-cis-feruloyltyramine, trigonelline, balanitol and cardiac glycosides (Amadou, Le, \& Shi, 2012; Koubala et al., 2013). Moreover, important phytochemical components (secondary metabolites) are useful for the treatment of a wide range of diseases and have potential insecticidal effects against medical, veterinary and agricultural pests. In Sudan $B$ aegyptiaca jeopardized due to desertification, overgrazing, and very important factor is cutting to produce a charcoal. (Lazim, 2007) report that B. aegeyptiaca leaves and twigs are useful in fodder due to richness of protein in dry season. The potential of B. aegyptiaca remains unexplored therefore, the objective of this review is to point out the overall potential use and future prospective as botanical insecticide.

\subsection{Botanical taxonomy}

The desert date tree Balanites aegyptiaca belongs to the family Balanitaceae (Zygophyllaceae) which comprised of approximately 25 genera and 240 species and is predominant in tropical, subtropical and warm temperate regions. It is often found in the drier areas in Africa and Asia. It is a perennial spiny shrub or tree with flowering and fruiting occurring annually (Bhandari, 
1990). It is appointed to the following botanical classification which was reported by many researchers (Chapagain \& Wiesman, 2006) ; Poongkodi, 2015 ; NPDC, 2017)

$\begin{array}{ll}\text { Kingdom } & \text { Plantae - Plants } \\ \text { Subkingdom } & \text { Tracheobionta - Vascular plants } \\ \text { Super division } & \text { Spermatophyta - Seed plants } \\ \text { Division } & \text { Magnoliophyta - Flowering plants } \\ \text { Class } & \text { Magnoliopsida - Dicotyledons } \\ \text { Subclass } & \text { Rosidae } \\ \text { Order } & \text { Sapindales } \\ \text { Family } & \text { (Balanitaceae) Zygophyllaceae - Creosote-bush family } \\ \text { Genus } & \text { Balanites Delile - balanites } \\ \text { Species } & \text { Balanites aegyptiaca (L.) Delile - desert date } \\ \text { Synonyms } & \text { Ximenia aegyptiaca L. (excl. Balanites roxburghii Planch) } \\ & \text { Agialida senegalensis van Tiegh., Agialida barteri van Tiegh } \\ & \text { Balanites latifolia (van Tiegh.) Chiov (Dwivedi et al., 2009) }\end{array}$

\subsection{Ecology}

Balanites aegyptiaca (L.) Delile is a branching thorny tree, a highly drought-tolerant evergreen plant (Figure 3.1a) and a dicotyledonous flowering species (Orwa et al., 2010). The plant can grow in different habitat and climatic conditions (Pandey, 2005). The tree survives in various kinds of soil but is mainly found on alluvial soils with deep sandy loam with free access to water such as valley floors, river banks or the foot of rocky slopes (Chothani \& Vaghasiya, 2011). The tree also has good adaptive mechanisms to grow and thrive under combined water and salinity stresses (Maksoud \& El Hadidi, 1988). The species is intolerant to shade, and thus, it prefers open woodland or natural savannahs for renewal (Berhaut, 1979; Arbonnier, 2000). The tree can be grown at highlands up to $2000 \mathrm{~m}$ altitude with a mean annual temperature of 20 to $30^{\circ} \mathrm{C}$ and mean annual rainfall of 250 to 400 mm (TWI, 1998; Schmidt; Lars \& Joker, 2001). 


\subsection{Botanical Description}

The plant can grow and reach up to $10 \mathrm{~m}$ in height (Rathore et al., 2005; Yadav, and Panghal, 2010). The leaves are alternate, bright green, leathery (Figure 3.1b), two foliate, petioles are 3-6 $\mathrm{mm}$ long, and leaflets are elliptic, obovate and have broadly pointed petioles up to $5 \mathrm{~mm}$ long (Chothani \& Vaghasiya, 2011). The spines of the plant are simple, straight, stout yellow, rigid, green, alternate, supra-axillary, up to $5 \mathrm{~cm}$ long. The inflorescence is supra axillary clusters or rarely supra cemose. Chapagain \& Wiesman (2006) reported that the flowers are small, bisexual, yellowish-white (Figure 3.1b), fragrant with 5-6 $\mathrm{mm}$ in diameter, in axillary clusters. The sepals are five in number (free), ovate and $3 \mathrm{~mm}$ long. The petals are five in number (two free), oblongobovate, longer than the sepals. The stamens are ten in number, filaments glabrous, and anthers are dorsifixed. The ovary is ovoid, silky, five-celled and ovules are solitary in each cell, the style is short and conical. The fruit is date-like and an ovoid drupe found on a short thick stalk and is faintly five grooved, ranges from 2 to $5.6 \mathrm{~cm}$ in length and from 1.5 to $4 \mathrm{~cm}$ in diameter. Immature fruit is green and tomentose (Figure 3.1c). The ripe fruit is yellow or pale brown with a brittle coat (Figure 3.1d) and it contains four layers ( Mohammed et al., 2002). According to Orwa et al., (2010) the outer skin, fleshy pulp, the woody shell within which the seed is found are referred to as epicarp (Figure 3.1e), mesocarp (Figure 3.1f), endocarp and the kernel of the nut (Figure 3.1g) respectively. The fruit is enclosed in a brown or reddish-brown sticky pulp, the pulp is bitter-sweet and edible. The seed (nut) is a hard stone with light brown, pendulous and ex-albuminous; 1.5 to $3 \mathrm{~cm}$ long (Figure 3.1g) (Kirtikar, K.R. and Basu, 1933).

Generally, flowering time occurs from October to April, whilst the fruiting takes place from December to July each year (Elghazali et al., 1994; Bein et al., 1996). A mature tree produces $100-150 \mathrm{~kg}$ of fruits annually. The plant starts flowering and fruiting at 5 to 7 years of age and continues fruits production for about two decades. Maximum fruit production is when the trees reach 15 to 25 years old. The trunk is grooved, short and often branching from near the base and its color ranges from dark brown to deeply grey, the bark is splintered longitudinally and ragged with yellowish-green color and patches where it is shedding (Chothani \& Vaghasiya, 2011). In Sudan, Balanites aegyptiaca was reported as one of the longest-lived savannah trees living more than a hundred years (Bourliere, F. \& Hadley, 1983; Orwa et al., 2010). 

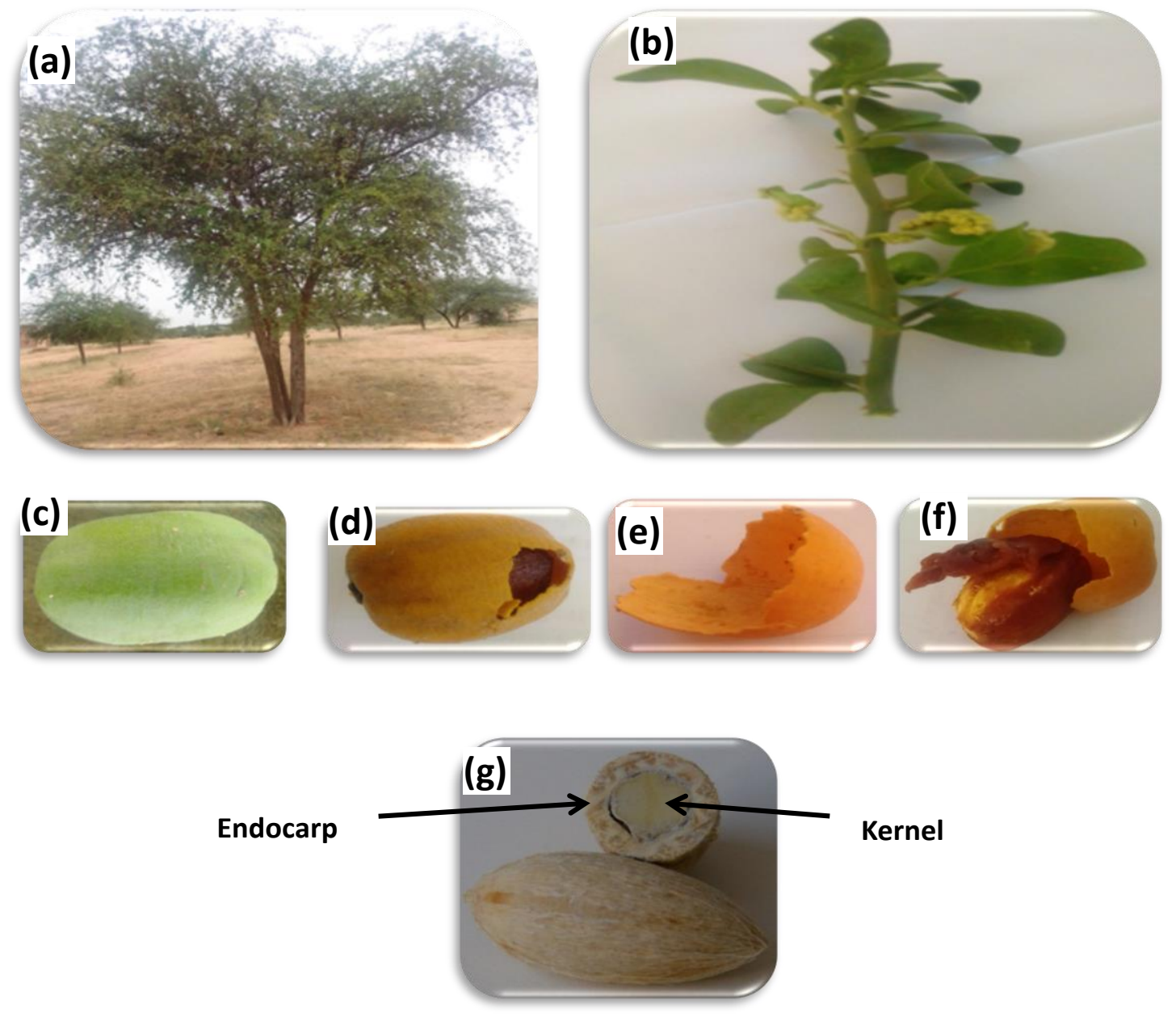

Figure 3.1 Balanites aegyptica (L.) Delile, (a) tree (b) Green leaves with yellow flowers (c) Immature fruit (d) Mature fruit (e) Epicarp (f) Mesocarp (g) Nut

\subsection{General uses}

The desert date; Balanites aegyptiaca is a multipurpose plant; almost every part of the plant is useful including roots, trunks, barks, leaves, flowers, seeds and fruits (Zang et al.,2017). The tree and its parts are used for food, fodder, shade, building and medicinal applications mostly in all parts of Africa and South Asia (Elfeel, A.A. \& Warrag, 2011). However, Gad et al., (2006) explained that the most important part of the tree is its fruits. The fruit is known as the desert date (English) and lalob (Arabic). Many researchers clearly explained that the fleshy pulp of both unripe and ripe fruit is edible and could be eaten fresh or dried as it contains essential minerals. 
The seed kernel produces high finesse of oil, the plant contains 30-60\%, which is edible and used as cooking oil for over thousand years (Vonmaydell, 1986; Obidah et al., 2009). Pulpy fruit contains sixty to seventy percent of carbohydrates, crude protein, steroidal saponins, vitamin A and C (Dawidar \& Fayez, 1969). The kernel is also rich in protein and mineral contents (Okia et al., 2011). The fruit is outstanding banana, guava, mango, and papaya in protein content and quality, it is similar to sesame and groundnuts oils (Abualfutuh, 1983). The leaf of Balanites aegyptiaca (L.) Del. is one of the preferable fodder among goats (Elseed et al., 2002), and it plays an important role as range plant in the desert during severe drought. In addition the living tree is used as trap for insect (Gour \& Kant, 2012), wind barriers and for agroforestry purposes (Guinand, Y. \& Lemessa, 2001; Tesfaye, 2015) . According to Zang et al., (2018) the bark produces fibres and natural gums that are used as glue. Furthermore, Orwa et al., (2010), pointed out that the branches are used as a fence for keeping livestock and the seeds are used to make beads and jewelry. The wood serves as a good source of firewood, charcoal and timber for indoor furniture and tool handles. For medicinal applications approximately all the parts of Balanites aegyptiaca are traditionally used in several traditional medicines worldwide. This plant has got enormous importance as being used in the treatment of wide range of illness and disorders, including among others jaundice, intestinal worm infection, skin boils, leucoderma, wounds, malaria, syphilis, epilepsy, dysentery, constipation, diarrhea, hemorrhoid, stomach aches, asthma and fever (Yadav, J. P. \& Panghal, 2010). Furthermore, the plant bark is used for the cure of leprosy, epilepsy, yellow fever, jaundice, syphilis and also acts as a fumigant for healing circumcision wounds (Sarker et al., 2000 ; Hamid, O, Wahab M, 2001; Bukar et al., 2004). The boiled root, root bark and root molding of the tree are used as chowder against stomach pain, anthrax, in cure of diarrhea, haemorrhoid and acts as an antidote for snake biting. Moreover, many researchers reported that the seed, fruit and fruit kernel are used as ointments, to cure cough, colic pain, oral hypoglycemic cure, hypocholesterolemic, diuretic, a mild laxative, purgative, mouth ulcer cure, anticancer, antioxidant, anti-inflammatory, antidiabetic antiparasitic and schistosomicide (Ojo et al., 2006; Motaal et al., 2012). 


\subsection{Balanites aegyptiaca as botanical insecticide}

According to Tesfaye, (2015) the tree is a multipurpose with considerable economic possibilities for its enormous biological active components. All parts of the plant are used as food or have effects as antidote for cure of infections or pests' control. Also, he recommended that the ranch of tree acting as shelterbelt and soil reformer in arid regions and in saline soil and will be helpful in conservation of biodiversity. Most of the studies of Balanites aegyptiaca (L.) Del, that used different plant parts as botanical insecticide, have shown promising results of botanical and insecticidal activities against pest. In his study Mageed (1990) evaluated Balanites aegyptiaca as a Mosquito Larvicide. He found that water extracts of fruit kernel were very effective as larvicides against mosquitoes (Aedes aegypti, Aedes arabiensis and Culex quinquefasciatus). Also, significant effect of phytochemical (saponin extract, fruit mesocarp fraction and shoot extract) against larvae by causing larval mortality and dramatically reducing the number of mosquitoes was recorded (Gour \& Kant, 2012).

Different extracts from several parts of Balanites aegyptiaca were shown to raise antifeedants and molluscicidal activities against various snail pests (Plants \& Lymnaea, 2010). Seeds of desert date Balanites aegyptiaca (L.) Del. contain many phytochemicals which act as secondary metabolites and have different biocidal effects against store pests such as khapra beetle Trogoderma granarium (Elamin \& Satti, 2013). A study which tested the effect of leaf powder of Balanites aegyptiaca as bio insecticide on Bean weevil Callosobruchus maculatus revealed high insecticidal activity increasing mortality rate and repellency (Sani, 2016). Furthermore, Bruchidae et al., (2013) reported that Balanites aegyptiaca acetone leaf extract has potential activity, insecticidal effect and repellency properties against cowpea bruchid Callosobruchus maculatus F., larvae and pupae. Moreover, hexane extracts from kernel and seed applied against khapra beetle (Trogoderma granarium) and red flour beetle (Castaneum tribolium) recorded complete mortalities, high insecticidal and superior effects (Mohamed, N. M. 2003). Recently, Wakawa, Sambo, \& Yusuf, (2019) tested leaves extract as anaesthetic on a beneficial organism (fish) and showed mortality at $3 \%$ concentration. 


\subsection{Conclusions}

Extensive studies carried out using different in vitro and in vivo techniques revealed that most parts and components of Balanites aegyptiaca (L.) Del. act as a potential natural pesticide and an alternative to synthetic chemical pesticides. It has been experimentally proved that $B$. aegyptiaca possesses effective components against pests. Similarly, the desert date Balanites aegyptiaca (L.) Del., tree can play a leading role and has promising functions to be an attractive and safe alternative in near future against manufactured chemical insecticides, especially in the management of pests of warehouses, houses and fields, in accordance with the global revolution against the widespread of chemical pesticides. Consequently, more extensive studies are needed to provide information on the active principle phytochemical components of this pioneer tree, especially on their nontoxic and environmentally friendly effects. 


\section{References}

Abualfutuh, I. M. (1983). Balanites aegyptiaca, an unutilized raw material potentially ready for agro-industrial exploitation. United Nations Industrial Development Organization (UNIDO), Report, Austria, Vienna, 10-494 Pp.

Al Ashaal, H. A., Farghaly, A. A., Abd El Aziz, M. M., \& Ali, M. A. (2010). Phytochemical investigation and medicinal evaluation of fixed oil of Balanites aegyptiaca fruits (Balantiaceae). Journal of Ethnopharmacology, 127(2), 495-501. https://doi.org/10.1016/j.jep.2009.10.007

Amadou, I., Le, G. W., \& Shi, Y. H. (2012). Effect of boiling on the cytotoxic and antioxidant properties of aqueous fruit extract of desert date, Balanites aegyptiaca (L) Delile. Tropical Journal of Pharmaceutical Research, 11(3), 437-444. https://doi.org/10.4314/tjpr.v11i3.13

Arbonnier, M. (2000). Arbres, arbustes et lianes des zones sèches d'Afrique de l'Ouest. Montpellier France : CIRAD-MNHN-UICN, 541.

Bein, E.; Habte, B.; Jaber, A.; Birnie, A.; and Tengnas, B. (1996). Useful trees and shrubs in Eritrea: Identification, propagation and management for agricultural and pastoral communities. Regional Soil Conservation Unit (RSCU), Technical Handbook No.12.SIDA, Nairobi, Kenya. 422 Pp.

Berhaut, J. (1979). La Flore illustrée du Sénégal. Préf. de L. Sédar Senghor. Journal d'Agriculture Tropicale et de Botanique Appliquée Paris, 21(269-270).

Bhandari, M. M. (1990). Balanites, 88: In Flora of the Indian Desert. . MPS Repros, Jodhpur. India, $435 \mathrm{Pp}$.

Bourliere, F. and Hadley, M. (1983). Present-day savannas: an overview. In: Bourliere, F. (Ed. ) Tropical Savannas Ecosystems of the World, Vol.13, Elsevier, Amsterdam Pp. 1-17.

Bruchidae, C., Nwaogu, J., Yahaya, M. A., \& Bandiya, H. M. (2013). Insecticidal efficcay of oil extracts of Balanites aegyptiaca seeds and cashew nuts against Callosobruchus maculatus Fabr. (Coleoptera: Bruchidae). African Journal of Agricultural Research, 8(25), 3285-3288. https://doi.org/10.5897/AJAR12.1978 
Bukar, A.; Danfillo, I.S.; Adeleke, O.A.; Ogunbodede, E. O. (2004). Traditional oral health practices among Kanuri women of Brono state Nigeria. Odonto-Stomatologie Tropicale $=$ Tropical Dental Journal 27, (107) :25-31.

Chapagain, B. P., \& Wiesman, Z. (2006). Phyto-saponins as a natural adjuvant for delivery of agromaterials through plant cuticle membranes. Journal of Agricultural and Food Chemistry, 54(17), 6277-6285. https://doi.org/10.1021/jf060591y

Chothani, D. L., \& Vaghasiya, H. U. (2011). A review on Balanites aegyptiaca Del (desert date): Phytochemical constituents, traditional uses, and pharmacological activity. Pharmacognosy Reviews, 5(9), 55-62. https://doi.org/10.4103/0973-7847.79100

Dawidar, A.A.M. and Fayez, B. E. (1969). Steroid Sapogenins. XIII. The constituents of Balanites aegyptiaca. Phytochemistry 8:261-265.

Dwivedi, A., Joshi, V., Barpete, P. K., Akhtar, A. K., Kaur, A., \& Kumar, S. (2009). Anthelmintic Activity of Root Bark of Balanites aegyptiaca ( L .) Del . Ethnobotanical Leaflets, 13, 564-567.

Elamin, M. M., \& Satti, A. A. (2013). Insecticidal potentialities of Balanites aegyptiaca extracts against the khapra beetle ( Trogoderma granarium ). 2(1), 5-10.

Elfeel, A.A. and Warrag, E. I. (2011). Uses and conservation status of Balanites aegyptiaca (L.) Del. (Hegleig Tree) in Sudan. Asian Journal of Agricultural Sciences 3, (4):386-390.

Elghazali, G.E.B.; El Tohami, M.S.; El Egami, A.A.B.; Abdalla, W.E.; and Mohamed, G. (1994). Medicinal plants of Sudan, Part II, Medicinal plants of northern Kordofan. Khartoum University Press, Khartoum.

Elseed, A. M. A. F., Amin, A. E., Khadija, A. A., Ali, J. S., Hishinum, M. and Henana, K. (2002). Nutritive Evaluation of Some Fielder Tree Species During the Dry Season in Central Sudan. Asian Aust. Journal Animal Science, 15(6): 844-850.

Fadel Elseed, A. M. A., Amin, A. E., Khadiga, Abdel Ati, A., Sekine, J., Hishinuma, M., \& Hamana, K. (2002). Nutritive evaluation of some fodder tree species during the dry season in central sudan. Asian-Australasian Journal of Animal Sciences, 15(6), 844-850. 
https://doi.org/10.5713/ajas.2002.844

Gad, M.Z.; El-Sawalhi, M.M.; Ismail, M.F.; and El-Tanbouly, N. D. (2006). Biochemical study of the antidiabetic action of the Egyptian plants fenugreek and balanites. Molecular and Cell Biochemistry 281, (1): 173-183.

Gour, V. S., \& Kant, T. (2012). Short Communication BALANITES AEGYPTIACA ( L .) DEL .: A MULTIPURPOSE AND POTENTIAL. 3(2), 472-475.

Guinand, Y. and Lemessa, D. (2001). Wild Food Plants in Ethiopia: Reflections on the Role of Wild Foods and Famine Foods at a Time of Drought. In: Kenyatta, C. and Henderson, A., Eds., the Potential of Indigenous Wild Foods. Workshop Proceedings, USAID/OFDA, Mombassa, Kenya.

Hall, J. B. (1992). Ecology of a key African multipurpose tree species, Balanites aegyptiaca (Balanitaceae): the state-of-knowledge. Forest Ecology and Management, 50(1-2), 1-30. https://doi.org/10.1016/0378-1127(92)90311-V

Hamid, O, Wahab M, H. E. (2001). Balanites aegyptiaca extract for treatment of HIV/ AIDS and leukemia. International Publication Number WO /49306 A1.

Hines, D. A., \& Eckman, K. (1993). INDIGENOUS MULTIPURPOSE MULTIPURPOSE TREES TREES OF INDIGENOUS USES AND AND ECONOMIC ECONOMIC BENEFITS BENEFITS FOR Indigenous Multipurpose Trees of of Tanzania : Economic Benefits for People People Uses and Economic by.

Kirtikar, K.R. and Basu, B. . (1933). Indian medicinal plants. Allahabad, Lalit Mohan Basu Publications, Allahabad, 1, 1347-1348.

Koubala, B. B.; Miafo, A.P.T.; and Bouba, D. (2013). Evaluation of Insecticide Properties of Ethanolic Extract from Balanites aegyptiaca, Melia azedarach and Ocimum gratissimum leaves on Callosobruchus maculatus (Coleptera: Bruchidae). ). Asian Journal of Agricultural Sciences, 5(93-101).

Lazim, A. . (2007). Proximate composition of some fodder trees in the south Kordofan State. Agricultural Research Corporation, Kadugli (Sudan). Kadugli Research Station, 138-145. 
Mageed, A. A. (1990). Balanites aegyptiaca as a Mosquito Larvicide Larval mortalities The percentage mortalities of the second and fourth instar larvae of An . 28(4), 267-271.

Maksoud, S. A., \& El Hadidi, M. N. (1988). The flavonoids of Balanites aegyptiaca (Balanitaceae) from Egypt. Plant Systematics and Evolution, 160(3-4), 153-158. https://doi.org/10.1007/BF00936042

Mohamed, A. M., Wolf, W., \& Spieß, W. E. L. (2002). Physical, morphological and chemical characteristics, oil recovery and fatty acid composition of Balanites aegyptiaca Del. kernels. Plant Foods for Human Nutrition, 57(2), 179-189. https://doi.org/10.1023/A:1015237612018

Mohamed, N. M. A. (2003). Efficacy of Selected Plants Extracts on the Control of Khapra Beetle Trogoderma granarium Everts. (Coleoptera - Dermistidae) and Red Flour Beetle Tribolium castaneum Herbst. (Coleoptera - Tenebrionidae). Ph.D Thesis, University of Khartoum, Sudan.

Motaal, A. A., Shaker, S., \& Haddad, P. S. (2012). Antidiabetic activity of standardized extracts of Balanites aegyptiaca fruits using cell-based bioassays. Pharmacognosy Journal, 4(30), 20-24. https://doi.org/10.5530/pj.2012.30.4

NPDC. (2017). National Plant Data Center. Natural Resources Conservation Service National Plant Data Center NRCS. USDA.

Obidah, W.; Nadro, M.S.; Tiyafo, G.O. and Wurochekke, A. U. (2009). Toxicity of crude Balanites aegyptiaca seed oil in rats. Journal of American Sciences 5, (6): 163-165.

Ojo, O.O.; Nadro, M.S.; and Tella, I. O. (2006). Protection of rats by extracts of some common Nigerian trees against acetaminophen-induced hepatotoxicity. African Journal of Biotechnology (5):755-760.

Okia, A. C., Agea, G. J., Kimondo, M. J., Abohassan, A. A. R., Okiror, P., Obua, J., \& Teklehaimanot, Z. (2011). Value of balanite. Research Journal of Biological Sciences, Vol. 6, pp. 15-24.

Orwa, C.; Mutua, A.; Kindt, R.; Jamnadass, R. . and S. (2010). Agroforestree Database. Forestry 
Seeds, Species, Trees: a tree reference and selection guide version 4. World Agroforestry Centre (ICRAF) Nairobi, Kenya, 1-5.

Pandey, C. N. (2005). Gujarat Ecological Education and Research Foundation, Medicinal plants of Gujarat. Gujarat, India, 387.

Plants, M., \& Lymnaea, A. (2010). Evaluation of Mollucicidal Activity of Some Indian. (2), 308311.

Poongkodi, G. K. (2015). International Journal of Modern. 2(78), 78-86.

Rathore, M.; Arya, R.; Meena, R.K.; Kumar, H. (2005). Shuahk kshetro mei paye jane wale tailiya beejo ke vrikshon ki sambhavit upigoyita. AFRI Darpan (Hindi) 2:12-13.

Sani, U. M. (2016). Comparative antifeedant activities of the epicarp and mesocarp methanolic extracts of the seeds of Balanites aegyptiaca against cowpea bean (Vigna unguiculata ) storage pest ( Callosobruchus maculatus ). Journal of Medicinal Plant Studie, 4(6), 199203.

Sarker, S.D.; Bartholomew, B.; and Nash, R. J. (2000). Alkaloids from Balanites aegyptiaca. Fitoterapia (71): 328-330.

Schmidt, Lars ; and Joker, D. (2001). Glossary of Seed Biology and Technology. Danida Forest Seed Centre, Seed Leaflet. No.21. Humlebaek, Denmark. Available Online at: Http: //Www. Dfsc. Dk/.

Tesfaye, A. (2015). Balanites (Balanite aegyptiaca) Del., Multipurpose Tree a Prospective Review. International Journal of Modern Chemistry and Applied Science 2, (3): 189-194.

TWI. (1998). The wealth Of India, A Dictionary Of Indian, Raw material and Industrial product, Publication and Information Directorate. Council of Scientific and Industrial Research, New Delhi, 2, 3, 427.

Vonmaydell, H. J. (1986). Trees and Shrubs of the Sahel: Their Characteristics and Uses. Eschborn, GTZ, Germany, 525 Pp.

Wakawa, A. I., Sambo, A. B., \& Yusuf, S. (2019). Anaesthetic effects of aqueous crude leaf 
extract of desert date ( Balanites aegyptiaca ) on Nile tilapia ( Oreochromis niloticus ) fingerlings. International Journal of Fisheries and Aquatic Studies, 7(1), 147-152.

Yadav, J. P. and Panghal, M. (2010). Balanites aegyptiaca (L.) Del. (Hingot): A review of itstraditional uses, phytochemistry and pharmacological properties. . International Journal of Green Pharmacy, 140-146.

Zang, C. U.; Jock, A. A.; Garba, I. H.; Chindo, I. Y. (2017). Physicochemical and Phytochemical Characterization of Seed Kernel oil From Desert Date (Balanites Aegyptiaca). Journal of Chemical Engineering and Bioanalytical Chemistry 2 (1): 49-61.

Zang, C. U., Jock, A. A., Garba, H. I., \& Chindo, Y. I. (2018). Application of Desert Date (\&lt;i\&gt;Balanites aegyptiaca\&lt;/i\&gt;) Seed Oil as Potential Raw Material in the Formulation of Soap and Lotion. American Journal of Analytical Chemistry, 09(09), 423437. https://doi.org/10.4236/ajac.2018.99033 


\section{Chapter Four}

Potential applications of botanical extracts of the Balanites aegyptiaca against Helicoverpa armigera reared on okra 


\subsection{Abstract}

The effect of oil and water extract on the $2^{\text {nd }}$ instar larvae of Helicoverpa armigera reared on okra Abelmoschus esculentus were studied to evaluate the potential application of extracts of Balanites aegyptiaca as botanical pesticide. The efficacy of the oil and water extracts against the $H$ armigera was tested with $(2 \%, 5 \%$ (v: v) oil extract and 5\%,10\% (w/v) water extract) of seed kernel of $B$ aegyptiaca Del. All treatments significantly influenced the larval survival of the $H$ armigera. The $2 \%$ oil extract did not significantly differ from the 5\% $(0.469 \pm 0.516$ and $0.333 \pm$ 0.488 , respectively), however the number of survivals was higher in the negative control ( 0.869 $\pm 0.352)$ and Tween $800.01 \%(\mathrm{v}: \mathrm{v})(0.800 \pm 0.414)$ while for water extract it was higher in the control $(0.867 \pm 0.352)$ than in the $10 \%(\mathrm{w} / \mathrm{v})$ water extract $(0.333 \pm 0.488)$. Furthermore, no significant difference was detected between the control and 5\% (w/v) water extract. Oil and water extracts have properties of larvicidal against $H$ armigera which could potentially be used as an attractive alternative for pest management.

Keywords; Balanites aegyptiaca, Helicoverpa armigera, botanical insecticide, larvicidal, Abelmoschus esculentus 


\subsection{Introduction}

Cotton bollworm (Helicoverpa armigera Hübner 1808; Lepidoptera: Noctuidae) which is a polyphagous in nature is one of the important pests for many crops worldwide (Lammers \& Macleod, 2007). The larva is mainly responsible for causing crop damage and it attacks more than 182 plant species, including different important and cash crops, (cotton, sunflower, sorghum, maize), vegetables, fruit crops and tree species (Uddin el al., 2009). The annual yield loss by the cotton bollworm is estimated at about US\$2 billion in tropical and subtropical regions where approximately US\$ 500 million worth pesticides are applied to control it (Kass el al., 2018). The bollworms cause about 10 to $60 \%$ okra fruit yield loss and could even reach $80 \%$ loss under optimal environmental condition (Javed et al., 2019).

Concerns about the widespread of the environmental negative impacts of chemical insecticides coupled with the great damages in many areas that are expected to be caused by the bollworm have led to focus on environmentally sound and sustainable alternative strategies for pest control. Thus, a worldwide resurgence of interest in the use of predators, parasitoids and/or entomopathogenic microorganisms have intensively been studied for biological control of Helicoverpa armigera species (Gonzalez et al., 2016), and a significant advance in development and manufacturing of these agents in the future is expected with recent biotechnological discoveries (Hatting, 2012).

Plants or plant materials cantina diverse botanical insecticides that have been widely studied and utilized by researchers. The history of application of botanical insecticides for the protection of crops and stored products from insects has been reported back to 400. b. C in Roma (Dayan et al., 2009), in ancient China (Liu et al., 2007) and different parts of developed countries. Botanical insecticides were extensively used and have been touted as attractive alternative to synthetic chemical products for pest management (Dwijendra Singh, 2014). Prior to the development and commercial success of the synthetic insecticides, people widely used different modified parts of some aromatic plants as repellents against insects (Isman, 2006 ; Benelli et al., 2015)

The desert date tree (Balanites aegyptiaca) belongs to the family Balanitaceae (Zygophyllaceae) which comprise of approximately 25 genera and 240 species that are predominant in tropical, subtropical and warm temperate regions. It is often found in the drier areas in Africa and Asia. It 
is a perennial spiny shrub or tree with flowering and fruiting occurring annually (Bhandari, 1990). Balanites aegyptiaca (L.) Delile is a branching thorny tree, highly drought-tolerant evergreen plant and a dicotyledonous flowering species (Orwa et al., 2010). Many researchers clearly explained that the fleshy pulp of both unripe and ripe fruit is edible and could be eaten fresh or dried as it contains essential minerals. The seed kernel produces finest oil, which is edible and used as cooking oil for over thousand years (Vonmaydell, 1986; Obidah et al., 2009). (Orwa et al., 2010), pointed out that the branches are used as a fence for keeping livestock and the seeds are used to make beads and jewelry. The wood serves as a good source of firewood, charcoal and timber for indoor furniture and tool handles. For medicinal applications; approximately, all the parts of Balanites aegyptiaca are traditionally used in several traditional medicines worldwide. This plant has got enormous importance and is being used in the treatment of wide range of illness and disorders, including among others jaundice, intestinal worm infection, skin boils, leucoderma, wounds, malaria, syphilis, epilepsy, dysentery, constipation, diarrhea, hemorrhoid, stomach aches, asthma and fever (Yadav, J. P. \& Panghal, 2010).

According to Tesfaye, (2015), the tree is multipurpose with considerable economic possibilities for its enormous biological active components. All parts of the plant are used as food or have effects as antidote for cure of infections or pests' control. Most studies of Balanites aegyptiaca (L.) Del, that used different plant parts as botanical insecticide has shown promising results of botanical and insecticidal activities against pest. In his study on evaluation of Balanites aegyptiaca as a Mosquito Larvicide Mageed (1990) found that, water extracts of fruit kernel were very effective as larvicides against mosquitoes (Aedes aegypti, Aedes arabiensis and Culex quinquefasciatus). Also, significant effect of phytochemical (saponin extract, fruit mesocarp fraction and shoot extract against larvae by causing most lethal, larval mortality and significantly reducing the number of mosquitoes was recorded (Gour \& Kant, 2012). Bruchidae et al., (2013) reported that Balanites aegyptiaca acetone leaf extract has potential activity, insecticidal effect and repellency properties against cowpea bruchid Callosobruchus maculatus F., larvae and pupae. Moreover, hexane extracts from kernel and seed applied against khapra beetle (Trogoderma granarium) and red flour beetle (Castaneum tribolium) recorded complete mortalities, high insecticidal and superior effects (Mohamed, N. M. 2003). Recently, Wakawa and Yusuf, (2019) tested leaves extract as anaesthetic on a beneficial organism (fish) and showed mortality at $3 \%$ concentration. 
The aims of the study were:

- To propose essential oils extracted from Balanites aegyptiaca seed water extracts and seed crude oil in water emulsions as well. To evaluate the antifeedant and repellent of extracts from B aegyptiaca against $2^{\text {nd }}$ instar larvae $H$ armigera.

- To determine the possible significant implications of the produced bio-pesticides. 


\subsection{Materials and methods}

Experiments were carried out under greenhouse conditions and quarantine cabinet at the Department of Entomology, Faculty of Agriculture - Georg-August-University, Gottingen.

\subsubsection{Plant material and pest}

\subsubsection{Okra fruit diet}

Eggs of Helicoverpa armigera were brought from Bayer (Bayer Crop Science Monheim, Germany). Upon hatching, the newly larvae were then transferred separately and placed in rearing containers, petri-dishes $(9 \mathrm{~cm}$ in diameter). Each larva was supplied with okra fruit blocks. The pieces of fruits were maintained as fresh as possible by keeping them on moist filter paper (Fig 4.1a). The food was renewed daily and the larvae were kept in climate chamber at 22 ${ }^{\circ} \mathrm{C} ; 60 \% \mathrm{RH} ; 18: 6 \mathrm{LD}$. The petri-dishes were kept clean from faeces and food remains. When the larvae pupated, the date of pupation was recorded and adult emergence was watched closely to record the pupation period. The newly emerged adult moths were sexed, during which males and females were transferred into oviposition cage (Fig4.1b). The cages were simply constructed from a cylinder with its top covered with muslin cloth and its lower end fitted on pot fitted with water, the surface of water pot was separated from the contents of upper chamber by filter paper (125 mm diameter) sheet. Two small specimen glasses were fitted with sponger soaked into a 7\% honey solution and applied as food for adult moths and were tied on the walls of the cylinder, small fresh and tender branches of okra plant were placed inside the cage for deposition of the eggs. The branch stalk dipped in water and such branches renewed daily and examined for egglaying date. 

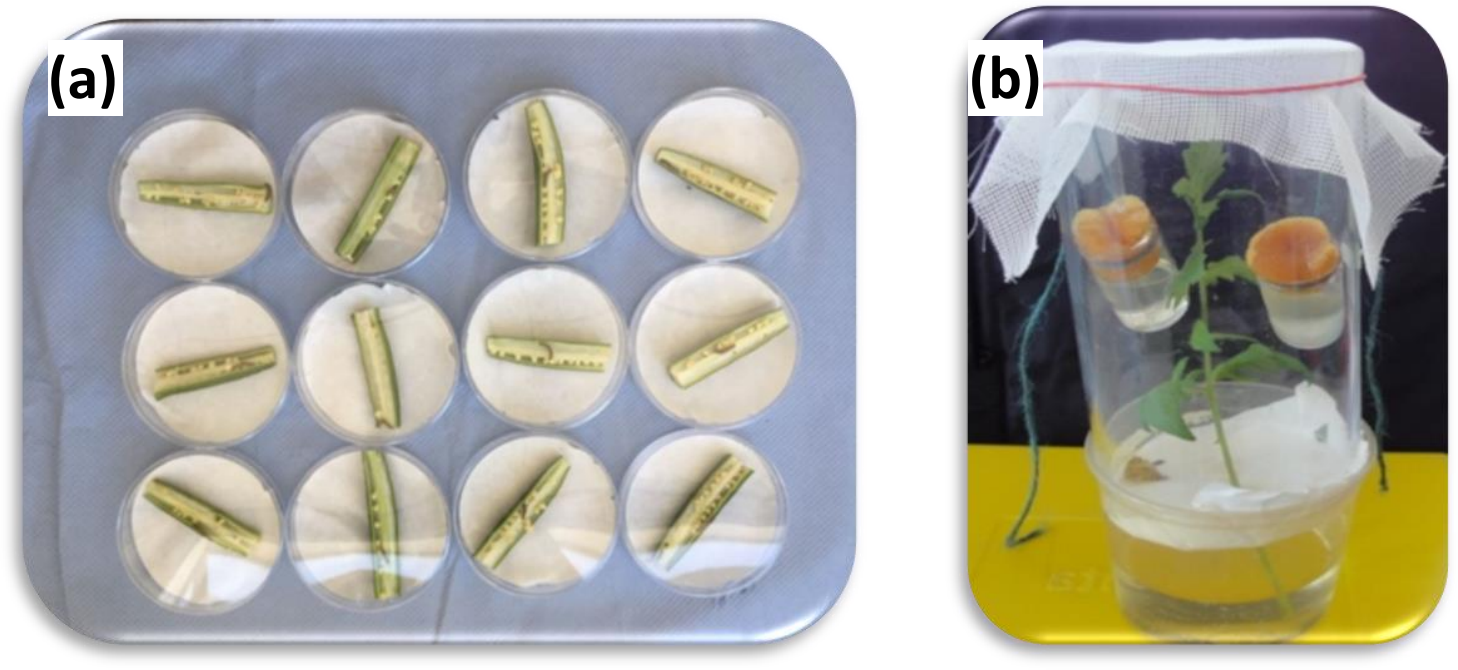

Figure 4.1 (a) Rearing petri-dishes ( $9 \mathrm{~cm}$ diameter) with okra block placed on moist filter paper (b) oviposition cage

\subsubsection{Seed test: Surface sterilization of okra seeds}

Okra seeds were surface-sterilized with $70 \%$ ethanol for $90 \mathrm{~min}$, then with $5.25 \%$ Sodium hypochlorite for $3 \mathrm{~min}$ and finally again with $70 \%$ ethanol for $90 \mathrm{~min}$. Thereafter, seeds were washed with sterile water three times, then air dried on a filter paper in bicarbonate. For sterilization test, randomly selected seeds were cultured on potato dextrose agar (PDA) and incubated at $25^{\circ} \mathrm{C}$ for 7 days.

\subsubsection{Plant materials}

Seeds of okra Abelmoschus esculentus (L.) obtained from Agricultural Research Corporation Sudan. Seedlings were grown in a greenhouse chamber $\left(23 \pm 3^{\circ} \mathrm{C}\right)$. Two-week-old plants were individually transplanted into plastic pots (15 cm diameter) with a mixture of non-sterile sand and soil. Plants were irrigated regularly and fertilized once a week.

\subsubsection{Host plant}

After surface sterilization, okra seeds were grown in pots with soil (Neundorfer Einheitswert) and one-third sand, and placed in a greenhouse until $\mathrm{BBCH} 22$, watered on demanded and 
fertilized with Hakaphos Blau (15/10/15 NPK) and micronutrients (Compo Expert Münster, Germany) according to manufacture instruction on a weekly basis.

\subsubsection{Seed powder}

fruits of Balanites aegyptiaca obtained from Agricultural Research Corporation -Sudan. The dry fruits of desert date were crushed lightly to remove epicars, the mesocarps were then dissolved in water for two days, cleaned and dried to obtain the nuts. The completely dried nuts were grounded as follows; before milling, the mill was cleaned with pressured air as well as $70 \%$ Ethanol. Then the nuts were put into a zip-lock plastic bag and cracked by hitting with stones and hammer. The husks and kernels were manually separated, milled (Retsch Haan, Germany, Type SK1; sieve No.2 with round $2 \mathrm{~mm}$ diameter perforation) and sieved through a metal tea sieve (1 mm mesh width). The powdered materials were then stored in darkness (wrapped in tin foil and stored in a box) at $10{ }^{\circ} \mathrm{C}$ until further analysis. (Fig 4.2)

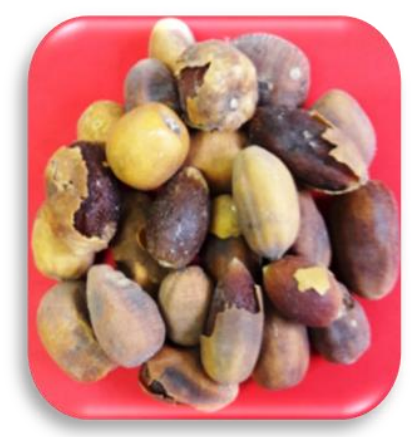

Mature fruits

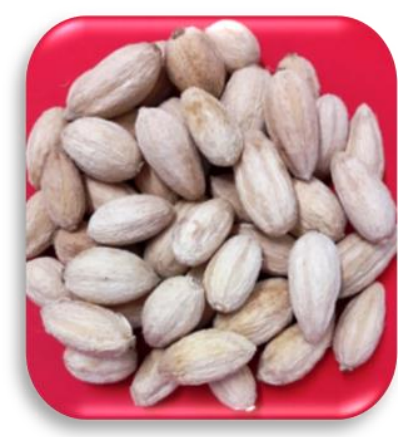

Nuts

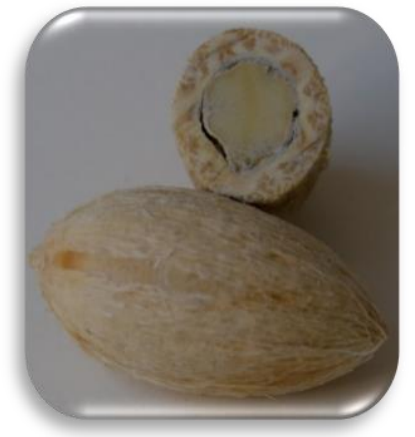

Kernel inside the nut

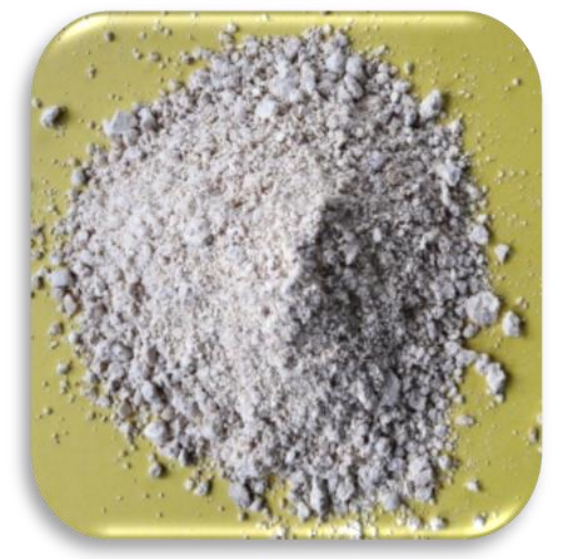

Kernels powder

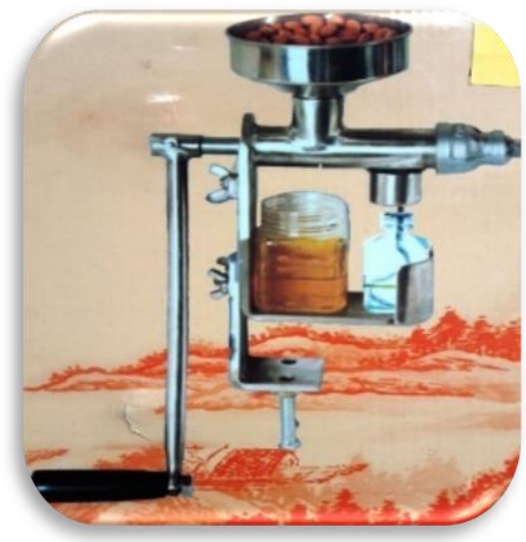

Oil extract machine

Figure 4.2 Process of oil and water extracts Balanites aegyptiaca 


\subsubsection{Crude oil extract}

Kernels were cut with a kitchen knife into smaller sized chunks and pressed with a hand oil press. Then the extracted crude oil was filtered through single layered gaze (mesh dimensions: $0.2 \mathrm{~mm}$ length $0.2 \mathrm{~mm}$ width). Crude oil and Tween80 were measured and transferred with Eppendorf pipets, $\mathrm{H}_{2} \mathrm{O}$ dest. The mixture was measured to the desired treatment amounts with a measuring cylinder and added to the respective spraying bottles (for spraying application) or glass bottles for the behavior assay. The filtered crude oil in its desired treatment concentrations and $0.01 \%$ Tween80 (v/v) in the respective concentrations was added with Eppendorf pipets. The compounds were stirred with a magnetic stirrer for $20 \mathrm{~min}$ at $1000 \mathrm{rpm}$. The resulting emulsions were stored in their respective bottles in darkness (wrapped in tinfoil and stored in a box) at $10{ }^{\circ} \mathrm{C}$ until further usage.

\subsubsection{Warm water extract}

Nut's powder was thoroughly mixed with a teaspoon. It was then weighed with a fine scale into the desired amounts for treatment concentrations and put into wide neck glass Erlenmeyer flasks. The flask contents were stirred with a magnetic stirrer for $20 \mathrm{~min}$ at $500 \mathrm{rpm}$ and then placed onto a shaker over night at $250 \mathrm{rpm}$. On the following day, the suspensions were sieved trough double layered gaze fabric (mesh dimensions: $0.2 \mathrm{~mm}$ length, $0.2 \mathrm{~mm}$ width) and the filtrates poured into fine muzzle hand spraying bottles for application (Bürkle turn'ńs spray, $1.2 \mathrm{ml}$ push1; $\pm 0.1 \mathrm{ml}$, Bürkle Bad Bellingen, Germany). The bottles were stored in darkness (wrapped in tinfoil and stored in a box) at $10{ }^{\circ} \mathrm{C}$ until further usage. Calculate the amount of seed material = $\mathrm{X}$ needed

$$
\mathrm{X}=(\text { Concentration }[\%] / 100) * \text { Suspension Amount }[\mathrm{ml}]
$$

\subsubsection{Measured variables}

\subsubsection{Eggs hatch rate}

Eggs boated from male and female were reared on okra fruit. Eggs harvested from upper side muslin cloth ((Fig 4.1b) oviposition cage) were carefully placed with a camel fine brush individually in sterile petri-dish $(9 \mathrm{~cm})$ with filter paper (ten eggs into petri-dish). Five different treatments namely; control, tap water, Tween80 0.001\% (v/v), 2\% (v/v) and 5\%(v/v) oil extracts of Balanites aegyptiaca sprayed with spray flask spray flask $(2.8 \mathrm{oz}, 200 \mathrm{ml})$ for efficacy test against hatched eggs in a climatic chamber under controlled condition $\left(22^{\circ} \mathrm{C} ; 60 \mathrm{RH} ; 18: 6 \mathrm{LD}\right)$, 
and each treatment was replicated 20 times. The rate of hatched eggs in each treatment was recorded.

\subsubsection{Repellent activity of water and oil extracts (Balanites aegyptiaca)}

The repellent biomasses of water and oil extract against the larvae of Helicoverpa armigera were tested in three treatments, namely; control, $5 \%(\mathrm{v} / \mathrm{v})$ oil extract and $10 \%(\mathrm{w} / \mathrm{v})$ water extract. Okra leaves were placed on moist filter paper in Petri-dishes, sprayed with the three above mentioned treatments, and allowed to dry under shade. The released ten $2^{\text {nd }}$ instar larvae were kept on climate chamber at $22{ }^{\circ} \mathrm{C} ; 60 \mathrm{RH} ; 18: 6 \mathrm{LD}$. Repellent activities were then observed after 2 days.

\subsubsection{Larvae survival}

The efficacy of oil and water extracts of Balanites aegyptiaca was tested by spraying the host plant, okra, with $2 \%(\mathrm{v} / \mathrm{v})$ and $5 \%(\mathrm{v} / \mathrm{v})$ oil extract and water extract 5\%(w/v) and 10\%(w/v). Before a leaf was sprayed, the bottle was shaked to ensure the homogeneity of botanical pesticide. The negative control and Tween control $(0.001 \%(\mathrm{v} / \mathrm{v})$ treated areas were allowed to dry for approx. $20 \mathrm{~min}$ then introduced with one $2^{\text {nd }}$ instar larva for each treatment and the respective areas were covered with clip cages. After caged leaf areas were consumed by the larvae, treatment applications were repeated on new leaves and the larvae with their clip cages were transferred. This process was repeated until larvae either dead or pupated, then the host plants were placed in a growing chamber at $22{ }^{\circ} \mathrm{C}$; $60 \mathrm{RH} ; 18: 6 \mathrm{LD}$. Each treatment was replicated 15 times.

\subsubsection{Pupae weight}

At the end of larval stage and the start of the pupal stage, the weight of each insect was determined on sensitive balance.

\subsubsection{Plant dry biomass}

The above-ground plant parts (leaves and stems) were collected. Plants were cut at soil surface and dried in an oven at $60^{\circ} \mathrm{C}$ for one week till constant weight was achieved. The efficacy of the treatment compared to the control was tested. 


\subsubsection{Statistical analysis}

Data were statistically analyzed with SigmaPlot version (SigmaPlot 14.0). Analysis of variance (ANOVA) was used to test for treatment effect if so, the differences were separated used Bonferroni test at a probability of 0.05 , unless otherwise stated. 


\subsection{Results}

\subsubsection{Repellent activity of water and oil extract}

The $2^{\text {nd }}$ larvae instar of Helicoverpa armigera avoided okra leave treated with 5\% (v/v) oil and $10 \%(\mathrm{w} / \mathrm{v})$ water extracts compared to the control which indicates the potential efficacy of extracted materials as depicted in (Fig 4.3)

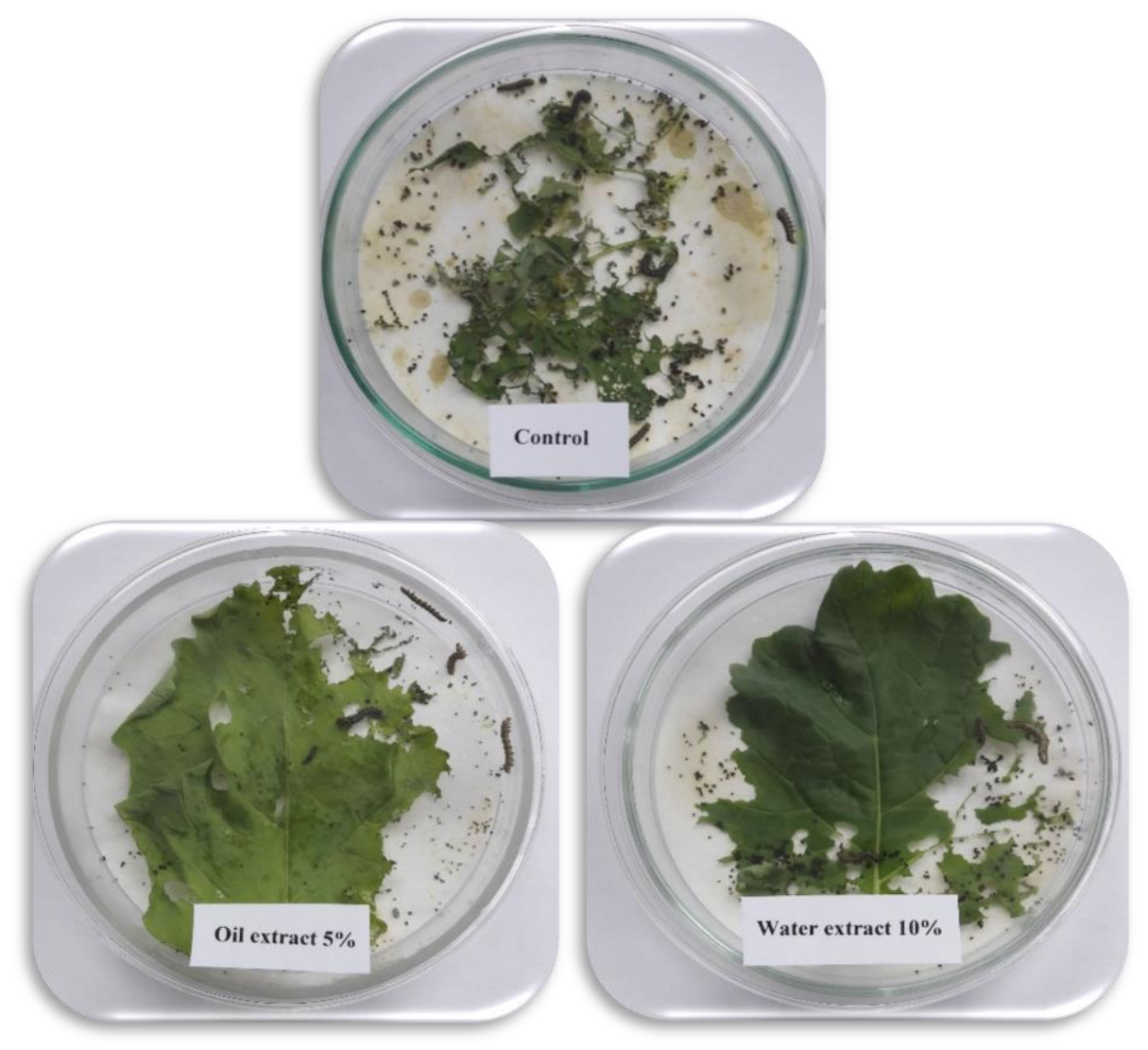

Figure 4.3 Repellent activities of water and oil seed of Balanites aegyptiaca at $10 \%$, (w/v) 5\% (v/v) after $48 \mathrm{~h}$. 


\subsubsection{Eggs hatched rate}

The total number of hatched eggs was significantly $(\mathrm{P}<0.05)$ different between treatments. The recorded number of hatched eggs was significantly higher in the control $(0.950 \pm 0.224)$ than in oil extract $2 \%(0.450 \pm 0.510)$ and $5 \%(0.350 \pm 0.489)$. However, no significant difference was detected among the control, tap water $(0.850 \pm 0.366)$ and Tween $(0.700 \pm 0.470)$ treatments (Fig 4.4).

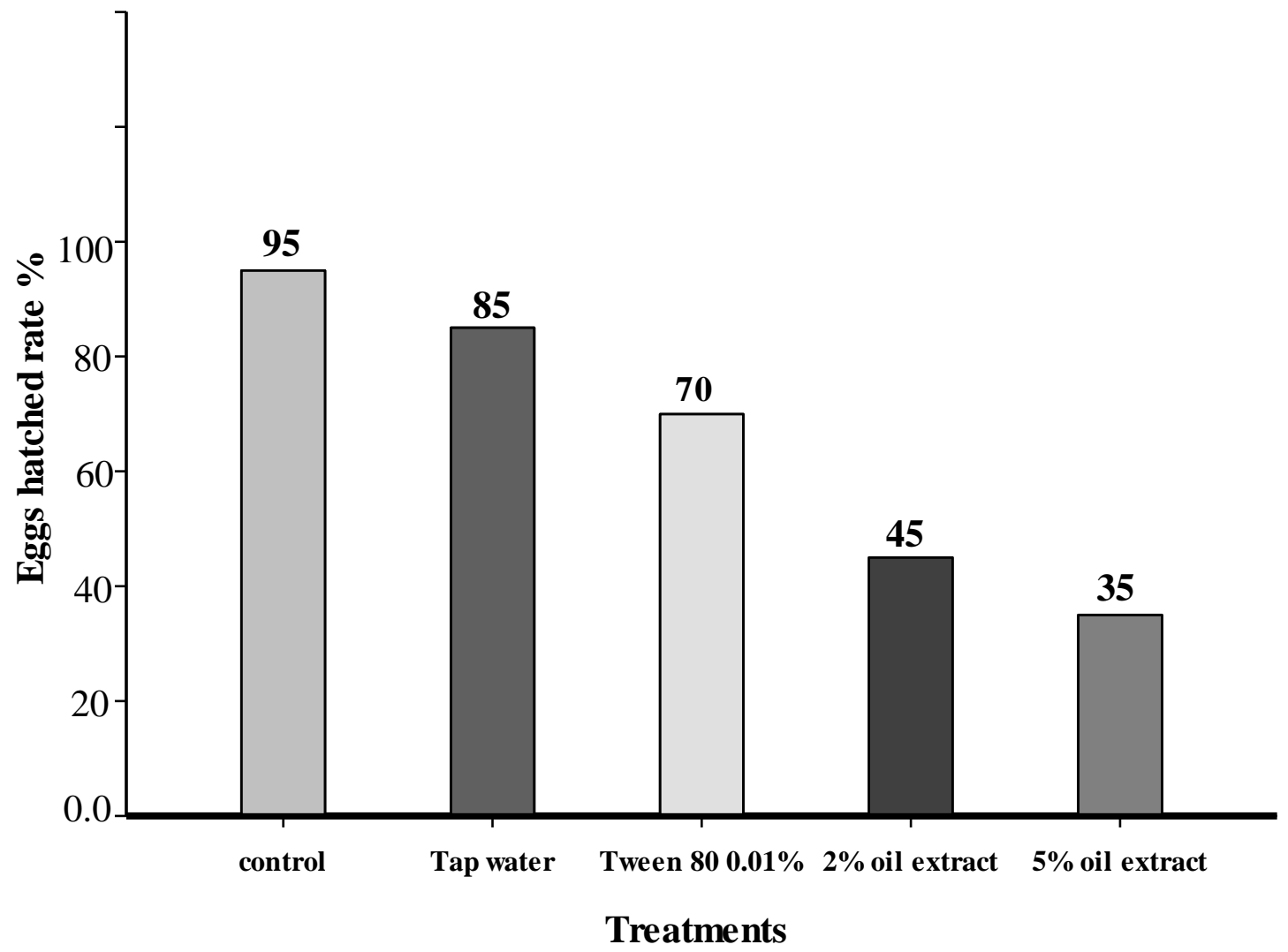

Figure 4.4 Percentage Eggs hatched rate of Helicoverpa armigera for each treatment (2\% (v/v) and 5\% (v/v) oil extract, Tween 80 0.01\% (v/v), Tap water, Negative control) 


\subsubsection{Effect of crude oil on Helicoverpa armigera $2^{\text {nd }}$ instar}

Survival was significantly $(\mathrm{P}<0.004)$ affected by treatment. (Fig 4.5) shows that no significant differences were observed between $2 \%$ and $5 \%$ oil extract treatment $(0.469 \pm 0.516$ and $0.333 \pm$ 0.488 , respectively) however, the number of survivals was higher in the negative control $(0.869 \pm$ $0.352)$ and Tween $(0.800 \pm 0.414)$, thus, no significant differences were recorded for the later treatments.

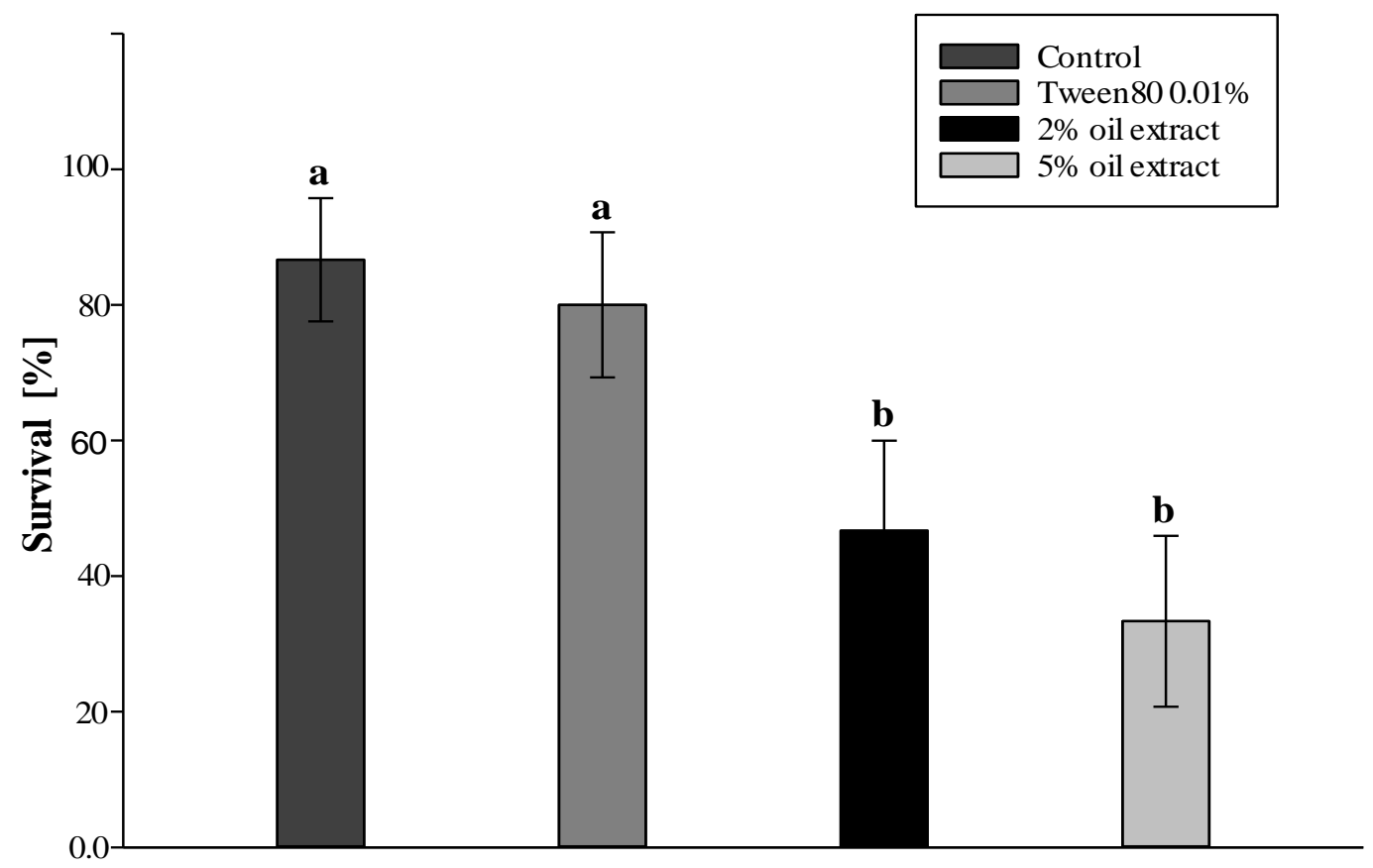

Figure 4.5 Effect of treatments $(2 \%(\mathrm{v} / \mathrm{v})$ and $5 \%(\mathrm{v} / \mathrm{v})$ oil extracts, Tween $800.01 \%(\mathrm{v} / \mathrm{v})$, Negative control) on larva survival. Same letters are not significantly different using the least significant difference (LSD) 
4.4.4 Effect of warm water extracts on Helicoverpa armigera $2^{\text {nd }}$ instar

Number of survivals differed significantly between treatments $(\mathrm{P}<0.012)$. The number was $0.867 \pm 0.352,0.333 \pm 0.488$ and $0.53 \pm 0.51$ for the control, $10 \%(\mathrm{w} / \mathrm{v})$ water extract and $5 \%$ $(\mathrm{w} / \mathrm{v})$ water extract, respectively. No difference was detected between the control and $5 \%(\mathrm{w} / \mathrm{v})$ water extract (Fig. 4.6)

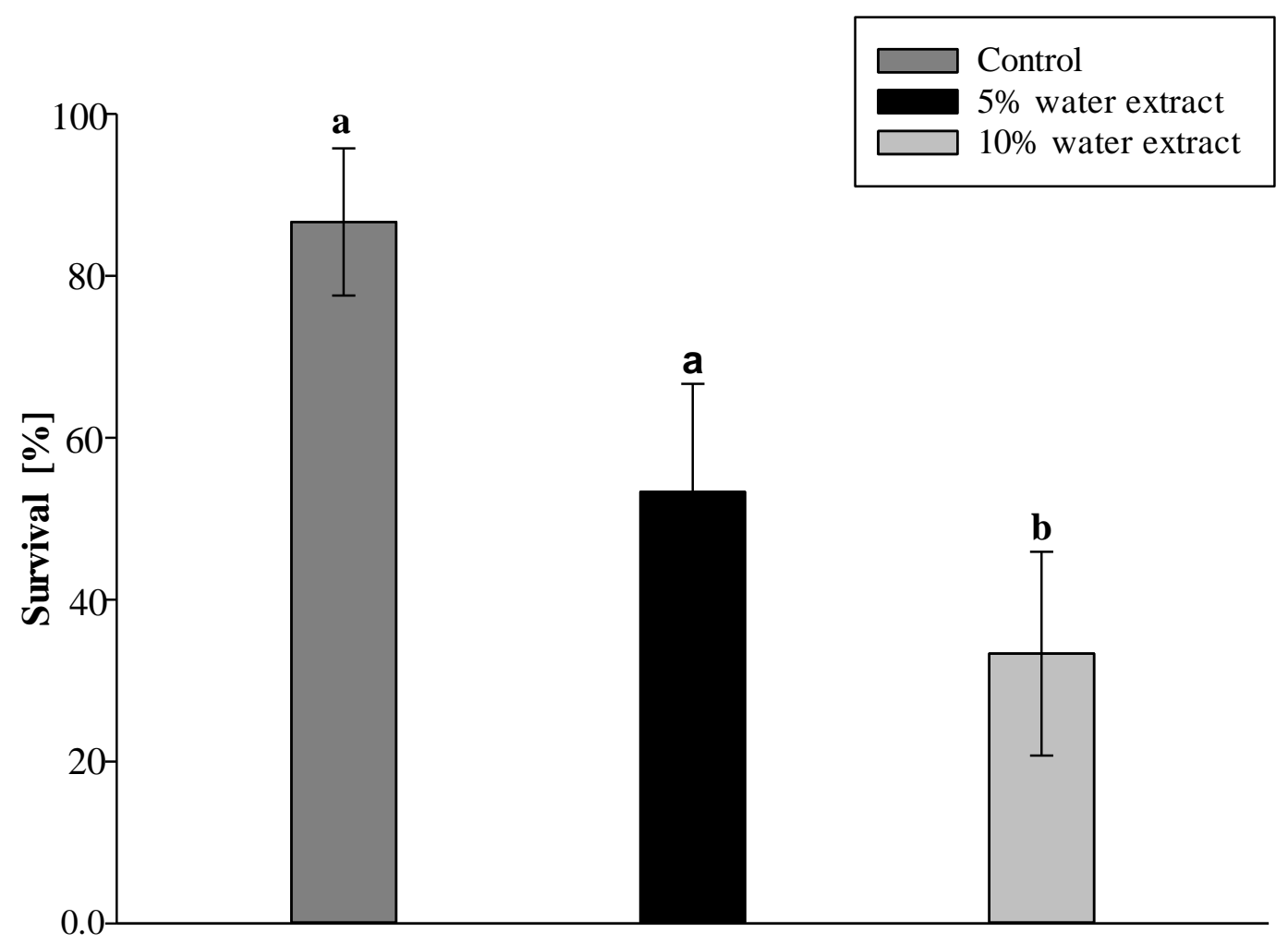

Figure 4.6 Effect of treatments (Negative control, 5\% (w/v) and 10\% (w/v) water extracts) on larval survival. Same letters are not significantly different using the least significant difference (LSD) 


\subsubsection{Pupae weight}

Pupae weight was significantly $(\mathrm{P}<0$. 001) influenced by treatments. The pupae weight was higher in the negative control $(0.357 \pm 0.102)$ and Tween control $(0.292 \pm 0.152)$ than in the $2 \%$ and $5 \%$ oil extract $(0.171 \pm 0.145$ and $0.141 \pm 0.137$, respectively) (Fig. 4.7)

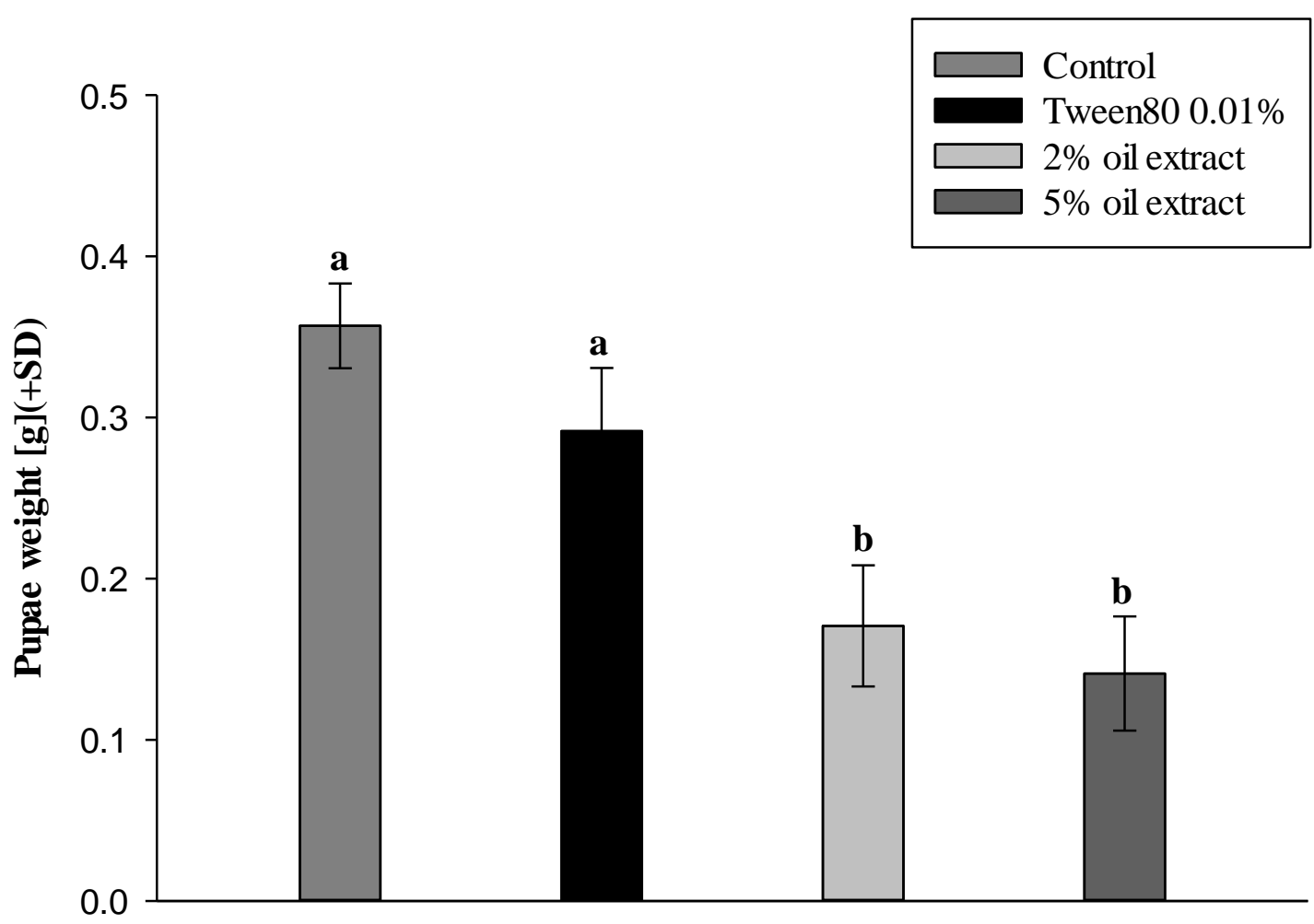

Figure 4.6 Effect of treatments (2\% (v/v) and 5\% (v/v) oil extracts, Tween $800.01 \%(\mathrm{v} / \mathrm{v})$, Negative control) on Pupae weight. Same letters are not significantly different using the least significant difference (LSD) 


\subsubsection{Plant biomass for oil extract}

Table 1 shows above ground dry biomass of the host plant harvested at 25 days. 5\% (v/v) and $2 \%(\mathrm{v} / \mathrm{v})$ oil extract Balanites aegyptiaca was significantly $(\mathrm{P}<0.001)$ higher than the negative control and Tween80 $0.01 \%(\mathrm{v} / \mathrm{v})$.

Table 1 Average above ground host plant biomass [g] ( \pm SD) assessed at 25 days. Sorted by treatments. Asterisks $(*)$ indicate significant differences between treatments

\begin{tabular}{l|l|l} 
Treatments & $\mathrm{N}$ & Mean $[\mathrm{g}](+\mathrm{SD})$ \\
\hline $5 \%(\mathrm{v} / \mathrm{v})$ oil extract & 15 & $5.34 \pm 0.91^{*}$ \\
\hline $2 \%(\mathrm{v} / \mathrm{v})$ oil extract & 15 & $5.18 \pm 1.23 *$ \\
\hline Tween $800.01 \%(\mathrm{v} / \mathrm{v})$ & 15 & $3.34 \pm 0.75$ \\
\hline Control & 15 & $3.090 \pm 0.56$
\end{tabular}

\subsubsection{Plant biomass for water extract}

Table 2 shows above ground dry biomass of the host plant harvested at 20 days. The results showed that $10 \%(\mathrm{w} / \mathrm{v})$ water extract was significantly $(\mathrm{P}<0.05)$ higher than $5 \%(\mathrm{w} / \mathrm{v})$ water extract and control.

Table2 Average above ground host plant biomass [g] $( \pm$ SD) assessed at 20 days. Sorted by treatments. Asterisks $(*)$ indicate significant differences between treatments.

\begin{tabular}{l|l|l} 
Treatments & $\mathrm{N}$ & Mean $[\mathrm{g}](+\mathrm{SD})$ \\
\hline $10 \%(\mathrm{w} / \mathrm{v})$ Balanites aegyptiaca water extract & 15 & $5.30+0.90^{*}$ \\
\hline $5 \%(\mathrm{w} / \mathrm{v})$ Balanites aegyptiaca water extract & 15 & $4.57+1.11$ \\
\hline Control & 15 & $3.74+.0 .83$
\end{tabular}




\subsection{Discussion}

The total of Helicoverpa armigera eggs hatched differed significantly between treatments ( $\mathrm{P}<$ $0.05)$ and was significantly higher in the control $(0.950 \pm 0.224)$ than in oil extract $2 \%(0.450 \pm$ $0.510)$ and $5 \%(0.350 \pm 0.489)$. However, no significant differences were detected between the control, tap water $(0.850 \pm 0.366)$ and Tween $(0.700 \pm 0.470)$ treatments. The results of oil extract on eggs hatching rate are consistent with many studies that explained that the oil extract of Balanites aegyptiaca depressed egg metabolic rate and led to decreased, rapid effect on eggshell by clogging pores which led to increase in water loss and a reduced viability of the eggs. This effect on the development of eggshells itself probably plays a role in controlling the diffusion of gasses that is consistent with Woods et al. (2005) who mentions in his experiment the wax and crystalline chorionic as candidate controlling oxygen and water traffic across the eggshell of Manduca sexta. Management over eggshell action may play several important roles in life cycle of $H$ armigera, moreover eggs of Tribolium confusum exposed to acetone vapors have achieved excellent mortality (Tunç et al., 1997) also Zrubek \& Woods (2006) pointed out that hypoxia depressed egg metabolic rates. The eggshell is consists of a waxy layer play the penetrated rather by of oil-based products then by water-based formulations (Campbell et al., 2016).

In all Balanites aegyptiaca with exception of the $5 \%$ water extract, survival $2^{\text {nd }}$ instar Helicoverpa armigera was lower than in the negative control and Tween oil extract which could be due to the toxic compound in oil and water extract. The higher saponins and tannins content of Balanites aegyptiaca could be the reason for decreased survival (Amos et al., 2001). Moreover, it concluded that saponin present in Balanites aegyptiaca, Ilex apocea, (Brem et al., 2002) Solanum laxum, (Soulé et al., 2000) Balanites roxburghii, (Simandi \& Publishers, 1991) Medicago truncatula (Lei et al., 2019) interfere with the insects feeding behavior or has property of entomotoxicity.

Un survival of $2^{\text {nd }}$ instar was due to the repellent effect of the phytochemical towards the larvae which reduce feeding by ingestion of the toxic substance which includes alkaloids, glucosides, flavonoids, phenolics, saponins, tannins, terpenoids, furanocoumarins, Diosgenin, N-transferuloyltyramine, N-cis-feruloyltyramine, trigonelline, balanitol and cardiac glycosides leading to decreased survival, This effect has also been observed by Gour \& Kant, (2012). Many 
researchers reported alkaloids have strong antifeedant properties agonist pests (Brem et al., 2002:Mao \& Henderson, 2007:Sani, 2014:Gabriel Paulraj et al., 2014).

(Shao, 2017) tested the oil extracted from Rosmarinus officinalis on Tribolium confusum and recorded $86.22 \%$ mortality rate, also Hamzavi \& Moharramipour, (2017) in their experiment observed $100 \%$ death rate on same pest treatment for the oil extracted from Eucalyptus camaldulensis. Moreover, Mageed (1990) on evaluation of Balanites aegyptiaca as a Mosquito larvicide found that water extracts of fruit kernel were very effective as larvicides against mosquitoes (Aedes aegypti, Aedes arabiensis and Culex quinquefasciatus). Also different extracts from several parts of Balanites aegyptiaca were shown to raise antifeedants and molluscicidal activities against various snail pests (Plants \& Lymnaea, 2010). Seeds of desert date Balanites aegyptiaca (L.) Del. contains many phytochemicals which act as secondary metabolites and have different biocidal effects against store pests such as khapra beetle Trogoderma granarium (Elamin \& Satti, 2013).

The results clearly indicate that both water and oil extracts of Balanites aegyptiaca showed survival and pupae weight reduction over control of $H$ armigera. Hence, it was concluded that hydrophilic compounds were present in desert date that involved in reducing survival of bollworm larvae. Moreover, it was concluded that there are some secondary metabolites present in Balanites aegyptiaca, Datura, (Jawalkar et al., 2016) Pyrethrum, (Ojiako, Dialoke et al., 2015) Rotenone, (Zubairi, Othman et al., 2016) Carvone, (Koul et al., 2008) Jatropha, (Bashir \& El Shafie, 2013) and Neem (Campos et al., 2016) that are capable of inhabiting the larval of herbivores.

Plant biomass was significantly influenced by treatments depending on the area consumed by larvae Helicoverpa armigera. For example, in the negative control and tween control the pest has the ability to consume the whole area around the clip cages which covers the treated area while for the oil and water extract of Balanites aegyptiaca it has less capability to damage the clip cages area due to phytochemical compounds acting as antifeedant and repellent substances. This agrees with Berenbaum, (2010) who mentioned that phytochemical such as furanocoumarins act as skip of a side against herbivores. Moreover, desert date has plenty of tannin compounds which have negative influence on the insect in addition to that other studies showed that saponins also have potent narcotic activity (Amos et al., 2001) 


\subsection{Conclusions}

The result illustrated that the extracts of Balanites aegyptiaca exhibited a wide spectrum of biopesticide activities, our results proved the repellent and antifeedant effect of oil and water extracts of desert date. This assessment also showed that oil and water extracts had an agedependent toxicity against $H$ armigera larvae $2^{\text {nd }}$ instar. Generally, our result demonstrates the efficacy of $B$ aegyptiaca against $H$ armigera and also pointed out the pathways in which the influence of oil and water extracts may be recognized as a means of managing bollworm. The reduction in the number of larvae could effectively reduce the old-world bollworm populations in subsequent generations. More research is needed to extensively study what is pointed out by our experiment which includes:

- localize the fraction which contains the active compounds

- The question here was whether the observed repellence of the compound responsible could be confirmed. 


\section{References}

Amos, S., Kolawale, E., Wambebe, C., Gamaniel, K. (2001). Behavioral effects of aqueous extract of Guiera senegalensis in mice and rats. Phytomedica, 8(356-361).

Bashir, E., \& El Shafie, H. (2013). Insecticidal and Antifeedant Efficacy of Jatropha oil extract against the Desert Locust, Schistocerca gregaria (Forskal) (Orthoptera: Acrididae). Agriculture and Biology Journal of North America, 4(3), 260-267. https://doi.org/10.5251/abjna.2013.4.3.260.267

Benelli, G., Murugan, K., Panneerselvam, C., Madhiyazhagan, P., Conti, B., \& Nicoletti, M. (2015). Old ingredients for a new recipe? Neem cake, a low-cost botanical by-product in the fight against mosquito-borne diseases. Parasitology Research, 114(2), 391-397. https://doi.org/10.1007/s00436-014-4286-X

Berenbaum, M. (2010). Furanocoumarins as potent chemical defenses.

Bhandari, M. M. (1990). Balanites, 88: In Flora of the Indian Desert. . MPS Repros, Jodhpur. India, $435 \mathrm{Pp}$.

Brem, B., Seger, C., Pacher, T., Hofer, O., Vajrodaya, S., \& Greger, H. (2002). Feeding deterrence and contact toxicity of Stemona alkaloids - A Source of potent natural insecticides. Journal of Agricultural and Food Chemistry, 50(22), 6383-6388. https://doi.org/10.1021/jf0205615

Bruchidae, C., Nwaogu, J., Yahaya, M. A., \& Bandiya, H. M. (2013). Insecticidal efficcay of oil extracts of Balanites aegyptiaca seeds and cashew nuts against Callosobruchus maculatus Fabr. (Coleoptera: Bruchidae). African Journal of Agricultural Research, 8(25), 3285-3288. https://doi.org/10.5897/AJAR12.1978

Campbell, B. E., Pereira, R. M., \& Koehler, P. G. (2016). Complications with Controlling Insect Eggs. Insecticides Resistance, (September 2016). https://doi.org/10.5772/61848

Campos, E. V. R., de Oliveira, J. L., Pascoli, M., de Lima, R., \& Fraceto, L. F. (2016). Neem oil and crop protection: From now to the future. Frontiers in Plant Science, 7(OCTOBER2016), 1-8. https://doi.org/10.3389/fpls.2016.01494 
Dayan, F. E., Cantrell, C. L., \& Duke, S. O. (2009). Natural products in crop protection. Bioorganic and Medicinal Chemistry, 17(12), 4022-4034. https://doi.org/10.1016/j.bmc.2009.01.046

Dwijendra Singh. (2014). Advances in Plant Biopesticides. Springer New Delhi Heidelberg New York Dordrecht London.

Elamin, M. M., \& Satti, A. A. (2013). Insecticidal potentialities of Balanites aegyptiaca extracts against the khapra beetle ( Trogoderma granarium ). 2(1), 5-10.

Gabriel Paulraj, M., Shanmugam, N., \& Ignacimuthu, S. (2014). Antifeedant activity and toxicity of two alkaloids from Adhatoda vasica Nees leaves against diamondback moth Plutella xylostella (Linn.) (Lepidoptera: Plutellidae) larvae. Archives of Phytopathology and Plant Protection, 47(15), 1832-1840. https://doi.org/10.1080/03235408.2013.859402

Gonzalez, F., Tkaczuk, C., Dinu, M. M., Fiedler, Ż., Vidal, S., Zchori-Fein, E., \& Messelink, G. J. (2016). New opportunities for the integration of microorganisms into biological pest control systems in greenhouse crops. Journal of Pest Science, 89(2), 295-311. https://doi.org/10.1007/s10340-016-0751-X

Gour, V. S., \& Kant, T. (2012). Short Communication BALANITES AEGYPTIACA ( L .) DEL $\therefore$ A MULTIPURPOSE AND POTENTIAL. 3(2), 472-475.

Hamzavi, F., \& Moharramipour, S. (2017). Chemical composition and antifeedant activity of essential oils from Eucalyptus camaldulensis and Callistemon viminalis on Tribolium confusum. International Journal of Agricultural Technology, 13(3), 413-424.

Hatting, J. L. (2012). Comparison of Three Entomopathogenic Fungi Against the Bollworm, Helicoverpa armigera (Hübner) (Lepidoptera: Noctuidae), Employing Topical vs per os Inoculation Techniques . African Entomology, 20(1), 91-100. https://doi.org/10.4001/003.020.0112

Isman, M. B. (2006). Botanical Insecticides, Deterrents, and Repellents in Modern Agriculture and an Increasingly Regulated World. Annual Review of Entomology, 51(1), 45-66. https://doi.org/10.1146/annurev.ento.51.110104.151146 
Javed, M., Majeed, M. Z., Luqman, M., \& Afzal, M. (2019). Development and Field Evaluation of a Biorational IPM Module against Okra Shoot and Fruit Borers, Earias vittella and Helicoverpa armigera (Lepidoptera: Noctuidae). Pakistan Journal of Agricultural Research, 32(1). https://doi.org/10.17582/journal.pjar/2019/32.1.170.176

Jawalkar, N., Zambare, S., \& Zanke, S. (2016). Insecticidal property of Datura stramonium L. seed extracts against Sitophilus oryzae L. (Coleoptera: Curculionidae) in stored wheat grains. Journal of Entomology and Zoology Studies, 4(4), 92-96.

Kassi, A. K., Javed, H., \& Mukhtar, T. (2018). Screening of okra cultivars for resistance against helicoverpa armigera. Pakistan Journal of Zoology, 50(1), 91-95. https://doi.org/10.17582/journal.pjz/2018.50.1.91.95

Koul, O., Walia, S., \& Dhaliwal, G. (2008). Essential oils as green pesticides: Potential and Constraints. Biopestic Int, 4(1), 63-84.

Lammers, J. W., \& Macleod, a. (2007). Report of a Pest Risk Analysis. Plant Protection Service (NL) and Central Science Laboratory (UK), (August), 1-18.

Lei, Z., Watson, B. S., Huhman, D., Yang, D. S., \& Sumner, L. W. (2019). Large-scale profiling of saponins in different ecotypes of Medicago truncatula. Frontiers in Plant Science, 10(July), 1-12. https://doi.org/10.3389/fpls.2019.00850

Liu, Z. L., Goh, S. H., \& Ho, S. H. (2007). Screening of Chinese medicinal herbs for bioactivity against Sitophilus zeamais Motschulsky and Tribolium castaneum (Herbst). Journal of Stored Products Research, 43(3), 290-296. https://doi.org/10.1016/j.jspr.2006.06.010

Mageed, A. A. (1990). Balanites aegyptiaca as a Mosquito Larvicide Larval mortalities The percentage mortalities of the second and fourth instar larvae of An . 28(4), 267-271.

Mao, L., \& Henderson, G. (2007). Antifeedant Activity and Acute and Residual Toxicity of Alkaloids from $<$ I $>$ Sophora flavescens $</$ I $>$ (Leguminosae) Against Formosan Subterranean Termites (Isoptera: Rhinotermitidae). Journal of Economic Entomology, 100(3), 866-870. https://doi.org/10.1603/0022-0493(2007)100[866:aaaaar]2.0.co;2

Mohamed, N. M. A. (2003). Efficacy of Selected Plants Extracts on the Control of Khapra Beetle 
Trogoderma granarium Everts. (Coleoptera - Dermistidae) and Red Flour Beetle Tribolium castaneum Herbst. (Coleoptera - Tenebrionidae). Ph.D Thesis, University of Khartoum, Sudan.

Obidah, W.; Nadro, M.S.; Tiyafo, G.O. and Wurochekke, A. U. (2009). Toxicity of crude Balanites aegyptiaca seed oil in rats. Journal of American Sciences 5, (6): 163-165.

Ojiako, F., Dialoke, S., Ihejirika, G., Ahuchaogu, C., \& Ohiri, C. (2015). Comparative Performance of Pyrethrum [Chrysanthemum cinerariifolium Treviranus (Vis.)] Extract and Cypermethrin on Some Field Insect Pests of Groundnut (Arachis hypogaea L.) in Southeastern Nigeria. American Journal of Experimental Agriculture, 7(2), 96-106. https://doi.org/10.9734/ajea/2015/15609

Orwa, C.; Mutua, A.; Kindt, R.; Jamnadass, R. . and S. (2010). Agroforestree Database. Forestry Seeds, Species, Trees: a tree reference and selection guide version 4. World Agroforestry Centre (ICRAF) Nairobi, Kenya, 1-5.

Plants, M., \& Lymnaea, A. (2010). Evaluation of Mollucicidal Activity of Some Indian. (2), $308-311$.

Sani, U. M. (2014). Phytochemical Screening and Antifeedant Activity of the Seed Extracts Of Parkia Biglobosa against Cowpea Bean(Vigna Unguiculata) Storage Pest (Callosobruchus Maculatus). International Journal of Innovative Research in Science, Engineering and Technology, 03(09), 15991-15995. https://doi.org/10.15680/ijirset.2014.0309030

Shao, Y. (2017). Research Article. SciFed Food \& Dairy Technology Journal, 1(1), 107-112. https://doi.org/10.23959/sffdtj-1000001

Simandi, I., \& Publishers, E. S. (1991). 0 1991. 5(April 1990), 395-400.

Soulé, S., Güntner, C., Vázquez, A., Argandoña, V., Moyna, P., \& Ferreira, F. (2000). An aphid repellent glycoside from Solanum laxum. Phytochemistry, 55(3), 217-222. https://doi.org/10.1016/S0031-9422(00)00273-9

Tesfaye, A. (2015). Balanites (Balanite aegyptiaca) Del., Multipurpose Tree a Prospective Review. International Journal of Modern Chemistry and Applied Science 2, (3): 189-194. 
Tunç, I., Erler, F., Dagli, F., \& Çaliş, Ö. (1997). Insecticidal activity of acetone vapours. Journal of Stored Products Research, 33(2), 181-185. https://doi.org/10.1016/S0022474X(96)00021-5

Uddin, M. A., Jahan, M., \& Uddin, M. M. (2009). Issn 1017-8139 study on nature and extent of damage of corn earworm,. Progress. Agric, 20(1), 49-55.

Vonmaydell, H. J. (1986). Trees and Shrubs of the Sahel: Their Characteristics and Uses. Eschborn, GTZ, Germany, 525 Pp.

Wakawa, A. I., Sambo, A. B., \& Yusuf, S. (2019). Anaesthetic effects of aqueous crude leaf extract of desert date ( Balanites aegyptiaca ) on Nile tilapia ( Oreochromis niloticus ) fingerlings. International Journal of Fisheries and Aquatic Studies, 7(1), 147-152.

Woods, H. A., Bonnecaze, R. T., \& Zrubek, B. (2005). Oxygen and water flux across eggshells of Manduca sexta. Journal of Experimental Biology, 208(7), 1297-1308. https://doi.org/10.1242/jeb.01525

Yadav, J. P. and Panghal, M. (2010). Balanites aegyptiaca (L.) Del. (Hingot): A review of itstraditional uses, phytochemistry and pharmacological properties. . . International Journal of Green Pharmacy, 140-146.

Zrubek, B., \& Woods, H. A. (2006). Insect eggs exert rapid control over an oxygen-water tradeoff. Proceedings of the Royal Society B: Biological Sciences, 273(1588), 831-834. https://doi.org/10.1098/rspb.2005.3374

Zubairi, S. I., Othman, Z. S., Sarmidi, M. R., \& Abdul Aziz, R. (2016). Environmental friendly bio-pesticide rotenone extracted from derris sp.: A review on the extraction method, toxicity and field effectiveness. Jurnal Teknologi, 78(8), 47-69. https://doi.org/10.11113/jt.v78.5942 


\section{Acknowledgements}

First of all, I would like to express my immense gratitude to my supervisor professor Dr. Stefan Vidal for his patient, guidance encouragement and excellent advice throughout this study. This thesis has only been possible through your support in both my personal development and academic research. Deeply thanks to PD DR. Rainer Meyhöfer co-supervisor.

I will like to are also express my gratitude to all staff members of Department of Crop Protection, Faculty of Agriculture Science, University of Georg-August Gottingen for their support in diverse ways during my MSC and $\mathrm{PhD}$ research.

My sincere thanks are to Dr. Katharina and Bianca for their technical assistance during experimental work. I am indebted to Dr. Issaka Abdulai for his support. Also, I thank Christian Bödeker for practical support.

Last but not least I wish to thank Dr. Sulieman Ali who did everything possible when I came to Germany. I am also grateful to Ute Behrens and Sebastian Schwarz for the good friendship and support in German integration.

"Behind every successful man is a woman", I am grateful to my dear wife Bothina for the love, patience, encouragement, continuous prayers and sacrifice to take care of the kids, God bless you!

My warmest gratitude goes to my families in Sudan, especially sisters, brothers, relatives, and friends with love and respect.

I extend my gratitude to all those who have contributed in making this thesis possible. Simultaneously; I would like to apologize unreservedly for any mistakes or failure to acknowledge fully. 


\section{Curriculum Vitae}

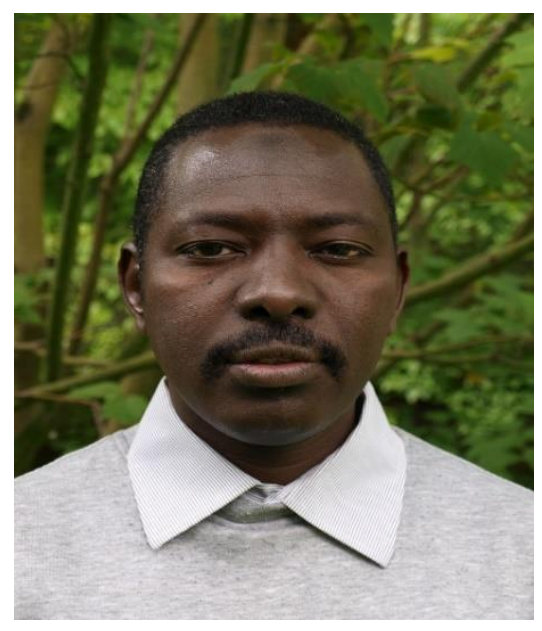

Name: Elhadi Ibrahim Mursal Morzog

Date-of-birth: 01. 01.1977

Place-of-birth: Wadiushar, Republic of Sudan

Address:

Agricultural Entomology

Georg-August-Universität Göttingen

Grisebachstraße 6

37077 Göttingen, Germany

Telephone: +49152113518621

E-mail: elhadi.marzog@uni-stud.goettingen.de

\section{Education}

2012 to Present: Georg-August-Universität Göttingen

International PhD in Agricultural Science (IPAG)

Thesis title: Management of Helicoverpa armigera (Hübner) with botanical extract

(Balanites aegyptiaca) and endophytic entomopathogenic fungus Metarhizium brunneum (6c1) reared on okra plant

M. Sc. Agriculture (Crop Protection, Entomology) Graduate College, August-University in Gottingen Germany, December 2014

M. Sc. Agriculture (Crop Protection, Entomology) Graduate College, University of Khartoum, March 2006.

B. Sc. Agriculture (Honours) $2^{\text {nd }}$ Class Division (1), option crop protection, Faculty of Agriculture University of Zalengei, June, 2000 


\section{Professional experience}

2001 Teaching Assistant at Faculty of Environmental Sciences and Natural

Resources, University of Al Fashir, Sudan.

2006 Lecturer at Faculty of Environmental Sciences and Natural Resources, Department of crop protection University of Al Fashir, Sudan

\section{Referees}

Prof. Dr. Stefan Vidal

Agricultural Entomology

Georg-August-Universität Göttingen

Grisebachstraße 6

37077 Göttingen, Germany

Phone: +49 (0)5513923732

Fax: $\quad+49(0) 5513912105$

Email: svidal@gwdg.de
PD DR. Rainer Meyhöfer

Institut für Gartenbauliche Produktionssysteme

Herrenhäuser Straße 2

30419 Hannover, Germany

Phone: +49511 7623096

Fax: $\quad$ +49511762 3015

Email: meyhoefer@ipp.uni-hannover.de 


\section{E C L A R A T I O N S}

1. I, hereby, declare that this Ph.D. dissertation has not been presented to any other examining body either in its present or a similar form. Furthermore, I also affirm that I have not applied for a Ph.D. at any other higher school of education.

Göttingen,

(Signature)

(Name in block capitals)

2. I, hereby, solemnly declare that this dissertation was undertaken independently and without any unauthorised aid.

Göttingen,

(Signature)

(Name in block capitals) 